University of Louisville

ThinkIR: The University of Louisville's Institutional Repository

Electronic Theses and Dissertations

$5-2021$

\title{
Re-visiting the Flutie effect: an exploration of athletic success' impact on student enrollment decisions.
}

\author{
Addison Pond \\ University of Louisville
}

Follow this and additional works at: https://ir.library.louisville.edu/etd

Part of the Higher Education Commons, and the Sports Studies Commons

\section{Recommended Citation}

Pond, Addison, "Re-visiting the Flutie effect: an exploration of athletic success' impact on student enrollment decisions." (2021). Electronic Theses and Dissertations. Paper 3620.

https://doi.org/10.18297/etd/3620

This Doctoral Dissertation is brought to you for free and open access by ThinkIR: The University of Louisville's Institutional Repository. It has been accepted for inclusion in Electronic Theses and Dissertations by an authorized administrator of ThinkIR: The University of Louisville's Institutional Repository. This title appears here courtesy of the author, who has retained all other copyrights. For more information, please contact thinkir@louisville.edu. 


\title{
RE-VISITING THE FLUTIE EFFECT: AN EXPLORATION OF ATHLETIC SUCCESS' IMPACT ON STUDENT ENROLLMENT DECISIONS
}

\author{
By \\ Addison Pond \\ B.S., Christian Brothers University, 2016 \\ M.S., Northern Illinois University, 2018

\begin{abstract}
A Dissertation
Submitted to the Faculty of the

College of Education and Human Development of the University of Louisville

In Partial Fulfillment of the Requirements

For the Degree of
\end{abstract} \\ Doctor of Philosophy in Educational Leadership and Organizational Development \\ Department of Health and Sport Sciences \\ University of Louisville \\ Louisville, Kentucky
}

May 2021 

RE-VISITING THE FLUTIE EFFECT: AN EXPLORATION OF ATHLETIC SUCCESS' IMPACT ON STUDENT ENROLLMENT DECISIONS

By

Addison M. Pond

B.S., Christian Brothers University, 2016

M.S., Northern Illinois University, 2018

A Dissertation Approved on

April 26, 2021

By the following Dissertation Committee:

T. Christopher Greenwell, Chair

Mary A. Hums

Evan L. Frederick

Michael B. Shuck 


\title{
DEDICATION
}

This dissertation is dedicated to my parents

\author{
Neil and Margaret Pond
}

Thank you for making me into the man I am today. I could not have done this without your support 


\section{ACKNOWLEDGEMENTS}

There are too many people to thank who helped me get to this point in my professional career. To anyone not explicitly mentioned in this page, I express my sincerest thanks for all of your help along the way. I hope you all know who you are.

The first person I would like to acknowledge is my committee chair, Dr. Chris Greenwell, for all of his help with both my dissertation, and my time in the program. When I joined the program in fall 2018, I was struggling tremendously and did not think I was going to make it through my first semester, much less the entire program. Dr. Greenwell struck a great balance of patience and constructive criticism, giving me the tools that I needed to grow and mature into the person I am today.

I would also like to acknowledge my other committee members for their feedback and support: Mary Hums, Evan Frederick, and Brad Shuck. Dr. Hums, thank you for always letting me interrupt your lunch and talk about baseball with you in your office for a couple of hours each week. Our countless talks about if the Red Sox or Braves had what it took to win the World Series were some of favorite memories of my time in the program. Dr. Frederick, on a similar note, thank you for indulging me in all of my unannounced visits to your office to quote South Park or other various, obscure pop culture references. Expect sporadic Adam Morrison references in the upcoming years. Thirdly, Dr. Shuck, thank you for your invaluable assistance, not just as my committee member, but as my professor in 780 . My time in your course served as a valuable 
stepping stone to my comps, and eventually to this point. I appreciate all of your help, and for always having a pertinent SpongeBob reference in your back pocket.

I would also like to acknowledge the other professors and advisors in my life that have gotten me to where I am at today, specifically: Dr. James Allen and Dr. Steve Howell. There is not nearly enough space in the acknowledgement section to give these two their due credit, but their influence has meant more than I can ever put into words.

Next, thank you to my parents, Neil and Margaret Pond, for supporting my endeavors and for their guidance in my attempts at navigating the world. Thank you to my tightest group of friends for sticking by my side: Patrick Nichols, Johnny Reber, Ramon Ramirez, Casey Goodwin, Ben Rhett, and Trey Tedford. Of course, tremendous thanks to my fiancé, Caylee, who has been with me every step of the way in my doctoral journey. Her advice and support has proven invaluable, and I would not have made it without her in my corner. 


\begin{abstract}
RE-VISITING THE FLUTIE EFFECT: AN EXPLORATION OF ATHLETIC SUCCESS’ IMPACT ON STUDENT ENROLLMENT DECISIONS

Addison Pond
\end{abstract}

April 9, 2021

With each passing year, FBS collegiate athletic departments are faced with increased expenditures (Huml et al., 2019). Subsequently, institutional funding has become an increasingly common and controversial method of athletic department funding (Jewell, 2020). These spending and subsidization patterns are commonly met with controversy, causing the need to further unpack the benefits that schools receive from these behaviors.

One anticipated benefit of athletic success is increased numbers of student applications. While the impact of football and basketball success on student interest (the "Flutie Effect) has been a popular topic in sport management literature, there is a lack of primary data to explain the relationship between these two variables. Specifically, the extent to which football and basketball success influences students' enrollment decisions, not just their applications decisions is unknown. Moreover, despite research on collegiate athletics' ability to foster campus sense of community (SOC), no research to date has uncovered how campus SOC changes with team performance. Thus, the purpose of this study was to examine football and basketball success' impact on student enrollment decisions, campus sense of community (SOC), and enrollment satisfaction, while also 
attempting to uncover the most important factors to students' subjective success perceptions.

The current study included 225 FBS undergraduate students. Responses were collected using a combination of administering surveys through Amazon Mechanical Turk, freshmen Facebook pages, and university professors/institutional officials. Results indicated football and basketball success perceptions did not significantly predict the importance of athletics in students' enrollment decisions. Rather, team identification was found to be the strongest predictor. However, football and basketball success perceptions were found to significantly predict SOC, with SOC also significantly predicting enrollment satisfaction.

Findings suggest that when attempting to justify their spending and subsidization by citing potential student interest, colleges and universities should avoid overemphasizing team performance. Rather, they should concentrate their efforts on using football and basketball success to convert potential students into highly identified fans. Once students enroll at their respective universities, institutions may be able to place more emphasis on football and basketball success and its ability to strengthen campus climate and student satisfaction levels. 
TABLE OF CONTENTS

PAGE

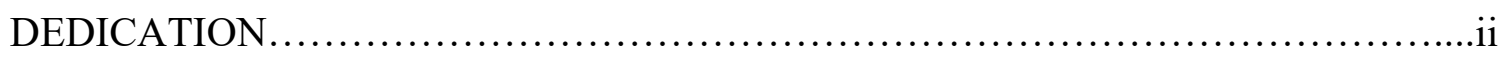

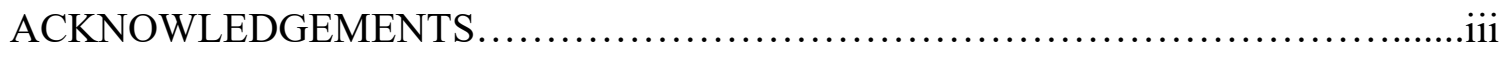

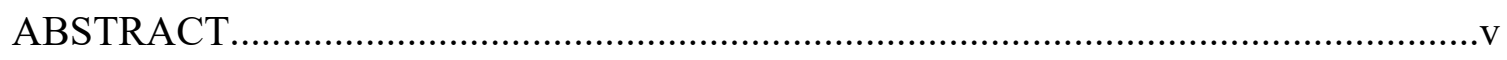

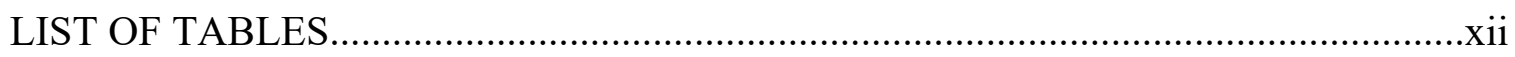

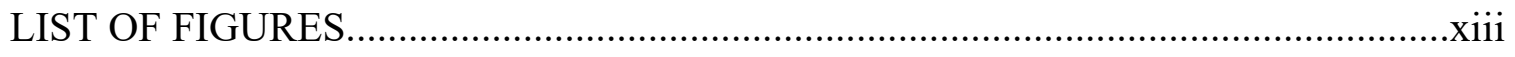

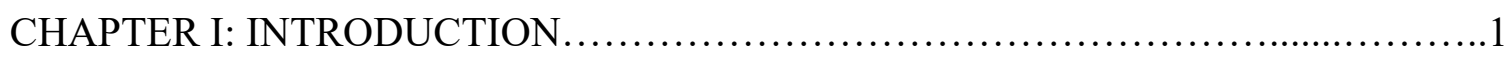

Background to Problem...........................................................................

Study Purpose.............................................................................

Theoretical Framework........................................................................

Study Significance.............................................................................

Practical Implications.....................................................

Theoretical Implications....................................................

Limitations/Delimitations..................................................................10

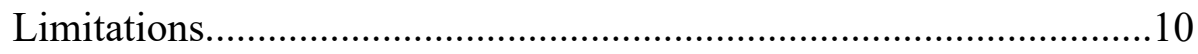

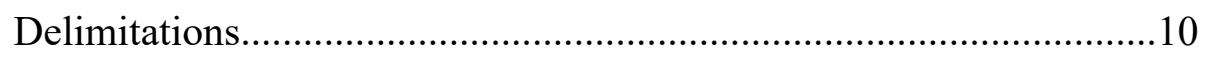

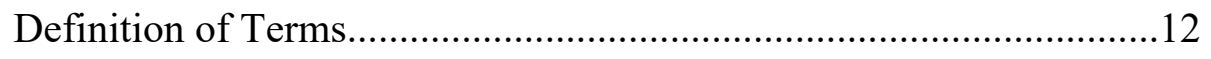

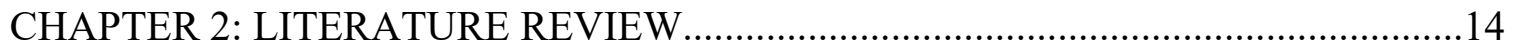

Athletic Success' Impact on Academics..............................................15

Football Success and Applications......................................15

Football Success and Academic Exclusivity......................17

Basketball Success and Applications...................................20

Basketball Success and Academic Exclusivity...................21

Athletic Success' Impact on Academics Summary...........23

Student College Choice Process..........................................................24

Student College Choice Process Summary.............................................29

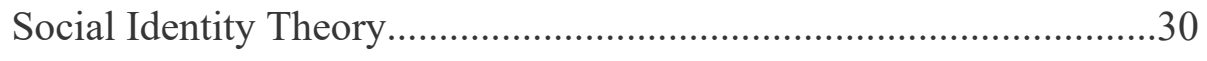


Social Identity Theory Background......................................30

Social Identity Theory and Sport..........................................33

Social Identity Theory and Flutie Effect.................................36

Social Identity Theory Summary..........................................37

Student Enrollment Satisfaction \& Sense of Community......................38

Student Enrollment Satisfaction \& Sense of Community Summary...42

Athletic Success Subjectivity............................................................43

Athletic Success Subjectivity Summary .................................................47

CHAPTER III: RESEARCH DESIGN/METHODOLOGY...........................................49

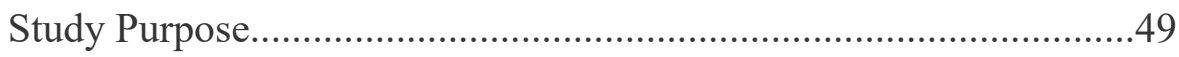

Research Questions.......................................................................50

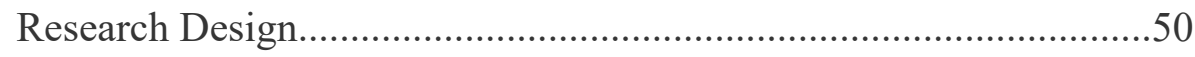

Sample/Data Collection.................................................................51

Sampling and Data Collection Procedure/Method...............................51

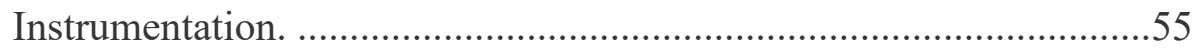

Research Question 1..........................................................5

Research Question 2......................................................59

Research Question 3........................................................62

Instrument Development and Reliability.............................................63

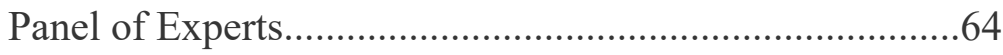

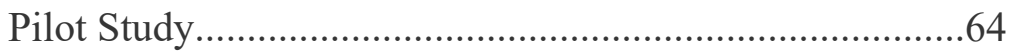

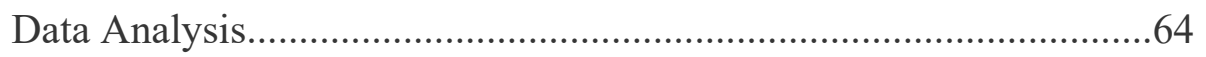

Exploratory Factor Analysis ..............................................65

Confirmatory Factor Analysis............................................65

Research Question 1............................................................66

Research Question 2........................................................69

Research Question 3 .......................................................73

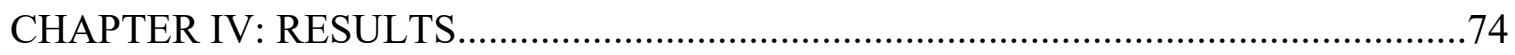

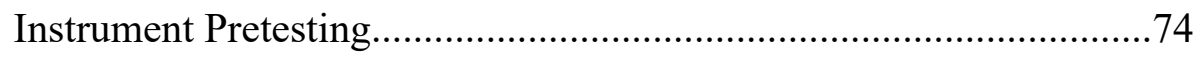

Panel of Experts............................................................

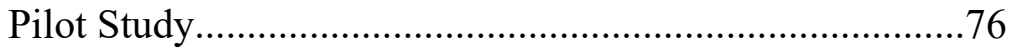




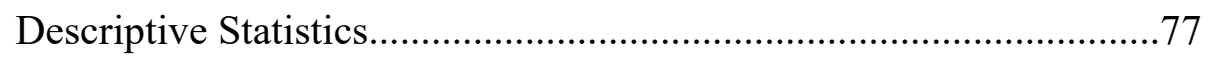

Sample Description..............................................................

Demographic Information......................................78

School Conference Information..............................79

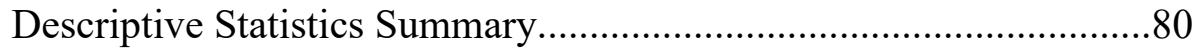

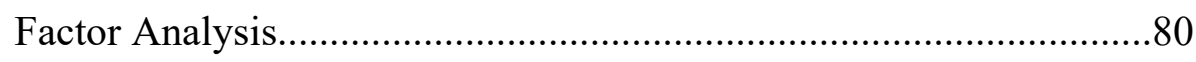

Exploratory Factor Analysis............................................... 81

Confirmatory Factor Analysis.............................................82

Research Question 1............................................83

Research Question 2..........................................86

Factor Analysis Summary..............................................................91

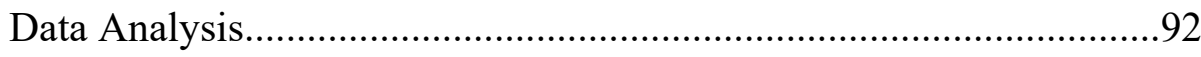

Assumptions of Multiple Regression..................................92

Descriptive Statistics............................................................95

Results and Analysis of Research Question 1....................95

Assumptions of Mediation Analysis...................................98

Results and Analysis of Research Question 2..................100

Mediation Model 1.................................................101

Mediation Model 2.............................................102

Results and Analysis of Research Question 3..................104

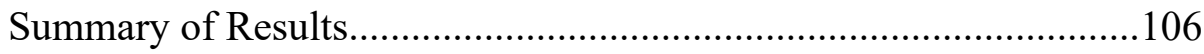

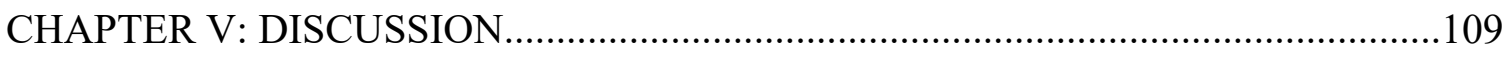

Interpretation of Study Results........................................................110

Sample Characteristics....................................................110

Athletic Success and Enrollment Decisions......................110

Sense of Community and Enrollment Satisfaction...........112

Success Perceptions.........................................................114

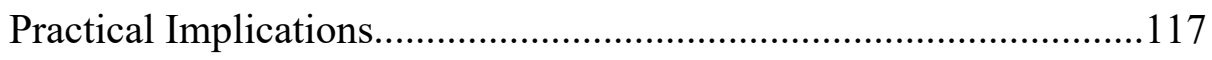

The Flutie Effect............................................................117

Sense of Community and Enrollment Satisfaction..........119

Success Perceptions.......................................................... 120 


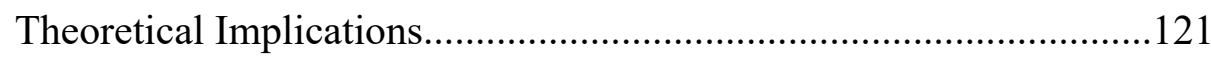

Social Identity Theory .....................................................121

The Flutie Effect................................................................122

Athletic Success, Sense of Community, and Enrollment

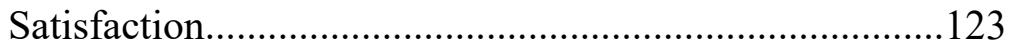

Athletic Success Subjectivity.............................................124

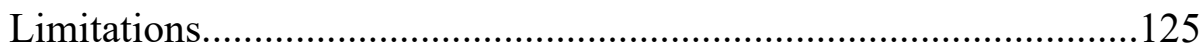

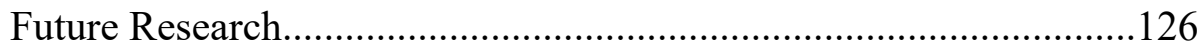

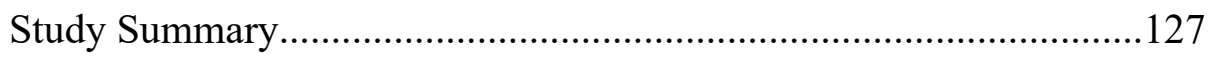

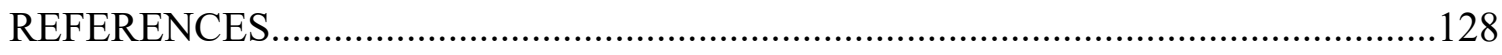

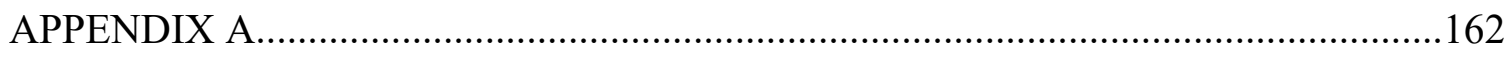

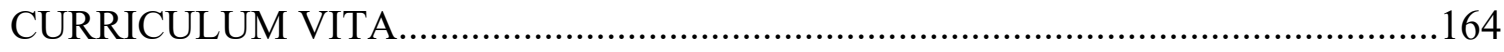




\section{LIST OF TABLES}

\section{TABLE}

1. Demographics of United States College Students..................................................55

2. Athletic Success Variables as Items........................................................................62

3. Demographics of College Students in sample and Entire College Student

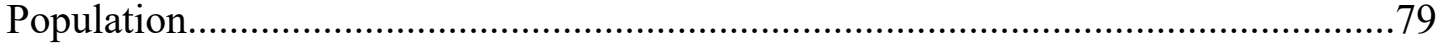

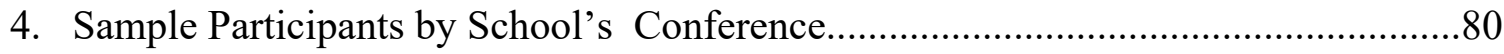

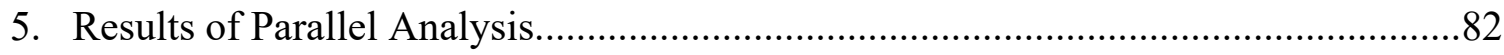

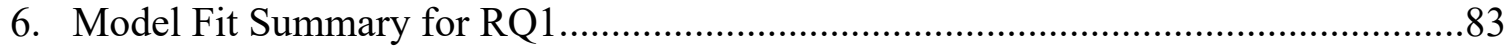

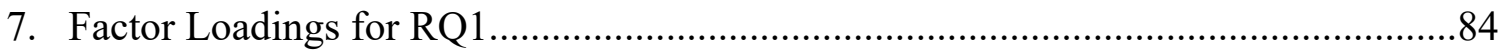

8. Correlation Estimates Between Variables-RQ1 ...................................................85

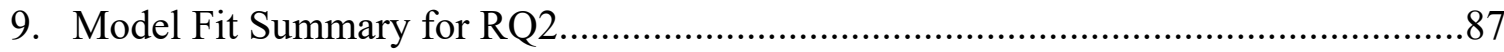

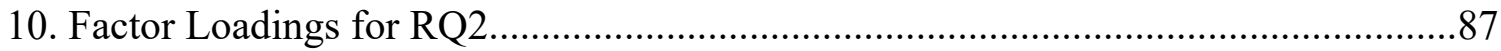

11. Correlation Estimates Between Variables-RQ2 ...................................................89

12. Descriptive Statistics of Independent and Dependent Variables.............................95

13. Results of Hierarchical Multiple Linear Regression Analysis for RQ1 ....................97

14. Mean Scores of Importance of Athletic Success Factors........................................ 105

15. Correlation Coefficients Between Team ID and Factors Influencing Athletic Success

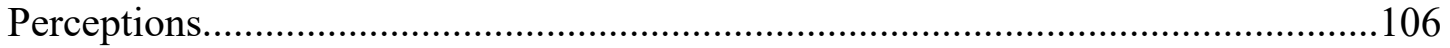

16. Rankings of Factors Influencing Athletic Success Perceptions................................114 


\section{LIST OF FIGURES}

\section{FIGURE}

1. RQ2 Moderated Mediation Model 1....................................................................... 70

2. RQ2 Moderated Mediation Model 2 ............................................................... 70

3. Scree Plot from EFA Using Maximum Likelihood Estimation with Varimax

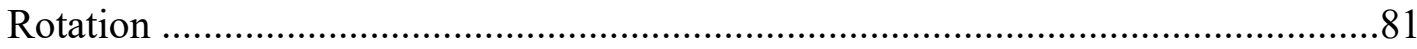

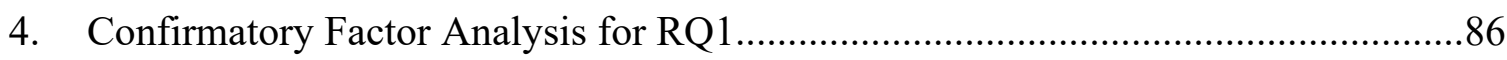

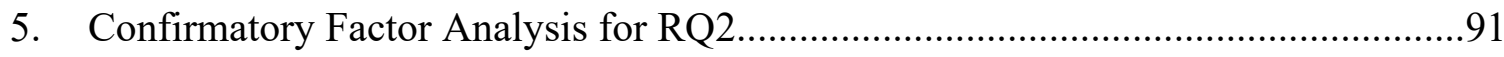

6. Histogram of RQ1 Dependent Variable (Importance of Athletics on Enrollment)...93

7. P-Plot of Regression Standardized Residuals (RQ1) ..........................................94

8. P-Plot of Regression Standardized Residuals (RQ2) .........................................99

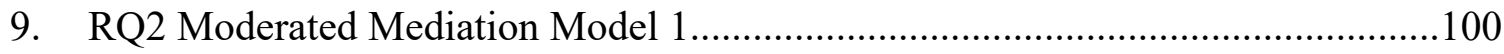

10. RQ2 Moderated Mediation Model 2 ...................................................................101

11. Results of Moderated Mediation Analysis \#1.................................................... 103

12. Results of Moderated Mediation Analysis \#2 .................................................. 104 


\section{CHAPTER I}

\section{INTRODUCTION}

\section{Background to Problem}

In 2006, California Rep. Bill Thomas penned a letter to NCAA president Miles

Brand and asked, “How does playing major college football or men's basketball in a highly commercialized, profit-seeking, entertainment environment further the educational purpose of your member institutions?" (Abrams, 2006, para. 8). Congressman Thomas' question may be more relevant now than ever, as Division I athletic department spending has reached unprecedented levels (Huml et al., 2019). Between 2005 and 2019, median total expenditures for Division I Football Bowl Subdivision (FBS) athletic programs increased from $\$ 34$ million to roughly $\$ 80$ million, a percentage increase of roughly $135 \%$.

Because of these enlarged budgets, the majority of Division I FBS athletic departments operate at a deficit (Jewell, 2020) and must rely on student fees to support their programs (Lipford \& Slice, 2018; Osborne et al., 2020). Student fees, or "mandatory fees assessed primarily (but not exclusively) to full-time undergraduate students that universities use to support intercollegiate athletics" (Jones \& Rudolph, 2020, p. 57) are becoming a progressively larger component of athletic department funding. Between 2004 and 2015, the average total amount of student fees collected by Division I institutions increased by roughly $\$ 1$ million (Jones et al., 2018). Further, between 2008- 
2018, the amount of student fees collected by Division I schools increased by $51 \%$ (Enright et al., 2020).

Many "Power Five" schools (Atlantic Coast, Big Ten, Big 12, Pacific-12, and Southeastern Conferences) generate significant revenues from this campus-based source. For example, during the 2017-18 school year, the University of Virginia's and Rutgers University’s athletic departments collected \$13.9 million and \$11.8 million, respectively, from student athletic fees (Pitcher, 2018; Schnaars et al., 2018). Schools in "Group of Five" conferences (American, Conference-USA, Mid-American, Mountain West, and Sun Belt) are even more reliant on student fees (Fulks, 2017; Hartsell, 2015), as these institutional subsidies typically account for around half of their athletic department operating revenue (Goins, 2017; Lavigne, 2016).

Institutional subsidization of athletics is controversial, as most students are unaware of the percentage of athletic department revenues these fees represent, or even that their mandatory fees are being used to support university athletic programs at all (Denhart \& Ridpath, 2011). However, the justification for this institutional funding is the belief that successful athletic programs can provide enhanced visibility and publicity to the school (Bass et al., 2015). As Bremmer and Kesselring (1993) note, universities' "primary form of media exposure (and advertising) derives from a distinctly nonacademic enterprise - intercollegiate athletics" (p. 409).

One of the main benefits schools hope to receive from athletic success is increased student applications. Previous literature has correlated athletic success to both a higher quantity (Chressanthis \& Grimes, 1993; McEvoy, 2005; Murphy \& Trandel, 1994; Toma \& Cross, 1998) and quality of applicants (McCormick \& Tinsley, 1987; Pope \& 
Pope, 2009). This particular benefit has been dubbed the "Flutie Effect," named after Boston College quarterback Doug Flutie, whose role in a 1984 upset victory over the University of Miami Hurricanes brought a sizeable increase in applications to the school (McCann, 2018; McEvoy, 2005).

\section{Study Purpose}

While the Flutie Effect has been a popular line of inquiry in higher education literature, the relationship between athletic success and student interest has only been researched using secondary data, where some measurement of athletic success (i.e., overall winning percentage, conference winning percentage etc.) is correlated to the number of student applications. For example, Toma and Cross (1998) found that football national championships tend to produce around a 10\% increase in student application numbers, and rarely more than a $20 \%$ increase. While this methodology provides some information about the quantifiable relationship between these variables, it fails to give a holistic view into why athletic success influences student interest and enrollment. As a result, it is difficult for athletic and admissions departments to pinpoint the role athletic success plays in student interest. Was the decision to apply to a certain university driven entirely by the successful sports programs? Was athletic success enough to actually make students enroll at the institution over another one? Conversely, was this just one factor in the decision? What other factors influenced this decision? The lack of insight into this relationship makes it difficult to determine whether the correlation between athletic success and number of student applications is also evidence of causation.

Potential students are not the only stakeholders in this relationship, as the benefits of successful athletic programs also extend to current students. This is largely due to 
athletics' ability to improve campus atmosphere by creating a stronger sense of community (SOC) (Roy et al., 2008; Stensland et al., 2019; Toma, 2003). SOC is a desirable outcome for campus officials, as it can lead to decreased student loneliness (Pretty et al., 1994), greater student satisfaction with school life (Noel-Elkins et al., 2019), and higher student retention levels (Bailey et al., 1998). If schools are able to positively channel SOC, they will be more effective in retaining students (Warner \& Dixon, 2011).

Despite the research connecting intercollegiate athletics and SOC, no studies to date have looked at how successful athletics shapes SOC on campus. Since many schools are increasing their athletic spending in the hopes of winning more games, failing to incorporate team performance is a major limitation of previous research. Thus, it is important to research how current students' perceived campus SOC changes with team performance. This relationship is further compounded when factoring enrollment satisfaction, or "college students' overall feeling about their experience in college" (Yoh et al., 2008, as cited by Yoon et al., 2016, p.27), into the model.

Previous studies have linked athletic support (Hanson et al., 2019) and SOC (Warner et al., 2011) to higher student satisfaction levels, as well as the presence of athletics to SOC (Stensland et al., 2019). However, no research to date has examined all three variables-athletic success, SOC, and student satisfaction levels - collectively. This is a necessary line for future research, as, due to SOC's benefits and outcomes, university officials need to know if athletic success increases students' perceived SOC, and if students who perceive higher SOC levels are more satisfied with their enrollment decision. If athletic success is found to increase SOC and enrollment satisfaction, schools 
may use this as an additional justification for increased athletic spending. Because of how athletic success may influence enrollment satisfaction through SOC, conceptualizing SOC as a mediating variable may help explain this relationship.

Another important element of Flutie Effect research is the conceptualization of "success." Previous research has measured "success" a variety of ways, including overall winning percentage (Smith, 2008), conference winning percentage (McCormick \& Tinsley, 1987; Murphy \& Trandel, 1994), national championship victories (Toma \& Cross, 1998), and relative changes in winning percentage (McEvoy, 2005). The usage of objective success measurements is also problematic, since success tends to be a subjective judgement. For example, football programs on the Group of Five level seldomly get the opportunity to compete for the national championship, as the four spots in the College Football Playoff (CFP) are almost always reserved for Power Five schools (Dellenger, 2019). Within college basketball, Power Five programs tend to be selected and seeded more favorably in the NCAA Tournament (Byrum, 2017; Duffy, 2014; Feinstein, 2019). Because of this lower "ceiling", it is possible that students attending Group of Five schools measure team success differently than students at Power Five schools, a distinction that needs to be considered when operationalizing "success."

The purpose of this study was to incorporate current students' perspectives to measure athletic success' impact on college enrollment decisions, campus SOC, and enrollment satisfaction, while also attempting to uncover the most influential factors in students' personal definitions of athletic success.

\section{Theoretical Framework}


The current study will utilize Social Identity Theory as its theoretical framework. Social Identity Theory, developed by Henri Tajfel (1978), posits that individuals base their self-concept around membership in a social group. This membership is primarily a way for individuals to raise their self-esteem, or "a favorable or unfavorable attitude toward oneself' (Rosenberg, 1965, p. 15) through their knowledge of belonging to the “ingroup" (Turner et al., 1979). Since Tajfel's (1978) seminal work, Social Identity Theory has been widely used to explore how individuals' social identities shape their perceptions and categorizations of themselves. At its root, Social Identity Theory attempts to answer the question "Who am I?" (Ashforth \& Mael, 1989, p. 21).

While Social Identity Theory has been most commonly used in psychology and sociology studies, its tenets make the theory a popular framework in sport management research as well. For example, being a sports fan, defined as an "enthusiastic devotee of a given diversion" (Sloan 1989, as cited by Robinson et al., 2005, p. 43), and joining groups of similar minded fans can be a way for one to enhance their self-esteem, a core principle of Social Identity Theory (Wann et al., 2000).

Because of Social Identity Theory's relevance to sport fandom, the framework's applicability extends to the current study. For instance, previous Flutie Effect research has shown that athletic success correlates to increased student interest. However, a major limitation is that secondary data does not tell us why athletic success makes a particular college more appealing to potential students. This explanation could be driven by vicarious achievement, a concept derived from Social Identity Theory, defined by Fink et al. (2002) as "the need for social prestige, self-esteem, and sense of empowerment that an individual can receive from their association with a successful team" (p. 198). For 
instance, with the Flutie Effect, students may feel that attending a school with successful athletic programs can raise their self-esteem and give them a sense of vicarious achievement. Conversely, they may view poor athletic performances as a threat to their self-esteem, and do not wish to attend a school with unsuccessful athletic teams. Moreover, Social Identity Theory may help explain other important factors to students' college choice decision, including campus and social life. For example, students may view a bustling social life with plenty of opportunities to develop friend groups, and subsequently watch and attend games together, as essential components for their future school.

Social Identity Theory may also explain athletic success' impact on SOC. Previous research has shown that sport fandom can generate a slew of social benefits, including community and solidarity, enhanced social prestige, and feelings of camaraderie, all of which may help individuals raise their self-esteem (Zillmann et al., 1989). Mixon and Trevino (2005) discuss the presence of a "football chicken soup" effect, where students acclimate to college by developing social relationships rooted around supporting the university's football team (p. 9). This phenomenon ties in closely with Social Identity Theory's emphasis on group membership, as students having a friend group to watch and attend games with may be instrumental in their campus SOC perceptions. Thus, while Social Identity Theory is suitable to examine students' enrollment decisions, it may also help explain intercollegiate athletics' impact on shaping campus SOC through fan group membership.

The subjective construct of "success" is also an important element to Flutie Effect and SOC research, particularly as it pertains to Power Five vs. Group of Five schools. 
Athletic performance standards for these schools are undoubtedly different and studying how this impacts fans' definitions of success is a valuable line of future research. If schools possess a more thorough understanding of how their students define success, they will be more efficient at using athletic success to attract potential students and foster SOC amongst current students. The following research questions were generated to guide this study:

- RQ1: Do subjective perceptions of football success and subjective perceptions of basketball success influence how students perceive the importance of athletics in their college choice decision?

- RQ2: Does Sense of Community (SOC) mediate the relationship between subjective athletic success and enrollment satisfaction?

- RQ3: Which factors are most important to Group of Five and Power Five students' subjective perceptions of athletic success?

\section{Study Significance}

\section{Practical Implications}

In the wake of increasing athletic expenditures, this study also has the ability to inform sport practice in several ways. Findings may illustrate whether schools are receiving the desired institution-wide benefits from successful, prominent athletic programs, by increasing potential student interest in the school, and improving current students' time at the university through SOC. Such a result would make it easier for schools, particularly those on the Group of Five level who rely disproportionately on institutional subsidies (Fulks, 2017; Hartsell, 2015), to justify their spending behaviors. If contrasting findings emerge, schools' athletic department spending justifications may 
become more problematic. In this case, schools may need to find alternative ways beside prominent athletic programs to appeal to potential and current students.

The third research question might also illuminate some important findings. If we find that students at Group of Five schools define success differently than those at Power Five schools, this may force schools to avoid taking a "one size fits all" approach to marketing their teams. For instance, results may show that Group of Five schools would be better off marketing conference championships, while Power Five schools should showcase AP Poll appearances and national championships. Possessing a thorough understanding of how their fans define success will assist practitioners in developing more efficient marketing campaigns.

\section{Theoretical Implications}

In addition to practical significance, this study will also advance research and theory. Using primary data to measure the Flutie Effect will allow academics to better understand how athletic success influences enrollment and enhances campus SOC. Additionally, future research on the Flutie Effect can benefit from knowing how students on the Power Five and Group of Five level define success. These findings will provide stronger justification for specific success measurements to be used in future studies on the topic. Secondly, this study has the ability to improve our understanding of Social Identity Theory. For instance, previous research that has used Social Identity Theory as a framework found that fans will identify with different elements of their teams based on team performance (Fisher \& Wakefield, 1998). However, there is a lack of research regarding how team success increases the overall social climate on college campuses, and how this community feeling may influence student enrollment satisfaction. Better 
understanding how these variables operate will aid academics' knowledge of Social Identity Theory.

\section{Limitations/Delimitations}

\section{Limitations}

Despite its practicality, this study is not without its limitations. First, is the timing of data collection. Due to the COVID-19 pandemic, many FBS teams faced delayed starts to their seasons and significantly limited attendance (Dodd, 2020). While this should not impact football success perceptions, the inability for some students to attend games with their friends' may impact their perceived SOC. Further, beyond athletics, COVID-19 limiting other social opportunities, such as parties and in-person classes, may also impact students' SOC perceptions.

Another limitation involves enrollment satisfaction. While some students, particularly juniors and seniors, may have a good grasp on how satisfied they are with their enrollment choice, younger students' responses may not reflect their satisfaction a few years from now. In other words, some students may report being highly satisfied with their college choice, but an unforeseen event, such as tuition increases, academic struggles, or a university scandal, could occur after data collection that alters their satisfaction level. COVID-19 may also have a significant impact on this relationship, as displeasure with the university's handling of the pandemic could decrease students' enrollment satisfaction after the study is completed.

\section{Delimitations}

While limitations are restrictions outside the researcher's control, delimitations refer to self-imposed limits set by the researcher (Theofanidis \& Fountouki, 2018). First, 
the study's results may not be generalizable to all schools on the FBS level. While students in the sample may place a heavy emphasis on athletic success when making their enrollment decision, this may not reflect student bodies at other institutions. Every college and university possesses a unique set of attributes, and with a complex issue such as enrollment decisions, results may not be fully generalizable.

Another limitation is the study sample only consisting of schools on the Division I Football Bowl Subdivision (FBS) level. Conducting a similar study with schools that compete in the Football Championship Subdivision (FCS) would be a valuable line of future research. Further, the FBS inclusion criteria eliminates several prominent basketball programs, such as Villanova, Gonzaga, Xavier, and Georgetown University. Looking at schools with decorated basketball programs that compete on the FCS level for football, or do not sponsor a football program at all would be beneficial. Secondly, this study only looks at athletic success' impact on enrollment decisions for students currently attending the institution. Surveying students who considered attending this same institution but decided to attend another university would also be fruitful. This might provide schools a better idea of whether or not athletics can be enough to get a potential student to enroll, or whether it merely serves as the first point of contact and more effort is needed beyond this to attract students. Another delimitation regarding the sample is only examining football and men's basketball success. Extending Flutie Effect research to include the impact of perennially successful women's programs on enrollment, such as the University of Connecticut women's basketball or University of Arizona softball teams would be a viable topic for future studies. 
Lastly, this study's cross-sectional design may also limit generalizability, as the researcher is only collecting data from participants at one point in time. Compounding this concern is the use of MTurk, as Follmer et al. (2017) points out that MTurk workers are more likely to complete surveys regarding topics of interest to them. Chapter three will discuss these issues more in-depth.

\section{Definition of Terms}

- Fan Identification: the personal commitment and emotional involvement customers have with a sport organization (Sutton et al., 1997)

- Flutie Effect: The relationship between athletic team performance and student applications (McEvoy, 2005)

- Group of Five: Division I athletic programs competing in the American Athletic Conference, Conference-USA, Mid-American Conference, Mountain West Conference, or Sun Belt Conference (Wanless et al., 2019)

- Identity: a set of meanings applied to the self in a social role or situation defining what it means to be who one is (Burke \& Tully, 1977)

- Power Five: Division I athletic programs competing in the Atlantic Coast, Big Ten, Big 12, Pacific-12, or Southeastern Conference (Wanless et al., 2019)

- Sense of Community: an environmental or community characteristic that leads to individuals feeling a sense of belonging and social support at the group-level (Sarason, 1974 as cited by Warner et al., 2013).

- Social Identity: that part of an individual's self-concept which derives from his [her] knowledge of his [her] membership in a social group (groups) together with the value and emotional significance attached to that membership (Tajfel, 1978) 
- Team Identification: the degree that the fan views the team as an extension of self-identity.... the extent to which the fan feels a psychological connection to the team (Wakefield \& Wann, 2006)

- Vicarious Achievement: the need for social prestige, self-esteem, and sense of empowerment that an individual can receive from their association with a successful team (Fink et al., 2002) 


\section{CHAPTER II}

\section{LITERATURE REVIEW}

On November 23, 1984, the Boston College Eagles football team played the defending national champion Miami Hurricanes. With six seconds remaining and his team trailing by four points, Boston College quarterback Doug Flutie threw a 48-yard "Hail Mary" touchdown pass to Gerard Phelan, completing the Eagles' upset victory (Chung, 2013). This play was instrumental in helping Flutie secure the Heisman Trophy, the annual award given to college football's top player (McEvoy, 2005). Flutie's performance also produced institution-wide benefits for Boston College. Over the next two years, student applications to the school increased by 30\% (McCann, 2018; McEvoy, 2005). Schools receiving increased exposure and student applications following successful athletic performances was subsequently coined the "Flutie Effect." It is important to note that the Flutie Effect should not be confused with the "front porch effect." The latter is merely the belief that successful athletics can provide enhanced visibility to the school (Bass et al., 2015), while the Flutie Effect refers specifically to successful athletics increasing student interest in the institution. Over the past 30 years, the Flutie Effect has been the subject of dozens of academic articles on the impact of football and basketball success on the number of applications, as well as the associated academic quality of this larger applicant pool. 
The literature review begins by summarizing research on the Flutie Effect, which includes the impact of football and basketball success on both number of applications and academic exclusivity. Following these sections is a summary of the student college choice process, which discusses how football and basketball success may overlap with high school students' college choice decision. The next topic in the literature review is Social Identity Theory, which provides an overview of the framework, followed by a synopsis of its usage in sport management studies, and lastly, a concluding section on Social Identity Theory's applicability to the current study. The final three sections in the literature review cover SOC, enrollment satisfaction, and athletic success subjectivity. The SOC section discusses how, in addition to potential students, athletic success can influence current students at the university, while the latter two sections provide a more holistic view of additional factors that need to be considered in research on the Flutie Effect.

\section{Athletic Success' Impact on Academics}

\section{Football Success and Applications}

Previous research has consistently linked football success to an increase in applications to the university. McEvoy (2005) examined student application numbers for schools in the six major Division I FBS conferences (Atlantic Coast, Big East, Big Ten, Big 12/Big Eight, Pacific Ten, and Southeastern), following a successful football season. McEvoy (2005) found a positive, significant relationship between football success and the number of applications received. Specifically, schools with an increase in conference winning percentage, or the percentage of in-conference games won, of at least $25 \%$ from the previous year, saw undergraduate applications rise by an average of $6.1 \%$. Similar 
findings emerged in Pope and Pope's (2009) study, which looked at football programs that finished the season ranked in the Associated Press' (AP) Poll between the years of 1980-2003. The researchers found that schools who finished in the top 20 of the AP Poll could expect between a $2 \%$ and $8 \%$ increase in applications the following year.

While football success has been shown to increase applications by an average of around 2-8\% (McEvoy, 2005; Pope \& Pope, 2009), several studies have found smaller applications increases. Murphy and Trandel (1994), who utilized a similar methodology to McEvoy (2005) by only including schools in the six major FBS conferences, produced more underwhelming results. The authors found that a $25 \%$ increase in football winning percentage will, on average, lead to a $1.3 \%$ jump in the number of applications received. Baumer and Zimbalist (2019) analyzed applications figures for all 65 Power Five schools between 2005-2016 and produced similar results. The researchers found that each additional football victory yielded schools around a $1.1 \%$ average increase in applications.

Thus, while football success has been shown to positively correlate with the number of applications received, upon further examination, this relationship does not appear to be exceptionally strong. The one notable exception is for schools winning the national championship. Toma and Cross (1998) examined the percentage change in applications received for football national championship schools between the years of 1979 and 1992, and found that, following a national championship season, schools saw an increase in applications, both in absolute terms, as well as in comparison to peer institutions. Specifically, of the 16 schools in the study that either won or shared a national title, seven (7) had an applications increase of $10 \%$ or more the following year, 
and two (2) saw an increase of $20 \%$ or more. The steepest increase in applications observed in this study came from the University of Miami (1987) and Georgia Tech University (1990), who enjoyed a 34\% and 21\% increase, respectively, in applications following their championship seasons.

Despite Toma and Cross' (1998) findings, literature suggests that Miami and Georgia Tech should be considered anomalies, as only one Division I FBS school can hoist the championship trophy each year. Putting McEvoy's (2005) and Pope and Pope's (2009) results into context, if a school were to receive 20,000 applications per year, a $6 \%$ increase following a successful football season would boost the total number of applications to just 21,200 . Such a marginal increase might not be a sufficient justification for schools to continue allocating millions toward athletics. In sum, football success has been shown to boost applications to the school. However, these increases appear to be contingent upon each school's unique performance in the previous year. Moreover, with the exception of national championship winners, research seems to indicate that these increases are marginal.

\section{Football Success and Academic Exclusivity}

Another important element of application increases brought on by football success is what schools choose to do with such an increase. As Bremmer and Kesslering (1993) point out, schools have two main avenues to handle increases in applications: accept a higher number of students and increase their tuition revenues or use this enlarged applicant pool to craft a more exclusive freshmen class (Bremmer \& Kesselring, 1993; McCormick \& Tinsley, 1987). This decision is an important element of Flutie Effect research, leading many academics to examine applications numbers and academic 
exclusivity in the same study. Despite the consensus on football success correlating with applications increases, albeit marginally, previous literature on football success' impact on incoming student quality has yielded mixed results. The first study to examine such a relationship was conducted by McCormick and Tinsley (1987). Here, the authors broke down schools into either "big-time" or "non-big-time" athletic participants, defined by their membership in a "major" athletic conference (Atlantic Coast, Southwestern, Southeastern, Big Ten, Big Eight, Pacific-Ten, with major independents classified as "big time" participants). McCormick and Tinsley (1987) concluded that, through SAT scores, schools that participated in major college athletics were generally better academic institutions than those who did not make a similar investment in athletics.

Tucker and Amato (1993) analyzed the AP Poll's end-of-year football rankings between 1980-1989 and compared these rankings with incoming freshmen's SAT scores at the 63 "big-time" athletic schools (defined the same way as McCormick and Tinsley's study). Football was shown to be a positive, significant influence on SAT scores, providing further support for McCormick and Tinsley's (1987) study. In another study on the topic, Tucker (2005) examined the impact of football success on incoming freshmen quality at the eight major FBS conferences (Atlantic Coast, Big 10, Big 12, Big East, Mountain West, Pacific-10, Conference USA, SEC, and Notre Dame) between 19902002. To measure football success, in addition to the AP Poll's end-of-year rankings, Tucker (2005) incorporated the number of postseason bowl appearances and winning percentages for each university. Tucker (2005) found that a successful football team, across all three measurements, significantly increased the quality of incoming freshmen, as measured by average SAT scores, further supporting previous literature's findings. 
Conversely, several studies have failed to produce evidence of football success increasing academic exclusivity. Bremmer and Kesselring (1993) explored the relationship between football success and incoming student quality, with the former defined as the number of times a school's football team appeared in a major bowl game (Cotton, Orange, Rose, or Sugar Bowl) in the 10 years prior to 1989. Bremmer and Kesselring (1993) concluded that, although athletic success increased applications to a university, the quality of the applicants, measured by their SAT scores, did not improve. Pope and Pope (2009) also sought to measure the impact of football success on applicant quality. Using the end-of-year AP Poll between the years of 1980-2003, the authors reached a similar conclusion to Bremmer and Kesselring (1993). Pope and Pope (2009) found that, while football success was positively and significantly correlated to the number of applications received, schools with successful football programs tended to increase their tuition revenues by accepting more students, as opposed to crafting a more exclusive freshmen class.

Despite these mixed findings, schools may be able to bolster their image and reputation without actually becoming more exclusive. Goidel and Hamilton (2006) found that following Louisiana State University's (LSU) 2004 BCS National Championship victory, Louisiana residents perceived LSU to be a more prestigious school. This is an important finding, because, if a university wishes to use athletic success as a springboard to become more exclusive, they might not have to accept a smaller percentage of students. Rather, if the public merely perceives the school to now be more exclusive as a result of football success, this may achieve the same result. 


\section{Basketball Success and Applications}

Because football and men's basketball are often the most profitable and commercialized sports at colleges and universities (Whiteside et al., 2011), most studies on the Flutie Effect have examined football and basketball success' impact on applications simultaneously. Most research has indicated that basketball success' impact on applications is, at best, similar to football success. Pope and Pope (2009) found that appearing in the NCAA Basketball Tournament increased applications the following year by approximately 1\%, making the "Final Four" increased applications by $4-5 \%$, and winning the NCAA tournament increased applications by $7-8 \%$. These results are on par with the Pope and Pope's (2009) findings on football success, as the authors found that winning a national championship also increased applications by around 7-8\%.

Literature has more commonly shown basketball success to have a smaller impact on applications than football success (McEvoy, 2005). For instance, as previously discussed, of the 16 national championship football teams in Toma and Cross' (1998) study, seven (7) saw an increase of at least 10\% in applications the following year. Comparatively, of the 13 basketball national champions, only two (2) saw an increase in applications greater than 10 the following year (Georgetown University, 1984; University of Michigan, 1989). Further, of these 13 basketball national championship schools, three (3) actually saw a decrease in applications the following year, a trend that evident for only two (2) of the 16 football national championship schools in the sample. BattleMcDonald (2019) also found evidence of basketball success increasing applications by a smaller margin than football success. Measuring football success as placement in the endof-year AP Poll and basketball success as the number rounds advanced in the NCAA 
Tournament, Battle-McDonald (2019) found that basketball success increased applications by up to $3 \%$, while football success produced as high as an $11 \%$ applications increase.

While the findings regarding football success' impact on applications are a bit underwhelming, the same can be said unequivocally about basketball success. Given Pope and Pope's (2009) and Toma \& Cross' (1998) results, even if a school wins the NCAA Tournament, they will be lucky to see applications increase by more than $10 \%$ the following year. Realistically, any applications increase following a national championship will likely fall in the $7-9 \%$ range. This is also an extremely optimistic viewpoint, since only one team can win the national title each year. Further, being one of the last four teams competing in the NCAA Tournament has been shown to increase applications by an average of 4-5\%. These findings might make it even more difficult for basketball powerhouse schools to justify how much money they allocate into maintaining their elite programs. Therefore, all arrows seem to indicate that if schools are relying on basketball success to produce a significant increase in student applications, they will likely be disappointed with the results.

\section{Basketball Success and Academic Exclusivity}

Similar to the mixed results of football success' influence on incoming student quality, literature on basketball success and academic exclusivity has also produced inconsistent findings. Tucker and Amato (2006) examined the impact of basketball success on academic prestige, defining success as the number of appearances in the final AP Poll, as well as the number of games played in the NCAA Tournament, between 1993-2002. After breaking up their sample into two sub-samples (1993-1997 and 1998- 
2002), the authors produced contrasting results. For the 1993-1997 subsample, the number of NCAA Tournament games played was positively, significantly, correlated to higher SAT scores of incoming freshmen. Conversely, the authors observed no such relationship for the 1998-2002 subsample. Tucker and Amato (2006) conclude that there is no evidence that basketball success consistently increases academic quality, and that if such a relationship exists, it is short lived.

While Tucker and Amato's (2006) study simultaneously found evidence of basketball success increasing and failing to increase academic prestige, more studies have produced the latter result. Bremmer and Kesselring (1993) explored this relationship, defining success as the number of appearances a school's basketball team made in the NCAA Tournament in the 10 years prior to 1989. Similar to the authors' findings on football success and student quality, Bremmer and Kesselring (1993) found no evidence of basketball success improving student quality. Similarly, Smith (2008) examined the impact of basketball success on academic credentials for all NCAA Division I schools. Smith measured athletic success four (4) different ways: overall winning percentage, number of appearances in the NCAA Basketball Tournament, making the Final Four of the NCAA Basketball Tournament, and having a "breakout season," defined as: having a winning season for the first time in 13 or more years, making it to the NCAA Basketball Tournament for the first time in 13 or more years, and reaching the Final Four of the NCAA tournament for the first time in 13 or more years. Additionally, Smith (2008) incorporated three variables to measure student credentials: the proportion of freshmen in the top $10 \%$ of their high school class, the proportion of freshmen with a grade point average of B or better, and the number of entering National Merit Scholars. Despite 
Smith's (2008) wider sample size and multiple variable measurements, basketball success did not strengthen student credentials, making it difficult to support any increase in academic quality as a result of on-court success.

\section{Athletic Success' Impact on Academics Summary}

In sum, the relationship between athletic success and applications, as well as academic exclusivity, is a complicated one. No consistent evidence has emerged to either prove or disprove the notion athletic success strengthens incoming student quality. However, both football and basketball success have shown to produce marginal increases in applications. This increase then puts schools in a position to be more exclusive with the students that they accept. Whether the schools choose to do so by lowering their acceptance rate or opt to focus on accepting more students and receiving more tuition revenue appears to be a case-by-case decision.

Looking specifically at athletic success and applications, the limitations of previous research become apparent. While these studies may provide quantifiable justifications for the Flutie Effect, they leave many questions unanswered. For example, why did students find Georgia Tech so attractive that applications increased $21 \%$ following the football team's 1990 championship season? Was the championship merely a contributing factor in applying, or were there other important considerations? Why did other schools in the same study actually see a decrease in applications following their championship seasons? The Flutie Effect may effectively answer the "what," regarding athletic success and applications, but is unable to answer the "why." Because of these limitations, future research should look beyond objective success' impact on applications and focus on perceived success' influence on students' actual enrollment decision. 
Another important consideration is the age of the studies on this topic. Athletic department spending has increased significantly since the 1990's (Huml et al., 2019), when most of these studies were published. Since then, there has been a lack of research on the effects of perceived athletic success. As a result of these budget challenges, it is imperative for academics to continue researching whether or not football and basketball success are effectively attracting more students to the university.

\section{Student College Choice Process}

In order to understand how athletic success may impact enrollment, it is important to understand how students choose which institution to attend. While numerous factors may drive high school students' college decision, including cost/financial aid (Hu \& Hossler, 2000; Maringe, 2006), institutional reputation and fit (Chapman, 1986; Galotti \& Mark, 1994, LaFave et al., 2018; Solikhah et al., 2016), campus facilities (Lee \& Chatfield, 2011; Price et al., 2003; Rickes, 2009) and proximity to home (Beswick, 1989), we must look at the differences between the application and enrollment decision to connect these outcomes to perceptions of athletic success research.

If institutions wish to effectively recruit students, they must first successfully sell them on the benefits of enrolling (Johnston, 2010). One of the most efficient ways to do so is by instilling a distinct institutional image in students' heads (Parameswaran \& Glowacka, 1995). A strong image can give schools a competitive advantage, as students use this to differentiate them from other institutions (Han, 2014). Landrum et al. (1998) discuss how athletics can shape institutional image, primarily through a "halo effect" (p. 55), where individuals take their impression of one aspect of an institution and use this to inform their impression of another aspect. With athletics, potential students may perceive 
a direct correlation between athletic and institutional quality, similar to what Goidel and Hamilton (2006) discuss. These findings align with previous research on the Flutie Effect, as the number of increased applications following successful seasons are possibly due to students perceiving a stronger institutional image. However, while the "halo effect" indicates athletics may increase student interest, does this translate to actual enrollment? Several studies on the student college choice process show that students' conversion from interest to enrollment is a complicated one.

Hossler and Gallagher (1987) developed a three-stage model to measure the college choice process. This model has since become one of the most popular to measure students' college choice decisions, due to its combination of economic and sociological factors (McEvoy, 2005). The three (3) stages in this model are predisposition, search, and choice. The predisposition phase involves high school students deciding whether or not they want to continue their education by attending a postsecondary institution (Hossler \& Gallagher, 1987; Terenzini et al., 2001). The search phase involves gathering information about various postsecondary institutions (Hossler \& Gallagher, 1987; Long, 2004). At the end of this phase, students narrow down their list of potential schools to a smaller list of schools they intend to apply to, referred to as the "choice set" (Jackson, 1982). Lastly, in the choice phase, students decide which college from their choice set they will attend (Hossler \& Gallagher, 2004; Terinzini et al., 2001). Hossler and Gallagher (1987) note that different factors and characteristics drive each of the three phases. For instance, student characteristics such as high school guidance counselors and parental education and influence dictate the search phase. When transitioning to the choice phase, students rely on primary information, such as financial aid and institutional quality. 
Chapman (1986) used a slightly different model to research students' college choice decision and produced many similarities to Hossler and Gallagher's (1987) study. Chapman's model included five (5) stages: Pre-Search Behavior, Search Behavior, Application Decision, Choice Decision, and Matriculation Decision. Pre-search behavior is very similar to Hossler and Gallagher's (1987) predisposition phase, where the student realizes/decides that they want to continue their education and need to attend a postsecondary school upon completion of high school. This phase involves weighing the costs and benefits of attending college, as well as weighing alternatives. The search stage entails an extensive information search on attending college, as well as the aforementioned alternatives. This phase concludes with students deciding which set of schools they will apply to, similar to the "choice set" mentioned by Jackson (1982). The application decision begins once students decide that they will almost certainly be attending college, and there are very few alternatives on the table. The choice decision is characterized by all of the schools to which a student applies and has been accepted. This phase usually concludes with the student officially deciding which school they will attend. Lastly, the matriculation decision involves the period between the student deciding which school they will attend, and actually setting foot on campus and starting their postsecondary education. During this stage, many factors can change, namely financial, family, or personal, which lead to the student never showing up to campus (the "no show" problem). Chapman discusses how, during the search behavior stage, students will seek out a variety of resources to gather information, such as, guidance counselors, friends, and family members. However, during the application decision, students will rely less on their inner circle, and more on the likelihood of being accepted to a specific 
school, as well as the tuition and fees. Thus, the resources that drive the search phase are different than those that drive the enrollment decision.

Galotti and Mark (1994) arrive at a similar conclusion. Here, the authors surveyed college-bound high school students about the factors they considered when making their college decision. They examined the information the students considered, decisionmaking activities they undertook, and how they evaluated the factors and information of each school. Galotti and Mark (1994) found that the major sources students consulted in the initial stages of their college choice decision were parents/guardians, friends, materials in the guidance center, and college brochures. However, as the year progressed and the time to make a decision drew closer, students placed less emphasis on brochures and other forms of secondhand information and prioritized getting information from the college admissions staff. Galotti and Mark (1994) concluded that as the decision process progressed, students sought out more institution-specific information, such as admissions requirements, course offerings, campus atmosphere, class size/student-faculty ratio, and financial aid. Thus, Galotti and Mark (1994), in conjunction with Hossler and Gallagher (1987) and Chapman (1986), show that the most important factors for schools to appear on potential students' radars are different than the factors that students use to make their actual enrollment decision.

These findings are especially important when factoring prominent athletics into the college choice process. LaFave et al. (2018) followed up on a 2009 longitudinal study on the characteristics that most influenced ninth graders' college choice decision. The authors surveyed the same group of students again in 2012 to see if these factors changed in the past three years. Of the 12 factors included in the study, students ranked school 
teams and spirit as the seventh most important factor, behind academic quality/reputation, desired program of study, job placement, cost of attendance, graduate school placement, and good social life. Thirty-three percent of the sample indicated that school teams and spirit was a very important factor in their college choice, $43 \%$ indicated it was somewhat important, and $24 \%$ indicated it was not important at all.

In a similar study, Braddock and Hua (2006), using data from a National Education Longitudinal Study, examined the most important college choice factors for high school students. Students were originally sampled when they were in the eighth grade, with three follow-up studies conducted when the participants were in $10^{\text {th }}$ grade, $12^{\text {th }}$ grade, and two years removed from high school. The sample was originally comprised of 14,915 students, of which Braddock and Hua (2006) then selected a subsample of 486 African-American students who had enrolled in a four-year college or university by the time of the third follow-up study. Braddock and Hua (2006) found that career factors had the strongest influence on students' college choice decision, while college athletic reputation was "not among the top factors considered" (p. 541).

While these findings seem to dispel support for the Flutie Effect, there are several limitations. Mainly, the aforementioned studies measure students' most important college choice factors while they are still in high school, but do not report which universities students ended up attending. As a result, this research is more aligned with the role of athletics on students' interest in a particular college or university, as opposed to current students' perspectives on the role of successful athletics on their actual enrollment decision. As Galotti and Mark (1994) and Hossler and Gallagher (1987) discuss, the factors influencing student interest are different than those that influence enrollment. For 
example, the Flutie Effect is predicated upon athletic success providing enhanced visibility and student interest in the school. Accordingly, there is no way to know if the specific schools that students in LaFave et al.'s (2018) or Braddock and Hua's (2006) study applied to became more attractive following a successful athletic season, which elevated the importance of athletics in the college choice model. Without knowing which schools students actually apply to and enroll at, the impact of the Flutie Effect on the college choice decision warrants further inquiry. For instance, if a university receives a $20 \%$ increase in applications following a successful football or basketball season, how many of these additional applicants enroll at the institution, versus how many decided to attend another institution? Such information is impossible to discern from secondary data.

As outlined in the previous section, multiple studies have linked athletic success to an increase in the number of applications to the university. However, this correlational data does not provide a holistic view of this relationship. For example, were students who applied to these respective universities doing so solely because of their successful athletic programs? Conversely, did success merely serve as a tool to get these schools on students' radars, and the decision to enroll came from other aspects of the university? To address these limitations, the current study will assess the impact of football and basketball success on college enrollment choice. The goal is to uncover if athletic success is an effective tool to increase student enrollment, not just general interest.

\section{Student College Choice Process Summary}

Research has shown students' process for choosing their postsecondary institution to be complex, with an abundance of factors to consider. Several studies (i.e., Chapman, 1986; Hossler \& Gallagher, 1987; Galotti \& Mark, 1994), have found that the factors 
which drive the enrollment decision and different than those which drive the application decision. This is a salient finding, as previous Flutie Effect research has relied exclusively on secondary data. Thus, while football and basketball success may increase the number of student applications, college choice literature suggests that this may not lead to increases in enrollment. This creates an even greater need for future research to gather primary data on the effects of perceived athletic success, and to uncover whether athletic success is effectively aiding universities' enrollment efforts.

\section{Social Identity Theory}

The following sections will outline Social Identity Theory's applicability to the current study. While the framework has been applied to studies in a variety of disciplines (Hogg \& Ridgeway, 2003; Rees, et al., 2015), including psychology (Abrams \& Hogg, 1998), organization and management science (Ashforth \& Mael, 1989; Hogg \& Terry, 2000), and political science (Brewer, 2001; Huddy, 2001), its core tenets also make it appropriate to examine sport management topics. Several key components of Social Identity Theory, such as ingroup bias/favoritism and the desire for self-esteem are especially salient in sport fandom. First, we will provide an overview of Social Identity Theory, followed by a section detailing its relevance to sport management research. Lastly, we will provide justification for Social Identity Theory's use in the current study, specifically as it pertains to the Flutie Effect.

\section{Social Identity Theory Background}

While Henri Tajfel's (1978) work is considered the seminal piece of literature on Social Identity Theory, the framework can be traced back to Festinger's (1954) Social Comparison Theory. Here, Festinger (1954) suggested that individuals strive to attach 
themselves to slightly better individuals (Jacobson, 2003). Building off of Festinger's (1954) work, Tajfel (1978) developed Social Identity Theory. While "identity" refers to "the meanings that persons attach to the multiple roles they typically play in highly differentiated contemporary societies" (Stryker \& Burke, 2000, p. 284), Tajfel (1978) defined social identity as "that part of an individual's self-concept which derives from his [her] knowledge of his [her] membership in a social group (groups) together with the value and emotional significance attached to that membership" (p. 63). According to Social identity Theory, individuals derive a large sense of self through their membership in social groups, such as organizational membership, religious affiliation, gender, and age (Tajfel \& Turner, 1986). As individuals immerse themselves deeper into these social groups, they begin placing less emphasis on their own self- interest and more on what benefits the group as a whole (Brewer, 1991).

In addition to deriving a sense of self through group membership, Social Identity Theory contends that individuals tend to possess ingroup bias, or "any tendency to favor the ingroup over the outgroup, in behavior, attitudes, preferences or perception" (Turner et al., 1979, p. 187). As a result, individuals use group membership to enhance their selfesteem, believing their group to be superior to the outgroup (Turner et al., 1979). Tajfel and Turner (1979) list three factors that underpin the emergence of group favoritism: "(1): the extent to which individuals identify with an ingroup and internalize that group membership as an aspect of their self-concept; (2) the extent to which the prevailing context provides ground for comparison between groups and; (3) the perceived relevance of the comparison outgroup, which itself will be shaped by 
the relative and absolute status of the ingroup" (Tajfel \& Turner, 1979, as cited by Rees et al., 2015, p.1084).

These favorable comparisons to outgroups are one of Social Identity Theory's main components, as individuals will leave their group and join a more positively-valued group when they no longer believe the ingroup comparison to be satisfactory (Festinger, 1954; Tajfel \& Turner, 1979).

Turner et al. (1979) conducted a well-known study on ingroup bias and favoritism. Here, Turner et al. (1979) assigned schoolchildren to either high-reward or low-reward conditions. The researchers told the children in each group that they would be compensated for their participation in the study, but let them decide their payment, with the high-reward group having more money available to distribute to their group than the low-reward group. Participants also decided who they perceived to be the relevant ingroup and outgroup. The results showed that individuals established ingroup superiority by overestimating ingroup performance and underestimating outgroup performance. Participants were even willing to sacrifice personal economic gain in order to establish a favorable ingroup comparison.

Ingroup favoritism is particularly important during incidences of intergroup conflict. When intergroup conflict occurs, members of the opposing group are more likely to behave as a function of their group membership, as opposed to their individual characteristics (Tajfel \& Turner, 1979, 1986). This behavior is largely driven by the desire to remain superior to the outgroup, as members believe that outgroup conflict makes it even more important for them to not have a similar intergroup conflict (Tajfel \& Turner, 1979). While these ingroup biases and favoritism behaviors occur in almost all 
social groups (Turner et al., 1979), they are particularly visible amongst sport fan groups, extending this framework to sport management topics.

\section{Social Identity Theory and Sport}

In addition to social and organization psychology research, Social Identity Theory has also been a popular framework in sport management literature. This is largely due to sport's social nature, as sport serves as a "near universal and nonthreatening conversation topic” (Wenner \& Gantz, 1989, p. 242), which allows individuals to form a bond with those who share a similar passion for sports (Phua, 2010). Donavan et al. (2005) examined the personality traits that serve as antecedents to sport fan identification, or "the personal commitment and emotional involvement customers have with a sport organization" (Sutton et al., 1997, p. 15). Donovan et al. (2005) found a positive relationship between fan identification and one's need for group affiliation. Further, Rees et al. (2015) argues that groups are not merely aspects of sporting events, but rather, elements that comprise an individual's sense of self, a notion consistent with Social Identity Theory. Thus, sport management research supports the idea that sport fan identity development is strongly influenced by the need for a positive social identity (Jacobson, 2003).

Sport management research has also shown motivations for sport fandom to be heavily rooted in self-esteem. Cialdini et al. (1976) conducted a study commonly regarded as the seminal piece of literature on sport consumption behavior (Jensen et al., 2016). Cialdini et al. (1976) monitored students' apparel at seven universities following their school's football game the previous weekend. Cialdini et al. (1976) found that students at these universities were more likely to wear team apparel following a win, 
using the victory to associate with a successful ingroup. The authors also noted students' tendency to use the term "we" when referring to the team's victory. Such behavior came to be known as "BIRGing," or Basking in Reflected Glory (Cialdini et al. 1976), a decision driven primarily by an individual's desire to maintain their self-esteem (Wann \& Branscombe, 1990). Cialdini et al. (1976) also noted that individuals frequently used the word "they" to refer to the team when they lost, behavior which later came to be known as "CORFing" or Cutting off Reflected Failure (Snyder et al., 1983, 1986). CORFing behavior also ties back to Tajfel and Turner's (1979) study, where the authors reported that individuals would attempt to find a new group to join if their current one was not producing desired results.

Another important factor when examining BIRGing and CORFing behavior amongst sport fans is how the fan group itself can be a means to enhance self-esteem. While sport fans are more likely to identify with successful teams (End et al., 2002), research suggests that a tendency to CORF does not necessarily mean finding a new team to support. Fisher and Wakefield (1998) examined how differences in group success impacted the factors that lead to group-supportive behaviors and team identification, the latter being defined as "the degree that the fan views the team as an extension of selfidentity.... the extent to which the fan feels a psychological connection to the team" (Wakefield \& Wann, 2006, p. 168). Fisher and Wakefield (1998) surveyed fans of two professional hockey teams: one successful and one unsuccessful. Fisher and Wakefield (1998) found that, while team performance was the most important factor amongst the successful team's fan group, fans of the unsuccessful team identified according to the group members' attractiveness, defined as their perception that individuals possessed 
"desirable or aspirational qualities" (p. 31). This suggests that even if a team is not successful, sport fans may base their self-esteem on their identification with the team's fan group (End et al. 2002; Fisher \& Wakefield, 1998). Thus, while team performance plays an important role in fans' tendency to BIRG and CORF, sport fans exhibit many of the same characteristics (i.e., basing their identity on group membership) as members of other social groups, such as gender and age groups. However, regardless of team performance, literature has indicated that BIRGing and CORFing behavior, as well as team identification, is ultimately rooted in the pursuit of maintaining self-esteem (Cialdini et al., 1976; Wann \& Branscombe, 1990), a core tenet of Social Identity Theory.

A key concept in BIRGing and CORFing behavior is vicarious achievement. Vicarious achievement's roots can be traced back to Maslow (1943), who proposed that people have an inherent need to achieve and be successful. Sloan (1989) suggested that individuals might not be able to meet this need through their own accomplishments and endeavors and would be forced to satisfy this need vicariously through others' achievements. Thus, the most common way vicarious achievement manifests itself in sport is fans BIRGing following a win (Kwon et al., 2008; Trail et al., 2012). For the current study, potential students who place an emphasis on athletic success when making their college choice are possibly motivated by the need for vicarious achievement. For instance, potential students may view a poorly performing football or basketball teams as a threat to their self-esteem. Conversely, a successful football or basketball teams gives them the opportunity to fulfill their need for achievement vicariously.

The "us vs. them" philosophy that underpins Social Identity Theory is also extremely common amongst sport fans. Uhlman and Trail (2012) explored ingroup 
differences between first and second-year season ticket holders of the Seattle Sounders FC. Team identification was found to be strongly related to fan superiority, indicating that the more identified fans were with the Sounders, the more likely they were to believe they were part of the "best" fan base in Major League Soccer. Similar results emerged in Sanderson's (2013) study. Here, Sanderson (2013) examined how University of Cincinnati Football fans used Facebook to manage a social identity threat following head coach Brian Kelly's departure for Notre Dame. Sanderson (2013) found that Cincinnati fans stigmatized Kelly's decision in order to reinforce their belief that Cincinnati was a better, more desirable program to be a part of than Notre Dame. In a similar study, Sanderson et al. (2016) explored Facebook and Twitter commentary following the St. Louis Rams' protest of Michael Brown's shooting at the hands of a Ferguson, Missouri police officer. Of the six primary themes, "renouncing fandom" was the most popular, generating 255 unique comments. Sanderson et al. (2016) posited that Rams players taking an opposing viewpoint on the issue presented a social identity threat for fans. Subsequently, individuals felt that their Rams fan group membership was compromised. These findings align with the superiority tenets of Social Identity Theory (Turner et al., 1979), extending this concept to sport fandom.

\section{Social Identity Theory and The Flutie Effect}

As discussed above, sport management research shows strong parallels between sport fandom and Social Identity Theory's underlying principles. For instance, ingroup superiority, bias, and conflict, and the preservation of self-esteem, are all prevalent in sport fandom behaviors. However, the framework may also help explain students' enrollment decisions as well. In addition to the aforementioned limitations of Flutie 
Effect research, secondary data also does not provide specific reasons students are more attracted to an athletically successful institution. It is possible that this relationship is driven by some of Social Identity Theory's core tenets. Students may wish to attend a school with successful athletics because affiliating with the university's teams can raise their self-esteem. For instance, students may feel that enrolling at a school with high levels of football or basketball success would give them a greater sense of vicarious achievement than attending a school with less successful athletics. Potential students may also feel that choosing an athletically successful institution would make them a member of a "superior" fan base (Uhlman \& Trail, 2012), increasing their social interactions and subsequent satisfaction (Boyle \& Magnusson, 2007). Social Identity Theory may also help explain why students who perceive higher levels of athletic success place more relative importance on social life when making their college enrollment choice. This leads us to the formulation of our first research question:

- RQ1: Do subjective perceptions of football success and subjective perceptions of basketball success influence how students perceive the importance of athletic in their college choice decision?

\section{Social Identity Theory Summary}

Since Henri Tajfel's (1978) seminal work, Social Identity Theory has been a popular framework within sport management literature (Fisher \& Wakefield, 1998; Wakefield \& Wann, 2006, Uhlman \& Trail, 2012). This is largely due to sport fans exhibiting similar behaviors and tendencies as those in other social circles, such as ingroup superiority (Sanderson, 2013; Uhlman \& Trail, 2012) and protection of self-esteem (Cialdini et al., 1976; Wann \& Branscombe, 1990). Social Identity Theory may also 
prove to be a valuable framework for the current study, as it could provide greater insight into the Flutie Effect. Specifically, it may help explain how athletic success' impact on enrollment decisions, campus SOC, and enrollment satisfaction is rooted in the social elements of football and basketball fandom.

\section{Student Enrollment Satisfaction \& Sense of Community}

Athletic success' impact on enrollment decisions becomes even more salient when viewing students as customers. Consumer behavior research has regularly found that businesses are more likely to retain satisfied customers (Darzi \& Bhat, 2018; Díaz, 2017; Han et al., 2018; Koay \& Derek, 2016). Within academia, satisfaction makes students more likely to persist in their education, as well as choose the same university again if they were to revisit their enrollment decision (Schreiner \& Nelson, 2013).

Consumer behavior research's findings have also extended into sport management literature. Athletic success has been correlated with higher student retention levels (Hickman \& Meyer, 2017; Tucker, 2004), while the presence of intercollegiate athletics has also been linked to higher student satisfaction levels (Hanson et al., 2019; Warner et al., 2011). These outcomes are strongly rooted in social concepts, as athletics may increase student interaction, subsequently strengthening social identity and satisfaction (Boyle \& Magnusson, 2007). However, it is unclear whether or not athletic success leads to higher student satisfaction with their enrollment choice. Because of these results and limitations, future research also needs to explore the relationship between athletic success and enrollment satisfaction. If schools wish to continue using prominent, successful athletics as a means to attract more students, it is imperative to know whether students 
whose enrollment decision is influenced by athletic success are more satisfied with this choice.

SOC is also an important variable in the relationship between athletic success and student satisfaction. Like satisfaction, SOC's role is rooted in social concepts, primarily due to its emphasis on group membership (McMillan \& Chavis, 1986, Schreiner, 2013) and social support (Warner et al., 2013). For instance, students may consider game attendance as an avenue to build a friend group and acclimate to college, similar to the "football chicken soup" effect (Mixon \& Trevino, 2005), which raises their SOC and subsequent enrollment satisfaction.

The term " psychological sense of community" first appeared in Sarason (1974), who defined it as "an environmental or community characteristic that leads to individuals feeling a sense of belonging and social support at the group-level" (cited in Warner et al., 2013, p.349). Building off this framework, Chavis and Newbrough (1986) developed the Sense Of Community Index. Since then, academics have commonly referred to this concept as simply "sense of community" (Clopton, 2007).

SOC includes elements such as membership, influence, integration, interdependence, feelings of ownership and contribution, fulfillment of needs, and shared emotional connection (McMillan \& Chavis, 1986, Schreiner, 2013). While SOC has been studied in various environments, including neighborhoods (French et al., 2013), recreational activities (Fairley \& Tyler, 2012), and prisons (Phillips, 2007), the importance of a strong SOC within an educational setting has made it an important area of research. SOC has been linked to several desirable educational outcomes, including higher student retention rates (Bailey et al., 1998; McCarthy et al., 1990), lower levels of 
delinquent behaviors (Battistich \& Hom, 1997), decreased loneliness (Pretty et al., 1994), higher levels of academic performance (Warner \& Dixon, 2013), better subjective wellbeing (Davidson \& Cotter, 1991), and greater satisfaction with school life (Noel-Elkins et al., 2019). A strong SOC can make individuals feel that they are part of a larger, more reliable, and more stable structure (Warner \& Dixon, 2013), making it vitally important for college and university officials to generate SOC on campus (Boyer, 1990).

Within the classroom, while SOC may lend itself to in-person, social interactions, several studies have posited that schools may also foster SOC in online-only settings. This is particularly important during the COVID-19 pandemic, as schools have been forced to reduce or eliminate in-person learning (Johnson et al., 2020), drastically limiting students' social interaction opportunities (Son et al., 2020). While remote learning can lead to students feeling disconnected, isolated, and distracted (Besser \& Donahue, 1996; Kerka, 1996, Twigg, 1997), Rovai (2002) posits that, given SOC's emphasis on connectedness and mutual interdependence, what students do is much more important to community than where they do it. McInnerney and Roberts (2004) suggest that synchronous communication, clear, effective communication, and active classroom discussion are just three of the ways that instructors may establish a SOC in their classes. Thus, even if students are not able to socialize before, during, or after class, colleges may still form a SOC amongst their students by facilitating an engaging online learning environment.

Beyond academic sources, numerous authors have posited that sport can serve as a viable channel to foster a SOC (Chalip, 2006; Lyons \& Dionigi, 2007, Mitrano \& Smith 1990). This is primarily due to sport functioning as a social agent, as identifying with a 
team can give individuals a sense of belonging by watching and attending games together (Clopton, 2007; Heere \& James, 2007; Schimmel, 2003; Swyers, 2005). This phenomenon may be even more important amongst college students. For example, DeNeui (2003) surveyed 120 incoming first-year students regarding their perceived SOC on campus: once at the beginning of the school year and again at the end. While DeNeui (2003) found no significant overall increases in SOC, the level of campus participation moderated this relationship. Specifically, there was a significant, positive correlation between students' participation in campus activities and their perceived SOC.

Several studies have replicated DeNeui's (2003) findings on campus involvement, such as Phipps et al. (2015), who found a significant and positive relationship between intramural sport participation and SOC levels. Noel-Elkins and Forrester (2011) also found involvement with campus recreation to be a significant and positive predictor of SOC. However, given Mixon and Trevino's (2005) discussion of football attendance as a means to campus acclimation (i.e., the "football chicken soup effect"), we can reasonably state that attending sporting events is one of the easiest, most common ways for students to become involved on campus, and increase their perceived SOC (DeNeui, 2003). Chu (1989) makes a similar comment, remarking that, "by affiliating with the [university] team, by caring for its scores, we declare allegiance to an interest greater than oneselfthe community" (p. 160).

Previous research supports this notion, as the presence of intercollegiate athletics has been shown to create a stronger SOC on campus (Stensland et al., 2019). However, several notable limitations exist. First, no research to date has examined the role that football or basketball success plays in creating a SOC on campus. Second, enlivening 
school spirit has been shown to be a primary motivation for institutional subsidization of football programs (Feezell, 2009). Since the ultimate goal of athletic subsidization is to create and maintain a winning program, not examining how SOC fluctuates with team performance presents a notable gap in the research, which warrants future consideration. Moreover, it is also possible that SOC is instrumental in the relationship between athletic success and satisfaction, as Warner et al. (2011) found SOC to have a "moderate to strong positive influence" on student satisfaction (p. 236). Conn (2017) also found perceived SOC to be the strongest predictor of student satisfaction with their tuition investment. However, as discussed above, no research to date has explored how athletic success shapes SOC on campus. Because of how athletic success may influence SOC, the former may not be directly impacting enrollment satisfaction. Rather, athletic success might create a SOC on campus, which will then lead to higher student satisfaction. Previous literature has established a relationship between athletic success and retention (Hickman \& Meyer, 2017; Tucker, 2004), as well as SOC and satisfaction (Conn, 2017; Warner et al., 2011). However, it is unclear whether athletic success influences student satisfaction through SOC. Thus, operationalizing SOC as a mediating variable may provide valuable insight into the relationship between athletic success and satisfaction. This leads us to our second research question:

- RQ2: Does Sense of Community (SOC) mediate the relationship between subjective athletic success and enrollment satisfaction?

\section{Student Enrollment Satisfaction and Sense of Community Summary}

In addition to attracting potential students, prominent, successful athletics may also influence current students. Specifically, athletic success may increase SOC levels on 
campus, which subsequently strengthens student enrollment satisfaction. While previous research provides some information about how athletics, SOC, and enrollment satisfaction operate, there is a lack of research regarding how athletic performance impacts these two variables. This is an important literature gap, as in order to continue justifying their spending, universities need to better understand the institution-wide benefits of football and basketball success.

\section{Athletic Success Subjectivity}

Another noteworthy element from studies on the Flutie Effect is the plethora of definitions used to measure success. In educational research, scholars have failed to reach a universal definition of "success" (Gardner, 2009). The same holds true in athletics, as the definition of "success" has been whatever measurement researchers choose to employ. For example, McEvoy (2005) defined success as a $25 \%$ or greater improvement in conference winning percentage from the previous year, while Tucker and Amato (2006) defined success as the number of games played in the NCAA Tournament. In both of these cases, success' entire definition is its unique, objective, operationalization within the study, with no consideration given to it being a subjective construct.

This is an important limitation, as it is possible that some portion of the variance in increase in number of applications, as well as academic exclusivity, can be attributed to success' operational definition. For example, in Tucker and Amato's (2006) study, when measuring basketball success using the number of NCAA Tournament games played, the authors found a positive, significant relationship between success and academic prestige. When success was measured using placement in the AP Poll, the authors found no significant relationship. 
Further, the schools that often benefit the most from increased applications following successful athletic seasons are smaller schools that lack the rich history of other programs (Smith, 2008). Chung (2013) discusses a similar concept, such as how Boise State University saw an $18 \%$ increase in applications after the football team's perfect season in 2006-07. Moreover, in 2013, Florida Gulf Coast University experienced a 39\% increase in applications following the men's basketball team's run to the Sweet 16 round of the NCAA Basketball Tournament (Dosh, 2018). Putting Boise State and Florida Gulf Coast's numbers into perspective, of the 16 football national championship schools in Toma and Cross' (1998) study, only three (3) saw a percentage increase in applications greater than what Boise State enjoyed, and no basketball national championship schools in the study saw a greater percentage increase in applications than what Florida Gulf Coast experienced.

Boise State and Florida Gulf Coast's situations are an important finding. The fact that these schools received a greater increase in applications than schools who won the national championship in the same sport provides anecdotal evidence of success subjectivity. Specifically, this raises the possibility that there is a nuance to success, and individuals may have different benchmarks for determining what constitutes a successful season on a team-by-team basis. Thus, using correlational, secondary data does not tell us how students define success. For instance, if a study uses conference winning percentage to measure football or basketball success, but students at this particular institution do not place high importance on conference winning percentage when defining success, this would significantly limit the findings. Without surveying students' perceptions of athletic 
success, we are unable to determine the exact institutional benefits received from successful basketball and football programs.

The concept of success subjectivity is further supported by current differences between Power Five and Group of Five schools. Lawrence (2013) points out that financial inequities are rampant throughout collegiate athletics, and are extant in all conferences, universities, and athletic programs. Financial equity problems in college sport have been exacerbated in the past few years, as Power Five schools continue to distance themselves from their Group of Five counterparts (Jones, 2018). Russo (2017) discusses a specific example of this increasing gap. In 2017, Washington State University, which competes in the Pacific-12 Conference, generated approximately $\$ 58$ million in athletic revenues, less than any other public school competing in a Power Five conference. However, Washington State's athletic department revenue was still roughly $\$ 18$ million more than Colorado State University, a member of the Mountain West Conference, who reported total athletic revenues of roughly $\$ 40$ million.

This example does not appear to be an anomaly, as Smith (2018) noted that of top 25 most profitable collegiate athletic programs in 2018, all but one belonged to a Power Five conference, the lone exception being Notre Dame, an FBS independent school. These financial equity issues go on to have a profound impact on the collegiate athletic landscape, as Power Five schools have more money to spend on facility renovations and upgrades, coaches' salaries, travel budgets, and player recruitment (Robinson, 2018). In turn, these inequities significantly affect the competitive balance of college sport, as the additional luxuries Power Five schools enjoy compounds the problem. Group of Five 
schools are subsequently unable to shrink the gap between themselves and their Power Five adversaries (Zimbalist, 2013).

In sum, the current makeup of collegiate athletics illustrates a clear discrepancy between Power Five and Group of Five in terms of inputs (i.e., finances/resources). Accordingly, we also see a difference in outputs, such as the lower "ceiling" for Group of Five schools (Dellenger, 2019). As previously discussed, no Group of Five school has appeared in the CFP during its six years of existence, despite several compelling cases for their inclusion. For example, the University of Central Florida (UCF) Knights of the American Athletic Conference finished the 2017 regular season with a pristine 12-0 record (Johnson, 2018). However, the Knights were not selected to compete in the CFP, despite all four Power Five teams that were selected entering the Playoff having at least one regular season loss (Tracy, 2017). The Knights completed another perfect regular season in 2018 and were again excluded from the CFP (Adelson, 2018).

The struggles Group of Five schools face are not exclusive to football. The NCAA Basketball Tournament committee has been frequently accused of favoring “major” schools (consists of all Power Five conferences, plus the Big East Conference) over "mid-major" schools (consists of all Group of Five conferences, plus the Atlantic10, Missouri Valley, Western Athletic, and West Coast Conferences) in team selection and seeding (Byrum, 2017; Duffy, 2014; Feinstein, 2019). Coleman et al. (2010) investigated evidence of such bias in the Division I Men's Basketball Tournament. The authors used data from the 910 teams who participated in the NCAA Tournament between 1999-2008 and found that the committee disproportionately selected major 
schools over mid-majors for tournament participation and tended to seed them more favorably.

Despite these differences between Power Five and Group of Five schools, no research to date has explored how these differences extend to fans' success perceptions. This is a notable gap in the literature, as schools might not be able to successfully market to students and other fans without a true understanding of what they consider successful. Group of Five schools could develop more efficient marketing campaigns if they know how their respective student bodies define success differently than those at Power Five institutions. For example, how successful would UCF fans perceive the football team's 2017 season to be, despite the absence of a CFP appearance? How would these perceptions be different than those for fans of a team that did make the CFP? The concept of success subjectivity, particularly as it pertains to smaller, less high-profile schools, leads us to our third and final research question:

- RQ3: Which factors are most important to Group of Five and Power Five students' subjective perceptions of athletic success?

\section{Athletic Success Subjectivity Summary}

In addition to the aforementioned limitations in studying the college choice process, the usage of secondary data in Flutie Effect research has also meant that success has only been measured objectively. This is problematic, since, in addition to financial inequities, Power Five and Group of Five athletic programs have unequal "ceilings" in regard to athletic performances, such as Group of Five schools' barriers to making the CFP. Thus, future research should strive to obtain a better understanding of which factors 
are most important to Power Five and Group of Five students' subjective views of success, and how these factors differ by institution. 


\section{CHAPTER III}

\section{RESEARCH DESIGN/METHODOLOGY}

The following chapter outlines the methodology for addressing this study's three research questions. We will first discuss the research design, followed by sections on the proposed sample and data collection strategy, instrumentation, instrument development and reliability, and data analysis.

\section{Study Purpose}

The purpose of this study was to measure athletic success' impact on college enrollment decisions, campus sense of community, and enrollment satisfaction, while also attempting to uncover the most influential factors of students' personal definitions of athletic success. While the Flutie Effect has been the basis for numerous academic studies (McEvoy, 2005, Pope \& Pope, 2009; Toma \& Cross, 1998), there is currently a lack of research using primary data to explore this relationship. Subsequently, we cannot determine whether athletic success plays a part in effectively recruiting students to the university. As athletic department expenditures skyrocket across the Division-I landscape, it is important for academics and practitioners to continue examining the institution-wide benefits of athletic success. The results will assist academics in pinpointing athletic success' impact on students' interest and satisfaction with their decision. Moreover, understanding how and what students consider successful will aid sport marketers in developing more effective strategies to appeal to students at FBS institutions. Admissions departments may also use information to better recruit and retain 
students. For example, if football and basketball is found to enhance campus SOC, admissions departments will be able to stress that successful athletic more effectively unify students on campus, creating a superior SOC than students would find at less athletically successful institutions. Such findings may also enhance academics' understanding of Social Identity Theory.

\section{Research Questions}

- RQ1: Do subjective perceptions of football success and subjective perceptions of basketball success influence how students perceive the importance of athletics in their college choice decision?

- RQ2: Does Sense of Community (SOC) mediate the relationship between subjective athletic success and enrollment satisfaction?

- RQ3: Which factors are most important to Group of Five and Power Five students' subjective perceptions of athletic success?

\section{Research Design}

The following study will utilize a cross-sectional survey design, which is most beneficial when seeking to use a representative subset of the population to make inferences about the population (Creswell, 2008; Martin \& Bridgmon, 2012). The specific data collection technique will be surveys. Surveys are one of the most widely used quantitative techniques, mainly due to their ability to represent the population (Queirós et al., 2017). Online surveys are also particularly beneficial, as they require lower development costs and project time than paper and pencil surveys (Porter, 2004). Further, online surveys allow researchers to reach their target population, while also providing greater design flexibility and survey implementation (Dillman et al., 2014). 


\section{Sample/Data Collection}

The target population for this study was students at institutions which compete on the FBS level. Since the FBS is the highest level of collegiate athletics competition, these institutions subsequently spend the most money on their athletic programs (Jewell, 2020). Because this spending is commonly justified by the same benefits the researcher seeks to uncover (increased student interest and SOC), this study targeted students at FBS institutions.

\section{Sampling and Data Collection Procedure/Method}

The current study employed a voluntary-response sample. This method consists of the researcher soliciting respondents for voluntary participation in the study. The voluntary response method is popular when it is difficult for researchers to obtain guaranteed access to the population (Weiner, 2018). However, voluntary response sampling contains two notable disadvantages. First, the researcher has minimal control over participant makeup (Moore \& Kirkland, 2007). This problem is best addressed by comparing participants demographic with that of the general population, which can be done via a Chi-square test. Secondly, voluntary-response sampling tends to disproportionately attract participants who are strongly opinionated on the topic. This risk is difficult to alleviate but is minimized when the study topic is not of a controversial nature (Moore, 1997).

The sampling method in this study consisted of utilizing several different methodologies, the first of which being Amazon Mechanical Turk (MTurk) workers. Amazon MTurk is a platform where researchers may post a specific task for individuals 
("workers") to complete for a monetary reward. The primary benefits of using MTurk are that it allows for a cheap, timely way to collect data. Moreover, Berinsky et al. (2012) notes that MTurk workers are generally younger, less wealthy, and less likely to be married than the general population. For instance, Berinsky et al. (2012) found that MTurk workers have a mean age of 32.3 years, a median household income of $\$ 45,000$, and a marriage rate of $39 \%$. Comparatively, the United States population had a mean age of 49.7 years, a median household income of $\$ 69,000$, and a marriage rate of $56.8 \%$. While this may be a significant concern in certain studies, this demographic information overlaps with that of college students. Thus, there should be an ample supply of MTurk workers who are also college students. Further, Hauser et al. (2018) notes that MTurk studies with undergraduate samples have produced similar findings to non-MTurk studies with undergraduate samples across a variety of disciplines, including cognitive psychology (Crump et al., 2013), social psychology (Klein et al., 2014), judgement and decision making (Paolacci et al., 2010), and economics (Amir et al., 2012).

However, MTurk is not without drawbacks. For instance, Follmer et al. (2017) voiced concerns that MTurk workers tend to choose surveys involving topics of interest to them, making a generalizable sample difficult. Follmer et al. (2017) stated that researchers must be cognizant of MTurk workers' baseline knowledge on the topic. If researchers want to avoid the majority of their respondents having a strong interest in the subject matter, MTurk may not be appropriate. This was a relevant concern for the current study, as we did not want the majority of respondents to be highly identified sports fans. If we are attempting to uncover the institutional benefits of successful athletics, we should strive to include students of all athletic interest levels. Failing to do 
so could be a threat to the study's generalizability. Thus, the researcher also made the decision to collect team identification information, should it be necessary to control for this variable.

In sum, while MTurk has several limitations, it also has benefits (i.e., low cost and short turnaround for data collection), so it was deemed suitable for several reasons. First, the researcher considered attempting to reach out to admissions departments to gauge their willingness to administer the survey to students. However, this data collection strategy would likely not have been feasible, nor would it have involved enough schools for a generalizable sample. Utilizing MTurk will allow the researcher to collect data from a greater number of institutions, which will help preserve generalizability. Secondly, since research question 3 involves uncovering the most influential factors when defining success, targeting students at a particular school is also a threat to study generalizability. For example, if the researcher chose to go through specific institutions to collect data, these factors may not be generalizable if the football or basketball teams are objectively successful and regularly compete for national championships (i.e., University of Alabama Football or Duke University Basketball). Given the anticipated difficulty of getting admissions departments to administer surveys, the researcher would not be in a position to be selective with which schools to include. Using MTurk will increase sample randomization by having more schools represented, as well as reduce the possibility of the majority of responses coming from highly successful football or basketball schools.

There were two MTurk surveys: one to determine participants meet the eligibility criteria, and another with the the full questionnaire. The initial questionnaire consisted of four questions: (1) a yes or no question about whether the participant is a college student, 
(2) if the participant reports being a college student, a fill-in-the-blank for participants to list their institution, (3) a fill-in-the-blank for participants to report their class, and (4) a 7-point Likert scale question, which will instruct participants to select "somewhat agree," in order to better ensure the previous three questions have been answered truthfully. Participants who were students at FBS institutions were invited to complete the second, full questionnaire. Prior to completing the full questionnaire, students were presented with a preamble, explaining the purpose of the study, which will include a disclaimer statement that their participation in the study is completely voluntary. The researcher will also collected several pieces of demographic information from participants, including race, age, and gender.

As MTurk did not generate a sufficient number of responses, a combination of university Facebook groups and undergraduate students were utilized. Previous research has suggested that using social media for data collection is a suitable approach for accessing a target population (Barratt et al., 2015; Seltzer et al., 2014). Further, approximately 96\% of college students use Facebook (Myrie, 2019), making Facebook a viable way to gain access to the target population of college students. However, King et al. (2014) also points out that the risk of duplicate responses is a concern of social media sampling. Thus, participants' Internet Protocol (IP) addresses were captured to ensure that no participant submitted multiple surveys.

Lastly, as MTurk and Facebook groups still did not generate enough responses, professors teaching non-sport management courses were contacted and asked to distribute the survey link to their classes. The decision to target non-sport management students was made to ensure study generalizability. Given this study's topic, it is reasonable to 
expect that sport management majors may have a skewed or non-generalizable interest in the topic. Thus, contacting students in general education and activity classes was the best way to ensure that students from a variety of majors completed the survey. Students were informed that their participation is voluntary and that their responses will remain anonymous.

Creswell (2008) stated that a sample must reasonably represent the target population, which will allow researchers to make generalizations about the population based on the sample. Thus, this study's sample must be representative of the college student population. A 2021 report from Educationaldata.org provided demographic data for college students in the United States. Per their report, $44.5 \%$ of college students were male while $55.5 \%$ were female. In terms of racial makeup, $55.2 \%$ of the population was white and $19.5 \%$ were Hispanic. This study utilized the data from Table 1 as a guideline to determine whether the demographic makeup of the participant sample accurately represented the target population.

Table 1

Demographics of United States College Students

\begin{tabular}{l|c}
\hline Sex & Percentage \\
Male & $44.5 \%$ \\
Female & $55.5 \%$ \\
\hline Race & \\
White & $55.2 \%$ \\
Black or African-American & $9.6 \%$ \\
Hispanic or Latino & $19.5 \%$ \\
Asian & $7 \%$ \\
American Indian/Alaska Native & $0.7 \%$ \\
Native Hawaiian/Pacific Islander & $3 \%$ \\
\hline
\end{tabular}

Source: Hussar et al. (2020)

\section{Instrumentation}




\section{Research Question 1}

To analyze research question 1 , which was concerned with perceptions of football and basketball success' influence on the importance of athletics on enrollment, two existing instruments were operationalized. One instrument measured students' perceptions of both football and basketball success, and the other measured athletics' overall influence on enrollment. This instrumentation allowed the researcher to assess how athletics' importance on enrollment decisions fluctuates based on students' perceived levels of team success. The independent variables for RQ1 were perceptions of football success and perceptions of basketball success, the dependent variable was the importance of athletics on students' enrollment decision, and the covariate will be football team identification and basketball team identification.

Perceptions of football and basketball success were measured using a section of Ross et al.'s (2006) Team Brand Association Scale (TBAS). The full instrument, which is designed to measure professional sport team brand associations, consists of 41 items and 11 team brand associations, one of which is a five-item section on the quality, performance, and/or success of a team.

The TBAS has been used in multiple sport management studies and proven to be reliable and valid (Arai et al., 2013; Biscaia et al., 2013; Ross et al., 2007; Walsh \& Ross, 2010). Ross et al. (2007) examined the TBAS' applicability, reliability, and validity. The authors used multiple goodness of fit measures, including the root-mean square error of approximation (RMSEA), Tucker-Lewis Index (TIL), comparative fit index (CFI), root mean squared residual (RMR), and goodness-of-fit index (GFI). Their results indicated that each goodness of fit measure reached acceptable criterion levels. For reliability 
estimates, Ross et al. (2007) reported that Cronbach's alpha coefficients and average variance extracted (AVE) values ranged from 0.71 to 0.89 and 0.51 to 0.73 , respectively. All values met the recommended criteria, as outlined by Nunnally and Bernstein (1994) and Fornell and Larcker (1981), suggesting the TBAS to be a reliable instrument. Walsh and Ross (2010) also produced similar evidence of the TBAS' reliability. The researchers conducted a confirmatory factor analysis on the TBAS, with Cronbach's alpha coefficients for the 11 scale dimensions ranging from .68 to .89. Using Nunnally and Bernstein's (1994) recommendation of satisfactory Cronbach's alphas being .70 or higher, Walsh and Ross (2010) concluded that only the TBAS' rivalry dimension failed to report acceptable reliability levels, ensuring that the quality, performance, and/or team success section of the TBAS was suitable for use in future studies.

In order to measure perceptions of both football and basketball success, the researcher employed the TBAS twice for this research question: once to measure perceptions of football success at the time of enrollment, and again to measure perceptions of basketball success at the time of enrollment. The items for each section were the same, but the wording prefacing the two respective sections clarified that one section was measuring perceptions of football success at the time of enrollment, while the other was measuring perceptions of basketball success at the time of enrollment. The following items, adopted from the team success section of the TBAS, gauged the extent to which fans considered their schools' football and basketball teams' performances successful at the time of their enrollment decision, and will be measured on a 7-point Likert Scale ( $1=$ Strongly Disagree and $7=$ Strongly Agree):

- The (football/basketball) team is not very successful (reverse scored)

- The (football/basketball) team is a great team 
- The (football/basketball) team is not very high quality (reverse scored)

- The (football/basketball) team has high quality players

- The performance of the (football/basketball) team is first-class

To measure students' enrollment decisions, the researcher created an instrument gauging the importance of athletics on students' enrollment decisions. This allowed us to uncover if students who perceive higher levels of football and basketball success place greater emphasis on athletics in their decision. The items were created with the thought that although students may perceive a schools' football or basketball teams as successful, this does not mean they will place high importance on athletics in their enrollment decision. For example, both the Coastal Carolina Chanticleers and Cincinnati Bearcats football teams finished the 2020 season undefeated (Brunt, 2020). While these are undoubtedly successful seasons, potential students' decisions to attend Coastal Carolina or Cincinnati may not be driven by their athletic programs, possibly due to the lower level of competition. Conversely, students may not view a school's football or men's basketball team as successful but place high importance on athletics. For instance, the 2020 Vanderbilt Commodores football team went 0-9 during the 2020 season (Sparks, 2020). However, due to playing in the Southeastern Conference, which is commonly regarded as the best conference in college football (Crawford, 2018; Palmer, 2018), potential students may be attracted to the higher level of competition, including being able to play the University of Alabama or LSU. Thus, while students may view FBS athletics an important factor when choosing their college, this does not necessarily mean they will perceive the football or basketball teams as successful.

The Athletics and Enrollment Scale consisted of four (4) items designed to measure the importance students place on FBS athletics in their enrollment choice, so that 
we may see how this importance fluctuates with success perceptions. All four items were measured on a 7-point Likert Scale (1=Strongly Disagree and 7= Strongly Agree):

- (School's name) athletics played an important role in my enrollment decision

- If it weren't for (school's name) athletics, I would have attended another school

- It was important for me to attend a school with FBS athletics

- (School's name) athletics attracted me to this school

Additionally, since team identification may explain some of the variance in the dependent variable (the impact of athletics on enrollment decisions), the researcher also collected team identification information to use as a covariate in the analysis. Team identification was measured using Trail and James' (2001) Team Identification Index (TII). This instrument has been used and suggested reliable in several other sport management studies (Kwon et al., 2008, Robinson \& Trail, 2005, Trail et al., 2003, 2005). The TII appeared twice in the survey instrument, once to assess identification with the football team and once to assess identification with the basketball team. This threeitem scale was measured on a 7 -point Likert scale $(1=$ Strongly Disagree and $7=$ Strongly Agree):

- I consider myself to be a "real" fan of the (team name) team

- I would experience a loss if I had to stop being a fan of the (team name) team

- Being a fan of (team name) is very important to me

\section{Research Question 2}

To measure the SOC's mediating effect on the impact of athletic success on enrollment decision satisfaction, three instruments were utilized. This allowed the researcher to uncover both the direct relationship between athletic success and enrollment 
decision satisfaction, as well as SOC's mediating role. For this research question, football and basketball success served as the independent variables, SOC served as the mediating variable, team identification served as the moderating variable between football and basketball success and SOC, and enrollment satisfaction served as the dependent variable.

To measure football and basketball success, research question 2 also employed the success section of TBAS. The items were the same as in research question 1, but the wording prefacing these sections asked respondents to rate their current success perceptions of their schools' football and basketball teams, as opposed to success perceptions at the time of enrollment. For example, research question 1 instructed participants to rate their level of agreement with the five items at the time of their enrollment, while research question 2 asked participants for their current level of agreement with the five items.

SOC was measured using Warner et al.'s (2011) College Sense of Community Scale (CSCS), a modified version of the Campus Atmosphere Scale (Lounsbury \& DeNeui, 1995, 1996). Both the Campus Atmosphere Scale (Clopton 2007, 2008; Lounsbury \& DeNeui, 1995) and the College Sense of Community Scale (Warner et al., 2011) have shown adequate reliability and validity in previous research. Warner et al. (2011) performed both an exploratory and confirmatory factor analysis on the CSCS. Following the exploratory factor analysis, Warner et al. (2011) reported a Cronbach's alpha coefficient of .87 for the revised CSCS, inferring satisfactory scale reliability and validity. Warner et al. (2011) also used multiple goodness of fit measures, including a standardized root mean square residual (SRMR) of .041, an RMSEA of .09, and a CFI of 
0.99 , all of which represented satisfactory model fit. Since research question 2 was concerned with students' current perceptions of campus SOC, the description instructed students to rate their current level of agreement with each statement. The CSCS consisted of six (6) items, all measured on a 7-point Likert Scale (1=Strongly Disagree to 7=Strongly Agree):

- $\quad$ There is a real sense of community at [this university]

- There is a strong feeling of togetherness on campus,

- There is a sociable atmosphere at [this university]

- I I feel very attached to [this university]

- I feel like I belong here at [this university]

- I I feel that I can get help from the university if I am in trouble

Team identification was also measured using Trail and James' (2001) TII. The three items were the same as those used for research question one. By employing team identification as a moderator for this research question, the researcher will be able to see whether football and basketball success' influence on campus SOC is contingent upon a certain level of team identification. In other words, do highly identified fans perceive higher levels of campus SOC than lowly identified fans?

To measure satisfaction, the researcher used a three-item measure developed by Oliver (1980). This three-item construct has been commonly used shown reliability to measure satisfaction with a variety of services (Cronin et al., 2000; Madrigal, 1995;

Oliver \& Swan, 1989). Within sport management research, the scale has also been used and proven reliable to measure satisfaction with bowling leagues (Ruihley et al., 2019), fitness centers (Šíma \& Ruda, 2019), long-distance running events (Hyun \& Jordan, 2019), and road racing events (Funk et al., 2011). The scale consists of three modified 
items adapted from Oliver (1980), each measured on a 7-point Likert scale $(1=$ strongly disagree and $7=$ strongly agree):

- I am happy that I attended [this university]

- I am satisfied with my decision to attend [this university]

- I did the right thing by attending [this university]

\section{Research Question 3}

To explore whether students at Group of Five schools define success differently than those at Power Five schools, students were asked to rate the importance of various criteria when determining how successful they perceived their school's football and basketball teams to be. This list consisted of success measurements used in previous literature on the impact of athletic success on applications and academic prestige, such as year-over-year improvement (McEvoy, 2005) and conference winning percentage (Murphy \& Trandel, 1994). Only success measurements that have been used in studies on the topic were included as items on the list. For example, students were asked to rate the importance of national championships in their personal definitions of success, based on Toma and Cross' (1998) study, which measured success as winning the college football or basketball national championship. A total of eight (8) criteria will be converted to items, and respondents were asked to indicate on a 1 to 7 Likert scale how important each measure is when formulating their personal definition of success for both football and basketball success. (1=Extremely Unimportant and 7=Extremely Important). The eight (8) criteria to be converted into items are summarized by the table below.

Table 2

Athletic Success Variables as Items

\begin{tabular}{|c|c|}
\hline Item & Author(s) \\
\hline National Championships & Toma and Cross (1998) \\
\hline
\end{tabular}




\begin{tabular}{|c|c|}
\hline Year-Over-Year Improvement & McEvoy (2005) \\
\hline Overall Winning Percentage & Smith (2008) \\
\hline Conference Winning Percentage & Murphy and Trandel (1994) \\
\hline Placement in Associated Press' AP Poll & Pope and Pope (2009) \\
\hline Major Bowl Game Appearances & Bremmer and Kesselring (1993) \\
\hline Appearances in NCAA Basketball Tournament & Pope and Pope (2009) \\
\hline Number of rounds won in NCAA Tournament & Mixon and Ressler (1995) \\
\hline
\end{tabular}

However, since this study was attempting to uncover factors influencing both football and basketball success, some success measurements are not applicable to both sports. For example, since "Major Bowl Game Appearances" is not applicable to basketball success, it will only appear in the football success section. Conversely, "Appearances in NCAA Basketball Tournament" and "Number of rounds won in NCAA Tournament " will only appear in the basketball success section. The first five (5) items from Table 2 appeared in both the football and basketball success section of the questionnaire. Research question 3 also gauged participant's identification with their school's football and basketball teams, which were again measured using Trail and James' (2001) Team Identification Index.

\section{Instrument Development and Reliability}

Prior to proceeding to the data analysis, the researcher took several steps to ensure instrument reliability and validity. Dillman et al. (2014) recommends a panel of experts and a field test/pilot study.

\section{Panel of Experts}


To check for content validity, the researcher consulted a panel of experts to review the full questionnaire. The researcher identified faculty members familiar with collegiate athletic research. The researcher informed faculty members of the study purpose, as well as the instruments utilized to measure the constructs. Upon their agreement to participate, the panel was asked to provide their thoughts on item wording and overall instrument clarity. Items were revised and re-worded based on recommendations from the panel (Dillman et al., 2014).

\section{Pilot Study}

For the pilot study, undergraduate students enrolled in sport administration courses at a Power Five research institution were asked to complete the questionnaire. The pilot study also included sport administration doctoral students at the same institution. Participants were asked to comment on instrument clarity and readability. Any items that participants indicate were unclear were modified.

To address Dillman et al.'s (2014) third recommendation, students participating in the pilot study were also asked to complete the questionnaire using a variety of devices, including smartphones, laptops, and desktop computers. Further, students were asked to complete the questionnaire through different web browsers, as assigned by the researcher, such as Safari, Google Chrome, and Mozilla Firefox. Any issues encountered during the field test were addressed accordingly.

\section{Data Analysis}

Prior to proceeding to the data analysis, an exploratory factor analysis (EFA) on the four-item Athletics and Enrollment Scale will need tp be conducted, as well as a confirmatory factor analysis (CFA) on several of the survey instruments. 


\section{Exploratory Factor Analysis}

An EFA was first conducted to examine the factor structure of items on the Athletics and Enrollment Scale. The researcher used three criteria to determine factor structure: retaining based on eigenvalues greater than one (Kaiser 1960), scree plot graph (Cattel, 1966), and performing a parallel analysis (Horn, 1965). Eigenvalues examine the variance in all variables explained by a factor. A scree plot (Cattel, 1966) is a graphical model factor retention which plots eigenvalues on the y-axis, and the number of factors on the $\mathrm{x}$-axis. The presence of an elbow in the graph indicates the retention cutoff. However, both eigenvalues and scree plots tend to overestimate the number of suggested factors for retention (Henson \& Roberts, 2006). Thus, Henson and Roberts (2006) suggest that a parallel analysis is the most accurate procedure to determine factor retention. A parallel analysis creates a parallel set of eigenvalues from random data and compares those to eigenvalues from the original data set (Horn, 1965). The researcher retained factors if eigenvalues are greater than the average eigenvalues generated from the random data.

\section{Confirmatory Factor Analysis}

Following the EFA, a confirmatory factor analysis (CFA) was conducted on several instruments to test for convergent and discriminatory validity. CFAs were conducted on the Athletics and Enrollment Scale, the College Sense of Community Scale, the Team Brand Association Scale, the Team Identification Index, and Oliver's (1980) satisfaction scale. To measure goodness of fit between the sample and the college student population, a Chi-square test was conducted. Per Hu and Bentler's (1999)

recommendation, since the Chi-square test can be sensitive to sample size, other potential 
measures to assess validity included the CFI and RMSEA. The CFI is a measure used to assess model fit, with $\mathrm{Hu}$ and Bentler (1999) recommending that values between .90 and .95 represent good model fit, while values greater than .95 represent a great fit between the data and the model. Secondly, Hu and Bentler (1999) report that the RMSEA, which is primarily used to assist Chi-square interpretations for large sample sizes (Steiger \& Lind, 1980), can be interpreted as follows: values less than .06 indicate great model fit, values between .06 and .10 indicate good model fit, and values greater than .10 indicate an unacceptable fit between the model and the data.

Evidence of convergent validity was also assessed by using the average variance extracted (AVE) statistic. Using Fornell and Larcker's (1981) suggestion, AVE values exceeding .50 defined good convergent validity, indicating that item scores align with the construct being measured. Discriminant validity was also established if the AVE for the construct being measured exceeded the squared correlations between that and any of the other constructs (Fornell \& Larcker, 1981; Trail \& James, 2001).

\section{Research Question 1}

Research question 1 was concerned with the relationship between football and basketball success on enrollment decisions. The independent variables were football success perceptions (at the time of enrollment) and basketball success perceptions (at the time of enrollment), respectively, as measured by mean scores on the team success section of the TBAS. As previously discussed, the success section of the TBAS appeared four times in the survey instrument: once to measure perceptions of football success at the time of enrollment, once to measure perceptions of basketball success at the time of enrollment, once to measure current football success perceptions, and once to measure 
current basketball success perceptions. Participants' mean scores on the former two sections served as independent variables for RQ 1 . The dependent variable for both RQ1 was participants' mean scores on the Athletics and Enrollment scale. Football team identification and basketball team identification, as measured mean scores on the TII, served as the covariate for RQ 1 . This allowed the researcher to uncover how football and basketball success influenced the importance placed on athletics in students' enrollment decisions, controlling for team identification levels.

To address this question, a hierarchical multiple linear regression analysis was conducted, with football success perceptions and basketball success perceptions at the time of enrollment serving as the independent variable and the importance of athletics on enrollment serving as the dependent variable. Before entering the independent variables and dependent variable into the equation, football team identification and basketball team identification were entered into the first block as control variables. Following the entry of control variables, football and basketball success perceptions at the time of enrollment, as measured by mean scores on the success section of the TBAS, were entered as the primary independent variables for the regression analyses.

The key statistics for interpretation were the $F$-statistic, $R^{2}$, and the unstandardized Beta coefficients. The $F$-statistic reported whether football and basketball success explain a significant amount of variance in the importance of athletics on enrollment. If the $F$-statistic is significant, this indicates that the predictor variables were significantly predictive of our outcome variable. The $R^{2}$ statistic reported how much variance in our outcome variable was explained by the predictor variables. Additionally, since variables were entered in blocks, the change in $R^{2}\left(\Delta R^{2}\right)$, indicated how much 
additional variance football and basketball success explained in the importance of athletics on enrollment, above and beyond our demographic variables and team identification. Predictor variables should ideally explain at least $6 \%$ of the variance in the outcome variable in order for the results to be considered meaningful (Cohen, 1992). Lastly, the unstandardized Beta coefficients indicated the subsequent change in our outcome variable with a one-unit change in our predictor variable.

Several regression diagnostics were also examined to ensure there were no violations of key regression assumptions. Per Field (2009), there are five major assumptions when performing a multiple linear regression analysis: Independence of responses, a normally distributed dependent variable, homoscedasticity among independent variables, linearity of the dependent variable, and an absence of multicollinearity among independent variables.

Independence of responses would require that each participant only completes the MTurk survey once. Thus, an IP address check was conducted to ensure that there are no duplicate IP addresses. To address the second assumption, normality was determined by checking histograms for normal distribution. Homoscedasticity of variance refers to elevated levels of random error amongst independent and dependent variables (Pituch \& Stevens, 2015). This assumption was addressed by generating a scatterplot graph of the residuals of the predicted dependent variable scores and checking for a linear relationship (Pituch \& Stevens, 2015).

Lastly, multicollinearity checks for excessive correlation between the independent variables, suggesting that at least one independent variable is redundant, which can make the regression analysis highly misleading (Pedhazur, 1997). Multicollinearity was 
assessed through the variance inflation factor (VIF). According to Midi and Bagheri (2010), VIF values greater than 10 indicated unacceptable multicollinearity levels.

However, due to the detrimental effects of high multicollinearity, this study implemented a stricter VIF cutoff, following Rogerson's (2001) recommendation of VIF values above 5 being labeled problematic.

\section{Research Question 2}

Research question 2 was concerned with SOC's mediation of football and basketball success on enrollment satisfaction. To address our second research question, two moderated mediation analyses were conducted, with football and basketball success, as measured by the current success perceptions sections of the TBAS, serving as the independent variables, SOC serving as the mediating variable, team identification serving as the moderator between football and basketball success and SOC, and enrollment satisfaction serving as the dependent variable. Per Baron and Kenny (1986), a variable may be considered a mediator if it accounts for or affects the relationship between the independent and dependent variable. Since this research question tested the relationship between athletic success and enrollment satisfaction, with the mediating effect of SOC, this meets the criteria of a mediating variable. The moderated mediation models can be found below:

Figure 1

RQ2 Moderated Mediation Model 1 


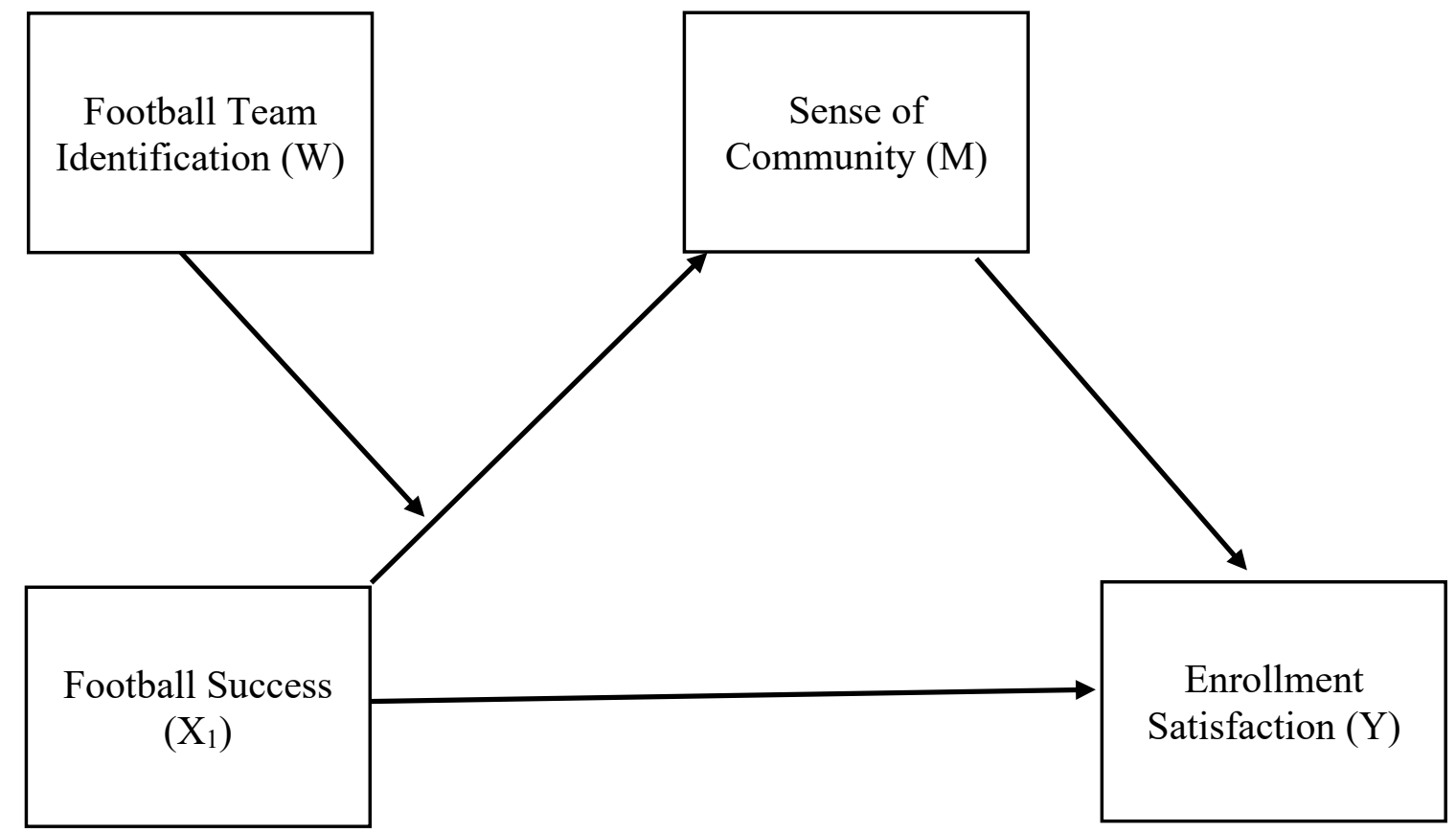

Figure 2

RQ2 Moderated Mediation Model 2

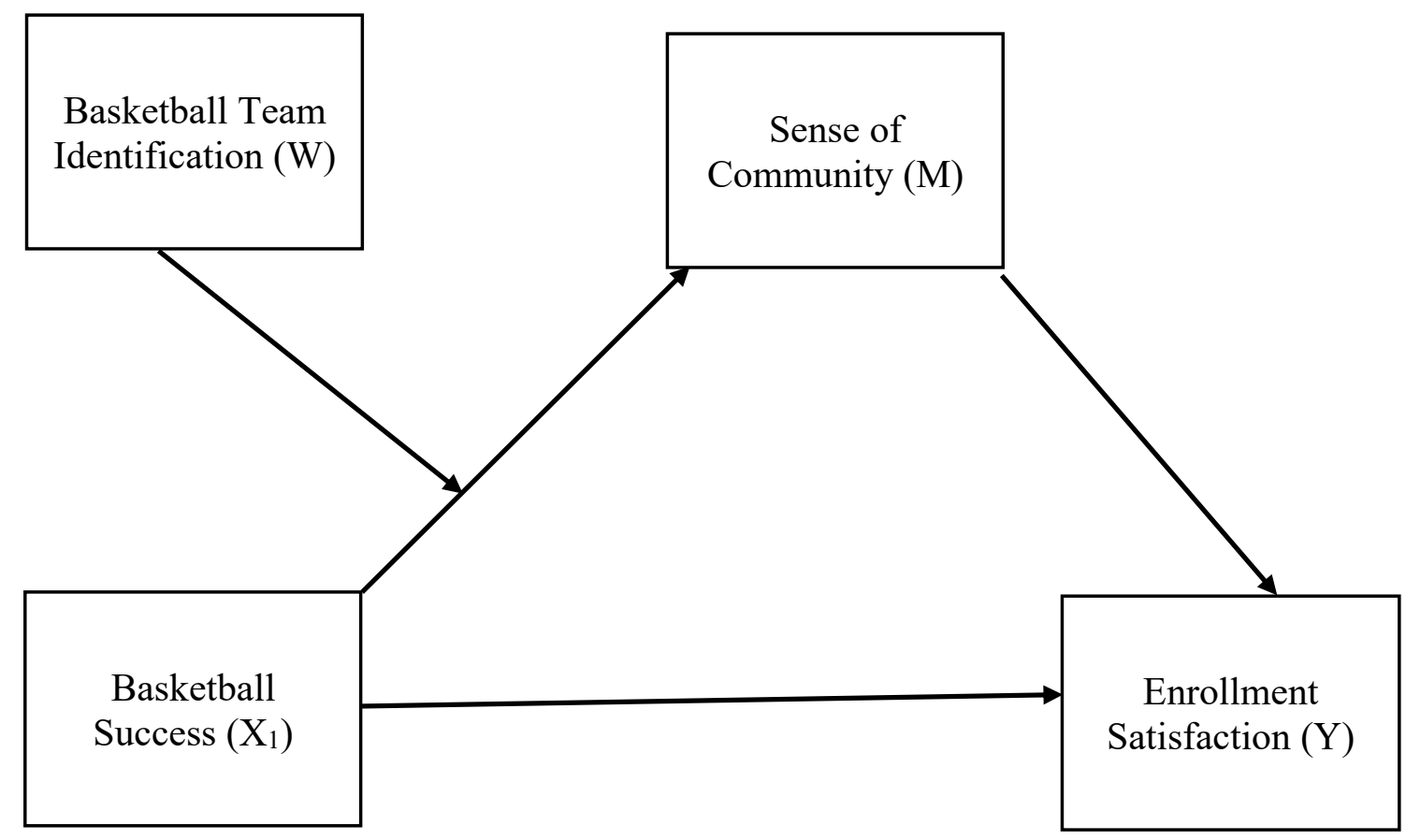


The moderated mediation analyses will be run using PROCESS, a free add-on available through SPSS. PROCESS has shown to be more accurate for conducting mediation analyses than traditional methods, such as Baron and Kenny's (1986) model (MacKinnon et al., 2007). Two mediation analyses were run: one with football success perceptions as the independent variable and football team identification as the moderator, and another with basketball success perceptions as the independent variable and basketball team identification as the moderator. Sense of community and enrollment satisfaction served as the mediating and dependent variables, respectively, in both analyses. Before proceeding to the analysis, mediation assumptions were addressed, which are similar to those used for traditional regression (Judd \& Kenny, 2010): independence of observations, normality, homoscedasticity, linearity, and a lack of multicollinearity amongst independent variables (Field, 2009).

The independence of observations and normality assumptions were assessed the same way as for research question 1 (histograms). To address the homoscedasticity assumption, similar to research question 1, scatterplots of the standardized predicted and standardized residuals scores of our dependent variable were obtained and checked for a linear relationship. To test the linearity assumption, scatterplots and histograms between the dependent variable and the two independent variables were produced (Field, 2009; Pituch \& Stevens, 2016). Lastly, multicollinearity was assessed with the same criteria used for research question 1.

Following these checks, the researcher proceeded to the data analysis. To account for effects on enrollment satisfaction, five (5) beta coefficients were obtained: football success on SOC, basketball success on SOC, football success and enrollment satisfaction, 
basketball success and enrollment satisfaction, and SOC and satisfaction. The beta coefficients were interpreted as the change in our outcome variable (enrollment satisfaction) for every one-unit change in our predictor variable. If the associated p-value for any of these coefficients fell below .05, a significant effect was assumed (MacKinnon et al., 2002).

To test the total effect of athletic success on enrollment satisfaction through SOC, several of the beta coefficients were multiplied together. First, multiplying football success' effect on SOC by the coefficient for SOC's effect on satisfaction, then adding the product to the direct effect of football success on enrollment satisfaction told us the total effect of football success on enrollment satisfaction, through SOC and moderating for team identification. These same measures were repeated to calculate basketball success' direct effect on SOC. However, merely assessing the total effect of an independent variable on a dependent variable through a mediator is not sufficient to determine a significant mediating effect. Rather, the size and significance of the indirect effect of our independent variable on the dependent variable is better evidence of mediation than the lack of a direct or total effect (Zhao et al., 2010).

To assess the indirect effect of both football and basketball success on satisfaction through SOC, with the moderating effect of team identification, the bootstrap test was used. The bootstrap test uses 5000 random bootstrap samples in order to determine a $95 \%$ confidence interval of where path coefficients may fall. If the range of lower-bound and upper-bound confidence intervals does not include zero, we concluded that there is a significant indirect effect. (Hayes, 2012; Hayes \& Rockwood, 2017). If the indirect effect is significant, while the direct effect is not, fully moderated mediation has taken place. If 
both the indirect and direct effects are significant, we concluded there is partially moderated mediation (Zhao et al., 2010).

\section{Research Question 3}

Research question three was concerned with differences in how Group of Five and Power Five students define success. For this research question, the researcher took mean scores for each success item (6 items for football success and 7 for basketball success) and compared them for Group of Five vs. Power Five students. Given the nature of this research question, the researcher believed it was best to compare Group of Five and Power Five students individually for each success item with descriptive statistics, as opposed to incorporating a model for all 13 variables cumulatively. To account for team identification levels, each mean score was accompanied with a correlation coefficient. This allowed the researcher to examine how the importance Group of Five and Power

Five students place on each success measurement fluctuated with students' team identification levels. For instance, as previously discussed, national championships are a largely unrealistic expectation for Group of Five schools, so does the importance of national championships decrease as team identification levels increase? Conversely, for Power Five students, do national championships become more important as team identification increases? 


\section{CHAPTER IV}

\section{RESULTS}

The purpose of this research was to enhance our understanding of the Flutie Effect. Specifically, this study examined perceived athletic success' impact on students' college enrollment decisions, campus sense of community, and enrollment satisfaction, while also attempting to uncover the most influential factors in students' personal definitions of athletic success. This study collected data from undergraduate students at FBS institutions. The following chapter will discuss instrument pretesting and the results of the three research questions.

\section{Instrument Pretesting}

To establish content validity, face validity, discriminant validity, and instrument reliability and consistency, a series of pre-tests were performed. Following Dillman's (2014) recommendation, a panel of experts, a field/pilot test, as well as a Confirmatory Factor Analysis (CFA) to confirm the instrument's factor structure were conducted.

\section{Panel of Experts}

A panel of experts reviewed the study questionnaire for content validity. The panel consisted of faculty members familiar with collegiate athletics or higher education research. Each panel member was contacted via email and was provided with a document containing the study purpose, the modified items, and definitions of each construct being measured. The panel of experts was asked to evaluate the items and construct definitions and provide feedback on the clarity of each item and its ability to appropriately represent 
the construct being measured.

The panel did not express any issues with instrument clarity but suggested several minor changes to item wording. Notably, in order to improve item clarity, the panel suggested changing the wording of all items in the football and basketball success perceptions at the time of enrollment sections to past tense. All items in these two sections were subsequently changed to past tense and prefaced with the phrase "When I decided to attend (university name)." For instance, instead of reading "the (university name) football team is not very successful," the item now read "When I decided to attend (university name), the (university name) football team was not very successful." Similar changes were made to all other items in these two sections. Moreover, for the current success perceptions sections, each item was edited and prefaced with the word "currently," to further reiterate to participants that these two sections were measuring current success perceptions, as opposed to perceptions at the time of enrollment.

The remaining two changes included changing "number of rounds won in the NCAA Tournament" in the factors influencing basketball success section to "number of games won in the NCAA Tournament.” The panel also advised that even highly identified sport fans may confuse "FBS" with "Power Five." Thus, the importance of athletics on enrollment section description was edited to include a list of the 10 conferences that are included on the FBS level.

\section{Pilot Study}

Following the panel of experts' review, sport management undergraduate and doctoral students participated in a pilot study of the instrument. The purpose of the pilot study was to check face validity and provide an initial assessment of scale reliability. For 
reliability purposes, the doctoral student participants were instructed to list the name of their undergraduate institution, as opposed to their current institution. The pilot study participants provided feedback on the overall readability and clarity of survey items as well as the structure and flow of the survey.

A total of 22 students participated in the pilot study. The one piece of feedback received from several participants was the ambiguity of the terms "high quality" and "first-class" in the football and basketball success perceptions sections. However, these terms were left in the instrument with their current wording. This decision was made primarily due to the nature of the construct being measured. These sections were designed to measure subjective perceptions of football and basketball success. Thus, it was determined that the terms "high quality" and "first class" did not necessarily need a clear-cut, objective definition as the participants could decide for themselves how "firstclass" and "high quality" are or should be defined.

The 22 responses also allowed scale items to be examined for internal consistency. To assess reliability for each section of the survey instrument, Cronbach's alpha coefficients were obtained. Based on the Nunnally and Bernstein's (1994) recommendation Cronbach's alphas greater than .70 indicated adequate internal consistency reliability. Table 2 shows each construct, the number of items included in the scale used to measure the construct, and Cronbach's alpha estimates of internal consistency reliability for each scale. Cronbach's alphas ranged from $.80-.98$, providing evidence of strong internal consistency reliability.

Table 2

Internal Consistency Reliability Estimates for Pilot Study

Scale

Number of Items Cronbach's Alpha 


\begin{tabular}{llc} 
Football Success Perceptions (Time of Enrollment) & 5 & .88 \\
Basketball Success Perceptions (Time of Enrollment) & 5 & .91 \\
Team Identification (Football) & 3 & .92 \\
Team Identification (Basketball) & 3 & .98 \\
Importance of Athletics on Enrollment & 4 & .82 \\
Football Success Perceptions (Current) & 5 & .84 \\
Basketball Success Perceptions (Current) & 5 & .80 \\
Sense of Community & 6 & .91 \\
Enrollment Satisfaction & 3 & .96 \\
\hline
\end{tabular}

\section{Descriptive Statistics}

\section{Sample Description}

The sample consisted of undergraduate students at FBS institutions. Data collection occurred through a combination of Amazon MTurk, university freshmen Facebook groups, as well as undergraduate students enrolled at FBS institutions. For the university freshmen Facebook groups, the researcher identified official class of 2024 Facebook groups for various FBS institutions. These groups were private and restricted to freshmen students at the respective universities, with anybody wishing to join or post in the group being required to enter their student ID number. In order to gain access to these pages the researcher contacted administrators to explain the purpose of the research. A total of four pages administrators granted access to post the survey link in the group. However, three of the four Facebook pages did not generate any responses. A total of eight responses came from a single school in the Big 12 Conference.

In order to maximize the study's sample size, students of all classes were eligible 
to participate (i.e., not just freshmen or sophomores). The original data collection plan was to exclusively recruit students using MTurk and to minimize issues of recall bias with success perceptions by also limiting the sample to freshmen and sophomore students. However, MTurk did not produce a sufficient number of responses to serve as the sole data collection source. Thus, the decision was made to increase the sample size by extending the eligibility criteria to undergraduate students of all classes, as well as to utilize Facebook groups and university professors.

Students received a Qualtrics link to the survey instrument either through Amazon MTurk, social media, via professors/administrators, or through an institutional official in the Dean's office. Undergraduate students at a single FBS institution comprised the majority of the survey responses (158 out of 225; see Table 4). However, the researcher took careful action to ensure that the student sample would be generalizable. For example, a total of 325 undergraduate students across a combination of seven activity courses at this university were invited to complete the survey. Targeting students in these seven courses enhanced the study's generalizability by including students from a variety of majors. Moreover, all undergraduate students within one college ( $\sim 2,100$ students) at this University received an email inviting them to complete the survey. This college offers seven undergraduate majors, further increasing the chances for students of differing backgrounds to participate in the study. The researcher also arranged for surveys to be distributed through the University's Cultural Center, as well as the Arabic Program. Therefore, necessary steps were taken to ensure that the student sample was not disproportionately concentrated to students of one particular background, major, or interest group, and that it was representative of the general student population. 
A total of 280 students submitted the questionnaire. However, 33 responses

(11.8\%) did not display a "finished" status on Qualtrics, indicating that the participant did not make it through the entire questionnaire. Of the remaining 247 responses, an additional 22 questionnaires $(9.0 \%)$ were eliminated due to missing data. Thus, the data cleaning process resulted in 225 complete, useable questionnaires for further analysis. This sample size met Suhr's (2006), Loehlin's (2004) and Jackson et al.'s (2013) guidelines for conducting a confirmatory factor analysis and producing generalizable results.

Demographic Information. The final sample of $225(n=225)$ was comprised of 103 males (46.8\%), 117 females (53.2\%), and five (2.2) who chose not to respond. Responses indicated that 159 (70.7\%) of the participants were white, 35 (15.6\%), were Black/African-American, 11 (4.9\%), were Asian, 11 (4.9\%), were Hispanic/Latino, two (0.9\%) were American Indian/Alaska Native, and seven (3.1\%) chose other/preferred not to respond. For class, 72 (32.0\%), of the participants were seniors, 54 (24.0\%), were juniors, 60 (26.7\%) were sophomores, and 39 (17.3\%) were freshmen. Table 3 displays the sample's demographic data, as well as that of the U.S. college student population, the latter of which is also presented in chapter 3.

Table 3

Demographics of College Students in sample and Entire College Student Population

\begin{tabular}{l|c|c}
\hline & Sample & College Student Population* \\
\hline Sex & Percentage & Percentage \\
Male & $46.8 \%$ & $43.3 \%$ \\
Female & $53.2 \%$ & $56.7 \%$ \\
Other/Prefer not to Respond & $2.2 \%$ & $\mathrm{~N} / \mathrm{A}$ \\
\hline Race & $70.7 \%$ & $52.4 \%$ \\
$\quad$ White & $15.6 \%$ & $12.7 \%$ \\
Black or African-American & $4.9 \%$ & $20.5 \%$ \\
Hispanic or Latino & $4.9 \%$ & $6.6 \%$ \\
Asian & $0.9 \%$ & $0.7 \%$ \\
American Indian/Alaska Native &
\end{tabular}




\begin{tabular}{l|l|l} 
Native Hawaiian/Pacific Islander & $0.0 \%$ & $0.27 \%$ \\
Other/Prefer not to respond & $3.1 \%$ & $6.83 \%$ \\
\hline
\end{tabular}

*Source: Hussar et al. (2020)

To assess whether the demographic makeup of the sample participants was representative of the college student population, Chi-square goodness of fit tests were conducted. The tests revealed significant differences between the sample and target population in regard to Race $(p<.05$. $)$ This result suggested that sample participants were not representative of the general college student population in terms of race. Therefore, for research question 1, race was dummy-coded into white vs. non-white students and entered into the hierarchical multiple linear regression analysis model as a control variable, along with team identification, to mitigate the effect of an unrepresentative sample on inferential results. However, the Chi-square test for Sex was not significant $\left(\lambda^{2}=1.11 p=.292\right.$.) This suggested that the sample participants were representative of the college student population meaning that Sex would not need to be entered as a control variable into the first block of the hierarchical multiple linear regression analysis.

School Conference Information. After analyzing participant demographics in relation to the target population, participants' schools were categorized into their respective conferences. Table 4 reveals approximately $79.6 \%$ of the responses came from students at Power Five institutions and 20.4\% came from students attending Group of Five institutions. On the Power Five level, one institution accounted for approximately (92.7\%) of the Power Five responses, and (74.0\%) of the total sample responses. A total of eight institutions were represented in the sample: four on the Power Five level and four on the Group of Five level.

Table 4 
Sample Participants by School's Conference

\begin{tabular}{lccc}
\hline Conference & $\mathrm{n}$ & Category Frequency & Overall Frequency \\
\hline Power Five & & & \\
Atlantic Coast & 165 & $92.2 \%$ & $73.3 \%$ \\
Big 12 & 13 & $7.3 \%$ & $5.8 \%$ \\
Big Ten & 1 & $0.56 \%$ & $0.44 \%$ \\
Group of Five & & & \\
American Athletic & 1 & $2.1 \%$ & $0.44 \%$ \\
Conference-USA & 2 & $4.4 \%$ & $0.89 \%$ \\
Mid-American & 43 & $93.5 \%$ & $19.1 \%$ \\
\hline
\end{tabular}
$N=225$

\section{Descriptive Statistics Summary}

The study sample was deemed representative of the general college student population in terms of Sex. However, the Chi-square test revealed significant differences in regard to Race. This means that the results needed to be interpreted cautiously. Despite $73.3 \%$ of responses coming from one school, a total of 10 schools were represented in the sample: five on the Power Five and five on the Group of Five level, with each level of competition also having three conferences represented (see Table 4).

\section{Factor Analysis}

In order to confirm the factor structure of the instruments being used, two confirmatory factor analyses were conducted, one for RQ1, and the other for RQ2. Additionally, an exploratory factor analysis was conducted on the importance of athletics on enrollment items that were created for this study. The sample size of 225 satisfied Fabrigar and Wegener's (2012) suggested minimum sample size of 200 to run an EFA, as well as Jackson et al.'s (2013) suggested minimum sample size of 200 for running a CFA.

\section{Exploratory Factor Analysis}

To examine the structure of the newly created importance of athletics on enrollment scale, an EFA using maximum likelihood estimation with varimax rotation was performed on the four-item instrument. The Kaiser-Meyer-Olkin measure of 
sampling adequacy was 0.827 , and the Bartlett's Test of Sphericity was significant (Approximate $\lambda^{2}=678.176, p<.01$ ), suggesting that the present data was suitable and there was sufficient correlation between the variables to proceed with the analysis (Pituch \& Stevens, 2015).

Three criteria were used to determine the total number of dimensions:

Eigenvalues (Kaiser, 1960), a scree plot graph (Cattell, 1966), and a parallel analysis (Horn, 1965). Using Kaiser's criteria of retaining eigenvalues greater than one suggested a one-factor solution, while an examination of the scree plot graph (figure 3), suggested a one factor solution as well.

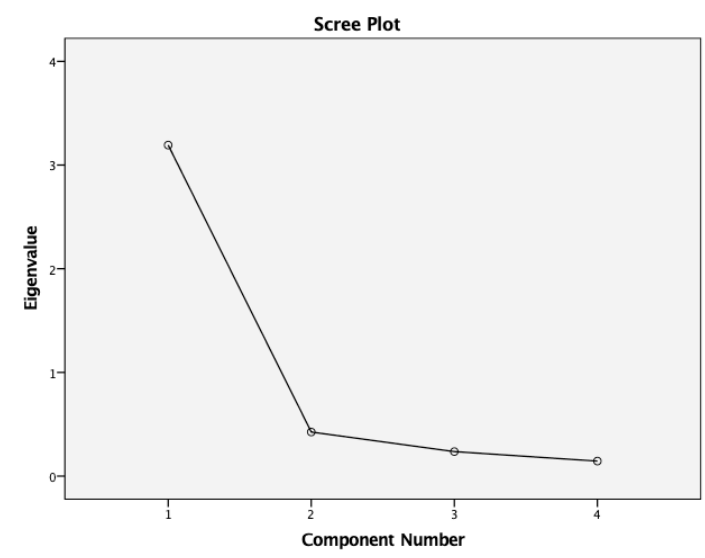

Figure 3

Scree Plot from EFA Using Maximum Likelihood Estimation with Varimax Rotation The parallel analysis also suggested a one-factor solution, as evidenced by only one factor having an initial eigenvalue greater than the random data eigenvalues from the parallel analysis (Table 5).

Table 5

Results of Parallel Analysis

\begin{tabular}{lcc}
\hline Factor & Real Data & Parallel Analysis \\
\hline Factor 1 & 3.192 & 1.15762 \\
Factor 2 & 0.422 & 1.038892 \\
Factor 3 & 0.242 & .952844 \\
Factor 4 & 0.144 & .851002 \\
\hline
\end{tabular}


Note: Values represent eigenvalues

The EFA identified a one-factor structure, which accounted for $79.80 \%$ of the total variance (eigenvalue $=3.192$ ) of the scale's items. The communality coefficients, which represent the total amount of variance in each item that can be explained by all of the factors (Pituch \& Stevens, 2016), ranged from 0.69 to 0.88 , with coefficients greater than .70 being considered high (Gorusch, 1983). Further, all four items had factor loadings of 0.83 or higher, satisfying Pituch and Stevens' (2015) recommended cutoff value of .40. Thus, the final importance of athletics on enrollment scale contained all four original items loaded onto one factor. The Cronbach's alpha coefficient was .92 for the revised scale.

\section{Confirmatory Factor Analysis}

In order to confirm the factor structure of the instruments being used, two (2) separate confirmatory factor analyses were conducted using SPSS AMOS Statistical Package. The first CFA consisted of items included in the RQ1 analysis (Team Success Section of the TBAS and the Importance of Athletics on Enrollment Scale), while the second CFA consisted of items included in the RQ2 analysis (Team Success Section of the TBAS, Team Identification Index, Campus Sense of Community Scale, and Oliver's (1980) Satisfaction Scale). Per Hu and Bentler's (1999) suggestion, at least two fit indices should be employed to measure appropriate model fit. Thus, in addition to the Chi-square analysis, the Comparative Fit Index (CFI) and Root Mean Square Error of Approximation (RMSEA) will also be used to assess model fit indices.

CFA for RQ1. The CFA model for RQ1 consisted of three latent variables (football success perceptions [at the time of enrollment], basketball success perceptions 
[at the time of enrollment], and the importance of athletics on enrollment), and a total of 14 observed variables. The 225-observation sample size met Suhr's (2006) standard of five subjects per parameter, as well as Jackson et al.'s (2013) 200-subject minimum for conducting a confirmatory factor analysis. Missing observations were eliminated prior to running the CFA, making the data appropriate for analysis. Table 6 summarizes the model fit summary for RQ1.

Table 6

Model Fit Summary for RQ1

\begin{tabular}{lcc}
\hline Model Fit Measure & Current Study & $\begin{array}{c}\text { Model Fit Standard } \\
(\text { Hu \& Bentler, 1999) }\end{array}$ \\
\hline Chi-square & .000 & $>.05$ \\
CFI & $.914^{*}$ & $>.90$ \\
RMSEA & .10 & $<.10$
\end{tabular}

*Indicates the model fit standard was met

The standard for model fit was met for the CFI, it was not met for the RMSEA. However, it is common for the RMSEA to report poor model fit for models with small degrees of freedom and sample size (Kenny et al., 2015). Therefore, the sample size issue, in combination with the reported RMSEA being directly at $\mathrm{Hu}$ and Bentler's (1999) cutoff for good model fit, the instrument for RQ1 was determined to be appropriate, meaning it could now be analyzed for convergent and discriminant validity.

First, construct validity is the "extent to which 2 domains or subscales relate to the same construct" (Wall et al., 2020, p.34). Table 7 reports the factor loadings of each item with its corresponding latent variable. Per Awang (2014), factor loadings on items for previously-developed constructs should be greater than .5 , while for newly developed constructs, factor loadings for all items should be above .6. Factor loadings for the RQ1 
CFA ranged from .57 (football success (time of enrollment) item 3), to .95 (basketball success (time of enrollment) item 2), suggesting satisfactory evidence of convergent validity.

Table 7

Factor Loadings for RQ1

\begin{tabular}{|c|c|c|}
\hline Factor & Item & Loading \\
\hline \multirow{5}{*}{$\begin{array}{l}\text { Perceived Football Success } \\
\text { (PFS; at time of } \\
\text { enrollment) }\end{array}$} & PFS-item \#1 & .68 \\
\hline & PFS-item \#2 & .88 \\
\hline & PFS-item \#3 & .57 \\
\hline & PFS-item \#4 & .57 \\
\hline & PFS-item \#5 & .77 \\
\hline \multirow{6}{*}{$\begin{array}{l}\text { Perceived Basketball } \\
\text { Success (PBS; at time of } \\
\text { enrollment) }\end{array}$} & PBS-item \#1 & .73 \\
\hline & PBS-item \#2 & .95 \\
\hline & PBS-item \#3 & .68 \\
\hline & & .79 \\
\hline & PBS-item \#4 & .77 \\
\hline & PBS-item \#5 & \\
\hline \multirow{4}{*}{$\begin{array}{l}\text { Importance of Athletics on } \\
\text { Enrollment (AOE) }\end{array}$} & $A O E$ - item \#1 & .94 \\
\hline & $A O E$ - item \#2 & .85 \\
\hline & $A O E$ - item $\# 3$ & .73 \\
\hline & $A O E-$ item $\# 4$ & .89 \\
\hline
\end{tabular}

In addition to convergent validity, it is also important to check for discriminant 
validity, or evidence that latent factors are not unduly correlated to the other constructs (Messick, 1989). Within a CFA, if the correlation between latent variables has an absolute value greater than .85 , this may suggest poor discriminant validity (Voorhees et al., 2016). Table 8 below shows the correlations between the three latent variables in the analysis. For this model, correlations ranged from .13 (Football Success Perceptions) $\leftrightarrow$ Basketball Success Perceptions) to .24 (Basketball Success Perceptions $\leftrightarrow$ Importance of Athletics on Enrollment). Since none of the three correlations in the RQ1 CFA exceeded an absolute value of .85, this suggested appropriate discriminant validity levels. In sum, the CFA performed for RQ1 suggested that the data was a good fit for the model, indicating that further analysis was appropriate. Figure 4 shows the full CFA performed for this research question.

Table 8 Correlation Estimates Between Variables

\begin{tabular}{lcc}
\hline Factor & Factor & Correlation Estimate \\
\hline $\begin{array}{l}\text { Perceived Football Success } \\
\text { (at time of enrollment) }\end{array}$ & $\begin{array}{c}\text { Perceived Basketball } \\
\text { Success (at time of } \\
\text { enrollment) }\end{array}$ & .13 \\
$\begin{array}{l}\text { Perceived Football Success } \\
\text { (at time of enrollment) }\end{array}$ & $\begin{array}{c}\text { Importance of Athletics on } \\
\text { Enrollment }\end{array}$ & .15 \\
$\begin{array}{l}\text { Perceived Basketball } \\
\text { Success (at time of } \\
\text { enrollment) }\end{array}$ & $\begin{array}{c}\text { Importance of Athletics on } \\
\text { Enrollment }\end{array}$ & .24 \\
\hline
\end{tabular}




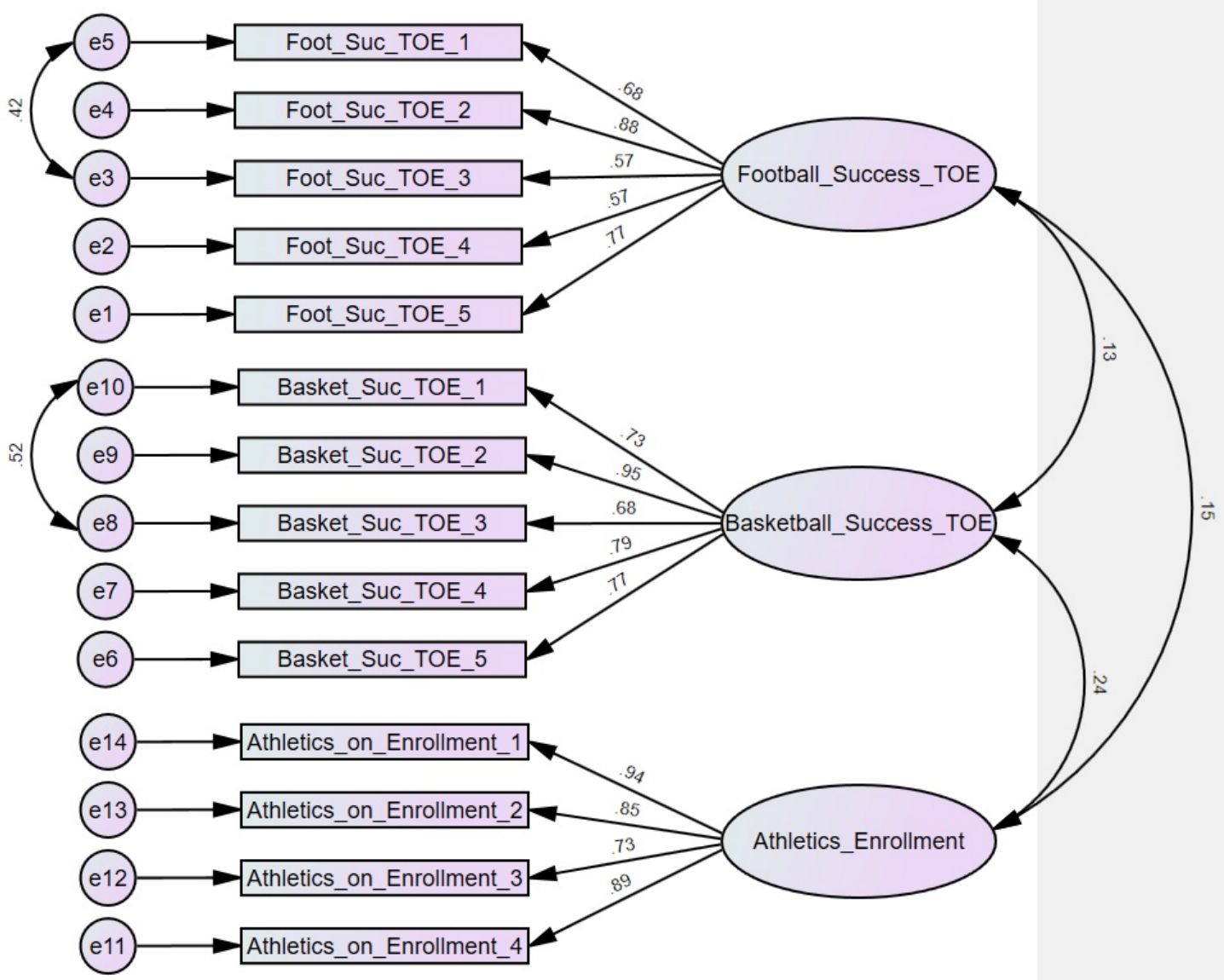

Figure 4

Confirmatory Factor Analysis for RQ1

CFA for RQ2. The CFA model for RQ2 consisted of six latent variables (football success perceptions [current] basketball success perceptions [current], football team identification, basketball team identification, sense of community, and enrollment satisfaction), and a total of 25 observed variables. The sample size again met Suhr's (2006) standard of five subjects per parameter. Table 9 shows the model fit summary for the RQ2 CFA. Similar to the CFA conducted for RQ1, the CFI model fit standard was met $(<.90)$. However, unlike RQ1, the RMSEA also met the model fit standard, satisfying Hu and Bentler's (1999) recommendation of RMSEA values below .10 representing good 
fit between the model and the data. Thus, the model was deemed suitable for further analysis.

Table 9

Model Fit Summary for RQ2

Model Fit Measure

Current Study

.000

$.92 *$

$.09 *$
Model Fit Standard

(Hu \& Bentler, 1999)
Chi-square

CFI

RMSEA

.

*Indicates the model fit standard was met

Convergent and discriminant validity were again assessed for the RQ2 model.

Factor loadings ranged from .55 (football success perceptions item \#3) to .98 (Basketball

Team Identification item \#3), satisfying Awang's (2014) criteria for previously-

developed scale items having factor loadings greater than .5. Table 10 lists the factor

loadings for each item and its corresponding factor.

Table 10

Factor Loadings for RQ2

\begin{tabular}{lcc}
\hline Factor & Item & Loading \\
\hline $\begin{array}{l}\text { Perceived Football Success } \\
\text { (PFS; current) }\end{array}$ & PFS-item \#1 & .59 \\
& PFS-item \#2 & .79 \\
& PFS-item 3 & .55 \\
& & .74 \\
& PFS- item \#4 & .80 \\
& & .59 \\
\hline $\begin{array}{l}\text { Perceived Basketball } \\
\text { Success (PBS; current) }\end{array}$ & PFS item \#5 &
\end{tabular}


PBS- item \#3

PBS-item \#4

PBS-item \#5

Football Team

FID-item \#1

.85

Identification (FID)

FID- item \#2

.90

FID-item \#3

Basketball Team

BID- item \#1

.88

Identification (BID)

BID- item \#2

BID-item \#3

\section{Sense of Community}

SOC-item \#1

.77

(SOC)

SOC-item \#2

SOC-item \#3

SOC-item \#4

SOC-item \#5

SOC-item \#6

Enrollment Satisfaction

Satisfaction-item \#1

Satisfaction-item \#2 
Following the convergent validity check, discriminant validity was also assessed by examining the correlations between the six latent variables. The correlations ranged from .18 (Football Success Perceptions $\leftrightarrow$ Basketball Team ID) to .87 (Football Team ID $\leftrightarrow$ Basketball Team ID). While the highest correlation between factors exceeded an absolute value of .85, Henseler et al. (2015) notes that when constructs are conceptually very similar, .90 can be used as a discriminant validity threshold, as opposed to .85 . Since the items on both Team ID scales were the same, only with "football" and "basketball" interchanged, it was determined that these constructs were conceptually similar, and the discriminant validity levels were acceptable. For example, this would not be the case if football team identification and SOC had a correlation of .87 , since these constructs are not conceptually similar, and would subsequently be a discriminant validity issue. Table 11 shows the full correlations list between each latent variable.

Table 11

Correlation Estimates Between Variables

\begin{tabular}{lcc}
\hline Factor & Factor & Correlation Estimate \\
\hline $\begin{array}{c}\text { Perceived Football Success } \\
\text { (current) }\end{array}$ & $\begin{array}{c}\text { Perceived Basketball } \\
\text { Success (current) }\end{array}$ & .57 \\
$\begin{array}{c}\text { Perceived Football Success } \\
\text { (current) }\end{array}$ & $\begin{array}{c}\text { Football Team } \\
\text { Identification }\end{array}$ & .23 \\
$\begin{array}{c}\text { Perceived Football Success } \\
\text { (current) }\end{array}$ & $\begin{array}{c}\text { Basketball Team } \\
\text { Identification }\end{array}$ & .29 \\
$\begin{array}{c}\text { Perceived Football Success } \\
\text { (current) }\end{array}$ & $\begin{array}{c}\text { Sense of Community } \\
\text { Perceived Football Success } \\
\text { (current) }\end{array}$ & Satisfaction \\
Perceived Basketball & & .21 \\
Success (current) & Football Team & .40
\end{tabular}




$\begin{array}{ccc}\begin{array}{c}\text { Perceived Basketball } \\ \text { Success (current) }\end{array} & \begin{array}{c}\text { Basketball Team } \\ \text { Identification }\end{array} & .43 \\ \begin{array}{c}\text { Perceived Basketball } \\ \text { Success (current) }\end{array} & \text { Sense of Community } & .43 \\ \begin{array}{c}\text { Perceived Basketball } \\ \text { Success (current) }\end{array} & \text { Satisfaction } & .32 \\ \text { Football Team } & \text { Basketball Team } & .87 \\ \text { Identification } & \text { Identification } & \\ \text { Football Team } & \text { Sense of Community } & .45 \\ \text { Identification } & \text { Satisfaction } & .30 \\ \text { Football Team } & \\ \text { Identification } & \text { Sense of Community } & .45 \\ \text { Basketball Team } \\ \text { Identification }\end{array}$

With the exception of Football Team ID $\leftrightarrow$ Basketball Team ID, no discriminant validity issues were present in the data. This suggested that the data collected was a good fit for the model, and suitable for analyzing RQ2. Figure 5 below shows the full CFA conducted for RQ2. 


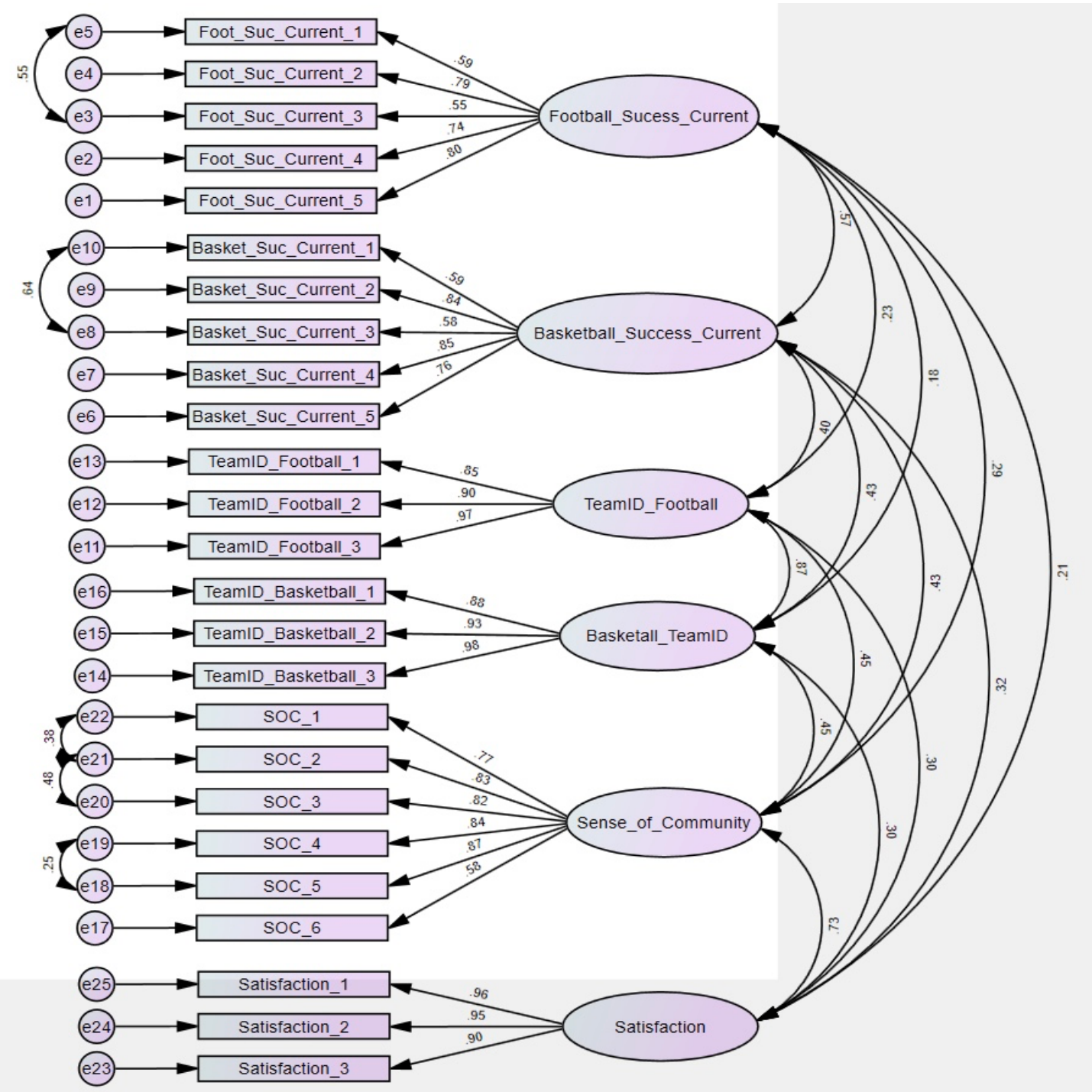

Figure 5

Confirmatory Factor Analysis for RQ2

\section{Factor Analysis Summary}

In sum, the Importance of Athletics on Enrollment scale was deemed suitable to analyze RQ1, with all four items loading significantly onto one factor. The two CFAs conducted also found that, in accordance with previous literature, the data appropriately fit the model. Convergent and discriminant validity benchmarks were also found to be appropriate. Ultimately, the data used was determined to be acceptable and further analysis was conducted on the research questions. 


\section{Data Analysis}

To analyze each of the three RQs, this study used a hierarchical multiple linear regression analysis, a moderated mediation analysis, and descriptive statistics. The following section will begin by discussing the assumptions of multiple regression, the inferential test used to analyze RQ1.

\section{Assumptions of Multiple Regression}

Per Field (2009), the five major assumptions that must be met when performing a multiple linear regression analysis are: (a) independence of responses, (b) a normally distributed dependent variable, (c) homoscedasticity among independent variables (d) linearity of the dependent variable, and (e) an absence of multicollinearity among independent variables.

Wong et al. (2020) notes that the easiest way to ensure independence of responses is to check for responses with duplicate IP addresses submitted in near time. Qualtrics respondents' IP addresses were checked to ensure that no such duplicate IP addresses existed within the dataset. The normality of the dependent variable assumption was checked by obtaining a histogram of the frequencies of respondents. Figure 6 shows the histogram for the RQ1 dependent variable, the importance of athletics on students' enrollment decisions. The histogram showed that this variable was normally distributed, satisfying the normality assumption. 


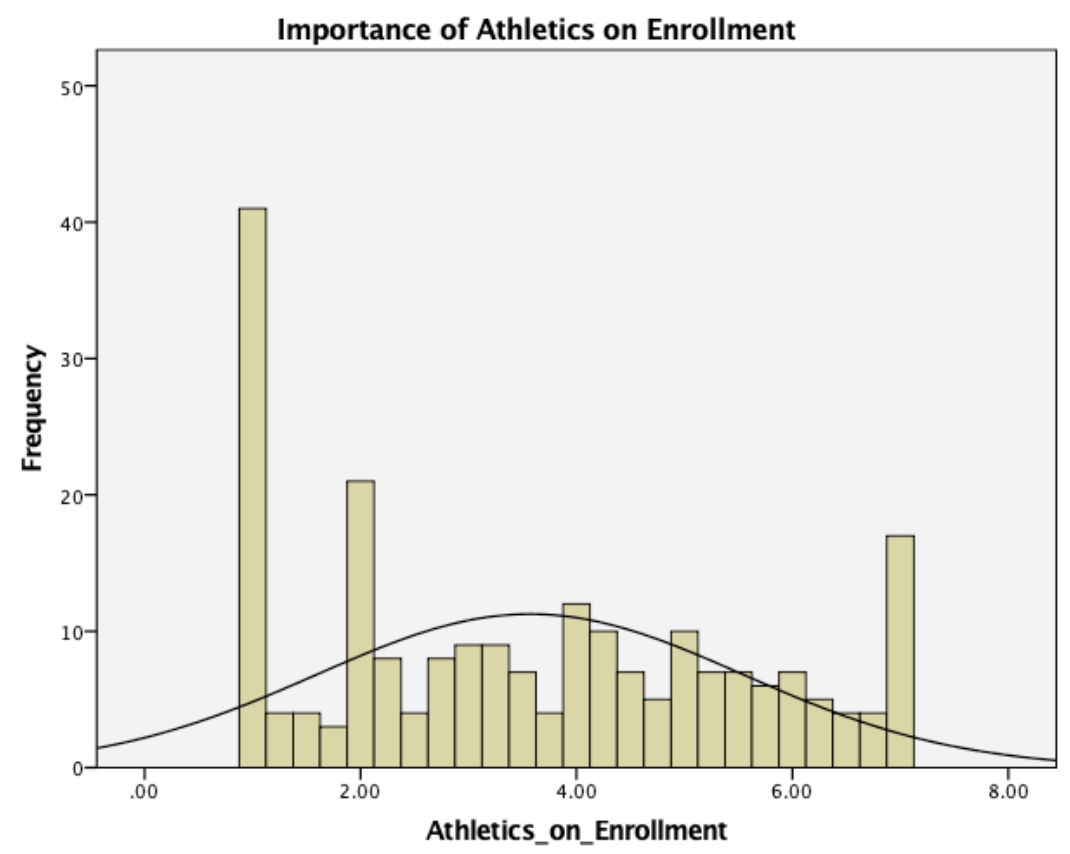

Figure 6

Histogram of RQ1 Dependent Variable (Importance of Athletics on Enrollment)

Thirdly, the dataset was checked for homoscedasticity assumption. A scatterplot was developed by plotting the regression standardized residuals with the standardized regression predicted value for the dependent variable and analyzing the scatterplot for cone-shaped patterns. No conical patterns were found, satisfying the homoscedasticity assumption as well. To address the linearity assumption, a probability plot of standardized residuals was obtained. This assumption was assessed by determining how closely the residuals follow the least squares regression line plotted on the scatterplot. Figure 7 shows that the residuals follow the least squares regression line, indicating a linear relationship between the independent and dependent variables and satisfying the linearity assumption. 


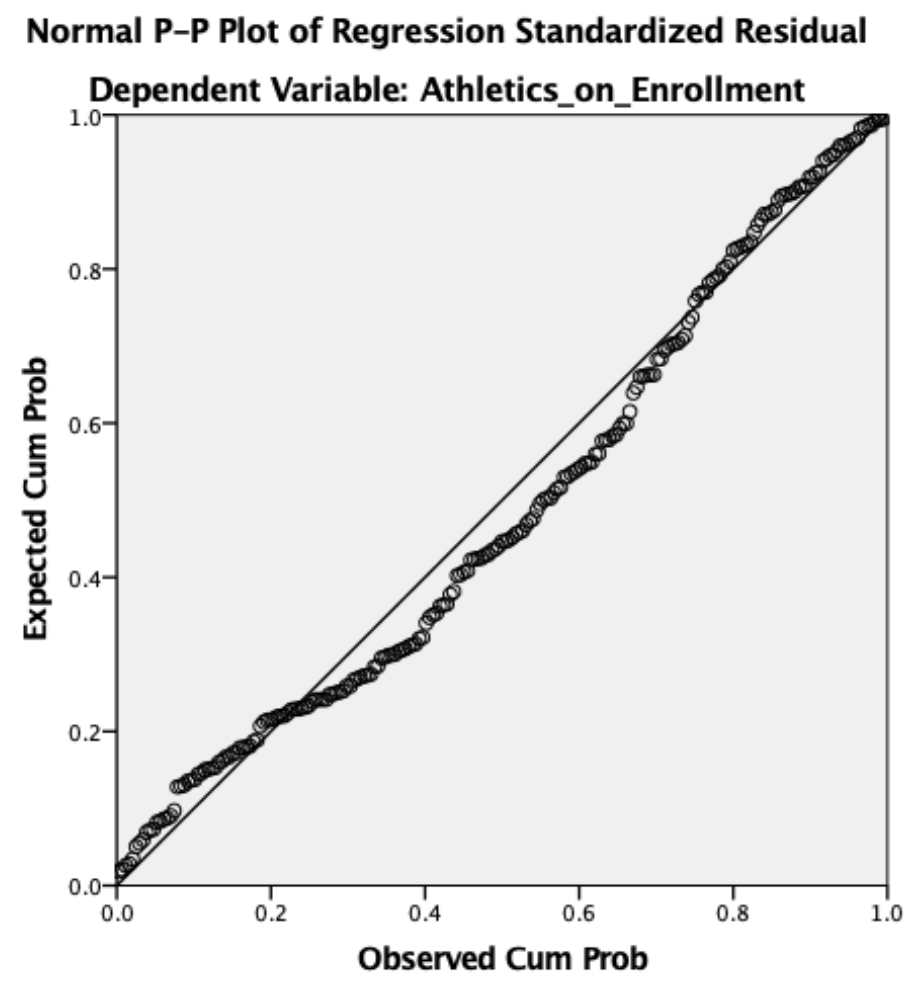

Figure 7

P-Plot of Regression Standardized Residuals(RQ1)

Lastly, the data was checked for multicollinearity among variables. As mentioned in chapter III, multicollinearity would indicate excessive correlation among the independent variables, preventing the researcher from accurately determining which of the two independent variables was predicting the change in the dependent variable (Pedhazur, 1997). Multicollinearity was checked using the variance inflation factor (VIF), and based on Rogerson's (2001) recommendation, a VIF higher than 5 was labeled problematic. The VIF's for RQ1 were reported for the following variables: Football Success Perceptions (VIF=1.024), Basketball Success Perceptions (VIF=1.248), Football Team Identification $(\mathrm{VIF}=3.385)$, and Basketball Team Identification VIF=(3.678). While the VIF's for both team identification variables were higher than the success perceptions variables, they were still below Rogerson's (2001) cutoff, suggesting no 
multicollinearity issues with the dataset. By meeting these five assumptions, it was appropriate to proceed with the data analysis.

\section{Descriptive Statistics}

Descriptive data was examined for abnormalities or patterns. For the two predictor variables, perceptions of football success (at the time of enrollment), and basketball success (at the time of enrollment), mean scores were 4.13 and 4.75, respectively. For the two control variables, football team identification and basketball team identification, the mean scores were 3.77 and 3.89, respectively. Lastly, for the dependent variable, the importance of athletics on enrollment, the mean score was 3.57. Table 12 shows a complete overview of the descriptive statistics.

Table 12

Descriptive Statistics of Independent and Dependent Variables

Variable

Football Success Perceptions (at time of enrollment)

Basketball Success Perceptions (at time of enrollment)

Football Team Identification

Basketball Team Identification

Importance of Athletics on Enrollment Decision

\section{Mean Standard Deviation}

1.21

4.75

3.77

1.84

3.89

1.96

3.57
1.97

\section{Results and Analysis of Research Question 1}


RQ1: Do subjective perceptions of football success and subjective perceptions of basketball success influence how students perceive the importance of athletics in their college choice decision?

To address the first research question, a single hierarchical multiple linear regression analysis was performed using two blocks. First, football team identification and basketball team identification were entered as control variables to determine whether these two variables were predictive of the importance of athletics on enrollment by themselves. Additionally, since the Chi-square test of independence showed that the sample significantly differed from the college student population with regard to race, this was also dummy-coded and entered. Next, the independent variables of football success perceptions (at the time of enrollment) and basketball success perceptions (at the time of enrollment) were entered into the second block of the regression equation to examine the unique variance they contributed to the linear equation, and not the control variables.

The control variables (football team identification and basketball team identification) explained a significant amount of variance in the dependent variable (importance of athletics on enrollment) $\left[R^{2}=.203, F(3,221)=18.73, p<.001\right]$. This suggests that football team identification and basketball team identification explain $20.3 \%$ of the variance in the importance of athletics on enrollment.

The second block of the linear equation, however, did not result in statistically significant amount of variance explained $\left[\Delta R^{2}=.012, F,(2,219)=11.986, p>.05\right]$, suggesting that the unique combination of the two independent variables explain $1.2 \%$ of the variance in the importance of athletics on enrollment. Among the two independent variables, neither football success perceptions $(B=.179, t,=1.803, p>.05)$ nor basketball 
success perceptions $(B=.020, t,=.189, p>.05)$ were significantly predictive of the dependent variable.

These results indicate that, controlling for football and basketball team identification, as well as demographic variables, football success perceptions and basketball success perceptions are positive, but non-significant predictors of the importance of athletics on students' enrollment decisions. Table 13 shows the results of the hierarchical multiple linear regression analysis used for RQ1.

Table 13

Results of Hierarchical Multiple Linear Regression Analysis for RQ1

$\begin{array}{llllllll}\text { Measurement } & \text { Unstandardized } & \text { Standardized } & p & F & R^{2} & \Delta R^{2}\end{array}$
coefficient coefficient

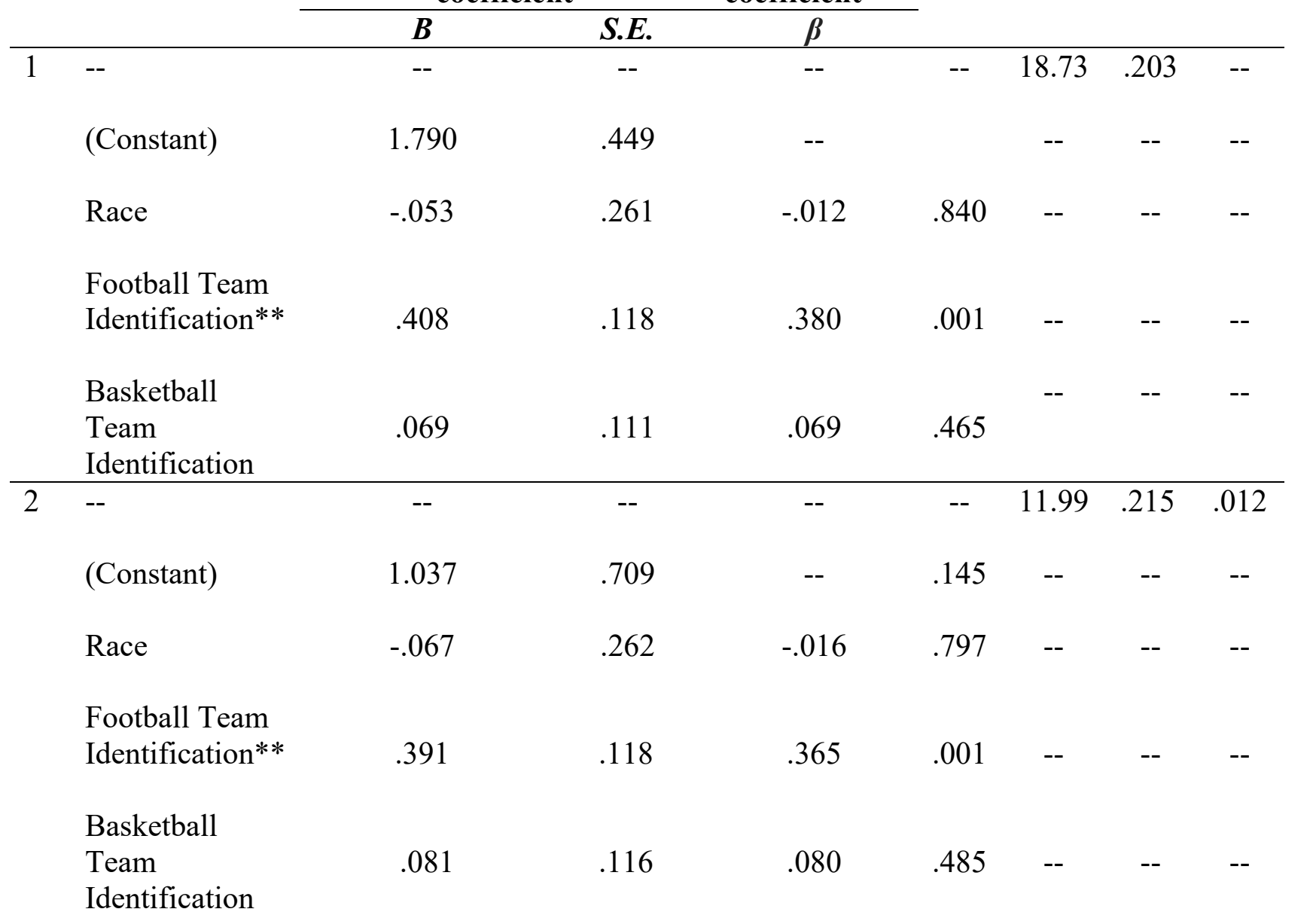


Football

.179

.099

.109

.073

Success

Perceptions

Basketball

Success

.020

.107

.013

.850

Perceptions

** Indicates significance at the $p<.01$ level

\section{Assumptions of Mediation Analysis}

Before proceeding to the RQ2 moderated mediation analyses, mediation

assumptions will be examined, which are very similar to those of a traditional regression analysis (Judd \& Kenny, 2010). The five (5) assumptions are: independence of observations, normality, homoscedasticity, linearity, and a lack of multicollinearity amongst independent variables (Field, 2009). First, independence of observations was assessed the same way as it was for RQ1.

Normality was also examined by obtaining histograms of the frequencies of responses. Given the nature of this research question, histograms were examined for both SOC and enrollment satisfaction. This was due to SOC's mediating nature, as SOC can operate as a dependent variable when regressed upon football and basketball success. In other words, in a mediation analysis, the mediating variable can serve as both an independent and dependent variable (Baron \& Kenny, 1986). Figure 8 shows the combined histograms for the two dependent variables in RQ2. Both frequency histograms exhibit normal distribution, thus satisfying the normality assumption.

Figure 8 Histogram of RQ2 Dependent Variables

Sense of Community (SOC) Enrollment Satisfaction



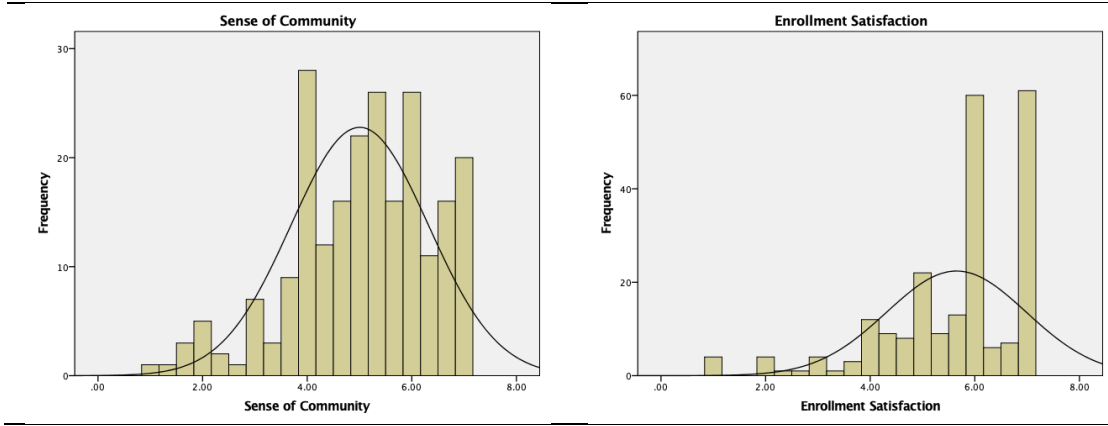

Homoscedasticity was examined by plotting the regression standardized residuals with the standardized regression predicted value for the dependent variables and analyzing the scatterplot for cone-shaped patterns. No conical patterns were found, satisfying the homoscedasticity assumption for RQ2. Linearity was again assessed by obtaining p-plots of standardized residuals. Figure 9 shows that the residuals closely follow the least squares regression line, indicating a linear relationship between the independent and dependent variables and satisfying the linearity assumption.

Figure 9

P-Plot of Regression Standardized Residuals(RQ2)

Sense of Community (SOC)

Lastly, multicollinearity was again analyzed through obtaining a VIF. The VIF's for RQ2 were reported for the following variables: football success perceptions 
(VIF=1.325), basketball success perceptions ( $\mathrm{VIF}=1.439)$, football team identification $(\mathrm{VIF}=3.365)$ basketball team identification $(\mathrm{VIF}=3.460)$, and Sense of Community (VIF=1.317), all of which fell within Rogerson's (2001) recommendation of VIF's being below five. Thus, no multicollinearity issues were present for RQ2, making further analysis appropriate.

\section{Results and Analysis of Research Question 2}

RQ2: Does Sense of Community (SOC) mediate the relationship between subjective athletic success and enrollment satisfaction?

To address RQ2, two (2) separate mediation analyses were conducted: one with football success perceptions as the IV and football team identification as the moderator, and another with basketball success perceptions as the IV and basketball team identification as the moderator. In both analyses, SOC was the mediator and enrollment satisfaction was the dependent variable. Figures 10 and 11 below depict these models.

Figure 10

RQ2 Moderated Mediation Model 1

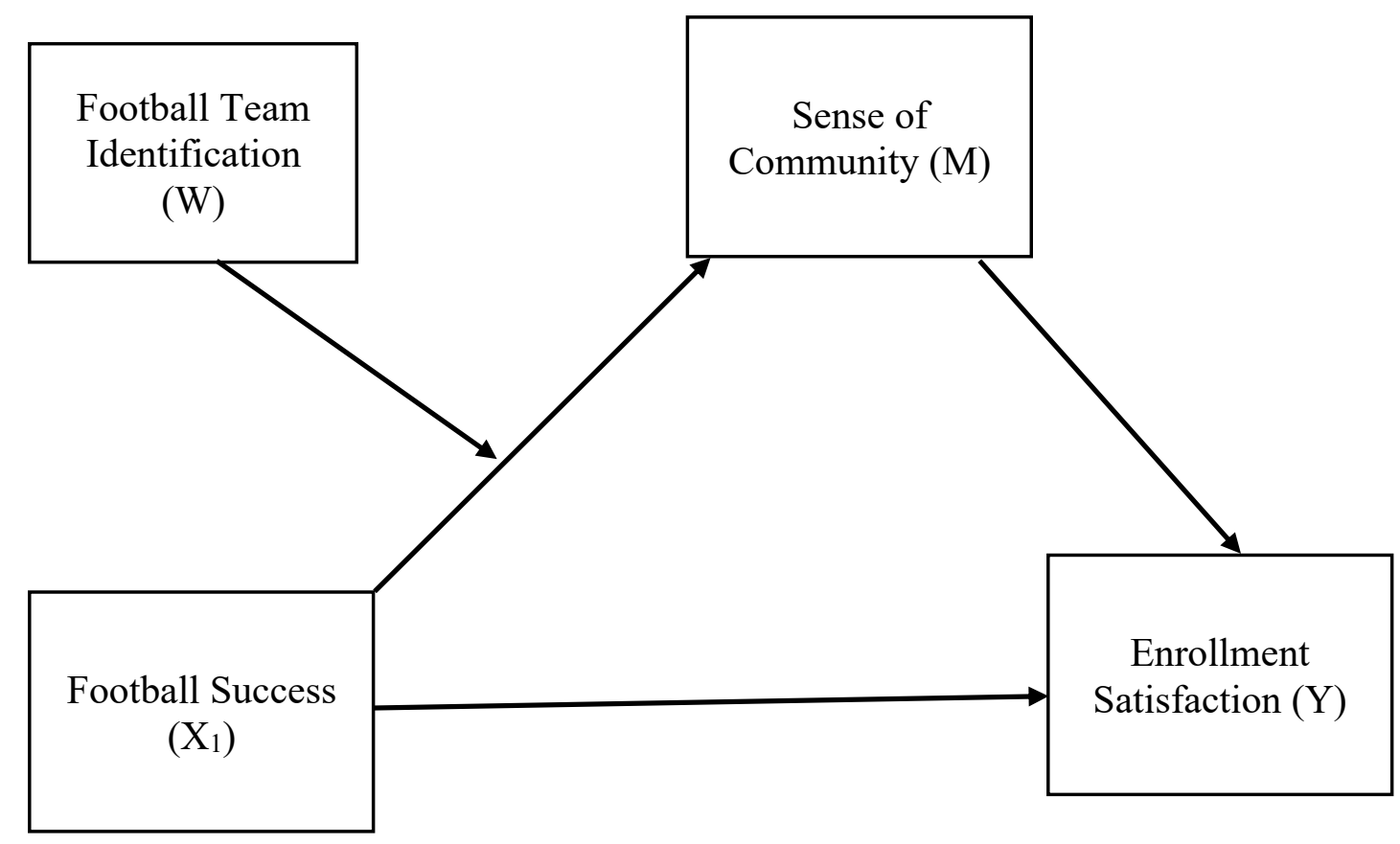


Figure 11

RQ2 Moderated Mediation Model 2

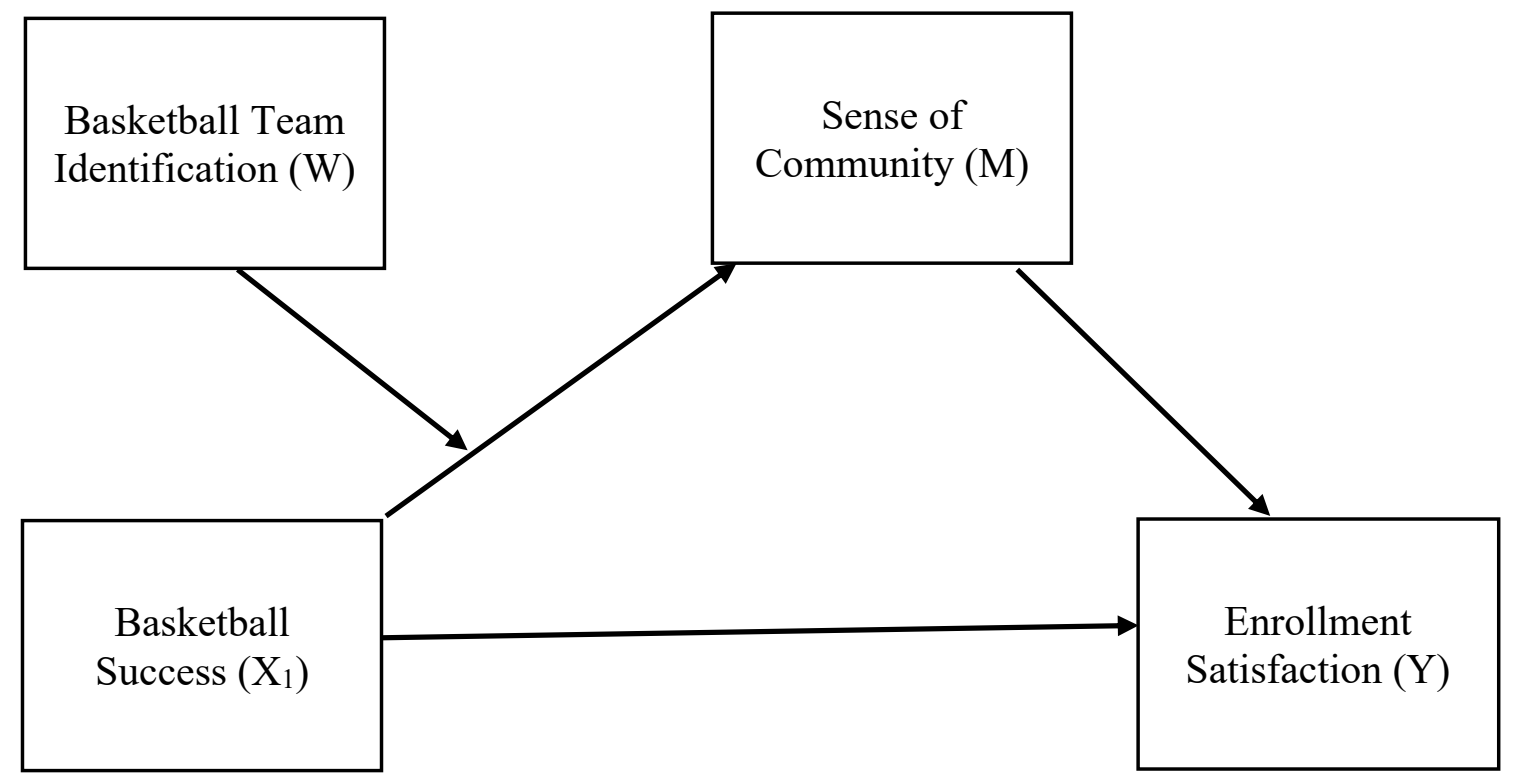

Moderated Mediation Model 1. Both mediation analyses were run using Model 7 of PROCESS Macro, a free add-on available through SPSS. The first moderated mediation model (see figure 10) was tested in a single model using a bootstrapping approach. The bootstrapping approach is designed to test for significant indirect effects at differing levels of the moderating variable (Hayes, 2013). Specifically, 95\% confidence intervals $(\mathrm{n}=10,000)$ are used to test for a significant indirect effect of a moderating variable (football team identification) on the relationship between a predictor variable (football success perceptions), an outcome variable (enrollment satisfaction), and a mediator (SOC). A significant moderated mediation effect is determined by the absence of zero in the confidence intervals.

Before examining the moderated mediation effect, several other effect sizes needed to be assessed. The first effect was the direct effect between football success and enrollment satisfaction. This effect was not significant $(\beta=.004, p>.05)$, signifying that 
football success perceptions does not directly influence enrollment satisfaction. However, when examining the path between sense of community and enrollment satisfaction, a significant relationship was observed $(\beta=.667, p<.01)$, as was the path between football success perceptions and sense of community $(\beta=.246, p<.01)$. Lastly, the moderated mediation effect was not significant, as evidenced by the bootstrap test $(\beta=-.017,95 \%$ $C I=-.069, .031)$. Since this confidence interval included 0 , this was evidence of nonsignificant moderated mediation.

These results suggest that, given the non-significant moderated mediation effect, combined with the significant path between football success perceptions and SOC, that subjective team performance does strengthen SOC on campus, regardless of students' team identification levels. Further, while SOC significantly relates to enrollment satisfaction, football success perceptions do not have a direct impact. The implications and practical suggestions of these findings will be discussed in more detail in chapter five.

Moderated Mediation Model 2. Mediation model 2 was also run using Model 7 of PROCESS Macro (see figure 11). As previously discussed, this second analysis was very similar to the first analysis, but with perceptions of basketball success and basketball team identification as the predictor and moderating variables, respectively. The bootstrap test was also used to assess the indirect effect.

The direct effect of basketball success perceptions on enrollment satisfaction was calculated first. Similar to model 1, this effect was found to be non-significant ( $\beta=.054$, $p>.05)$. However, just like model 1 , the path between sense of community and enrollment satisfaction was significant $(\beta=.653, p<.01)$, as was the path between basketball 
success perceptions and SOC $(\beta=.246, p<.05)$. Lastly, and again similar to model one's findings, the moderated mediation effect was not significant, as evidenced by the bootstrap test $(\beta=.010,95 \% C I=-.040, .053)$. Since this confidence interval included 0 , this was also evidence of non-significant moderated mediation. Figures 12 and 13 below present a graphic representation of these results

The results of these two moderated mediation analyses suggest that perceptions of athletic success do, in fact, increase SOC on campus, regardless of how identified students are with the football and basketball teams. While perceptions of athletic success do not directly influence enrollment satisfaction, the former increases campus SOC, which goes on to increase enrollment satisfaction. The implications and discussion for these findings can be found in the next chapter.

Figure 12

Results of Moderated Mediation Analysis \#1

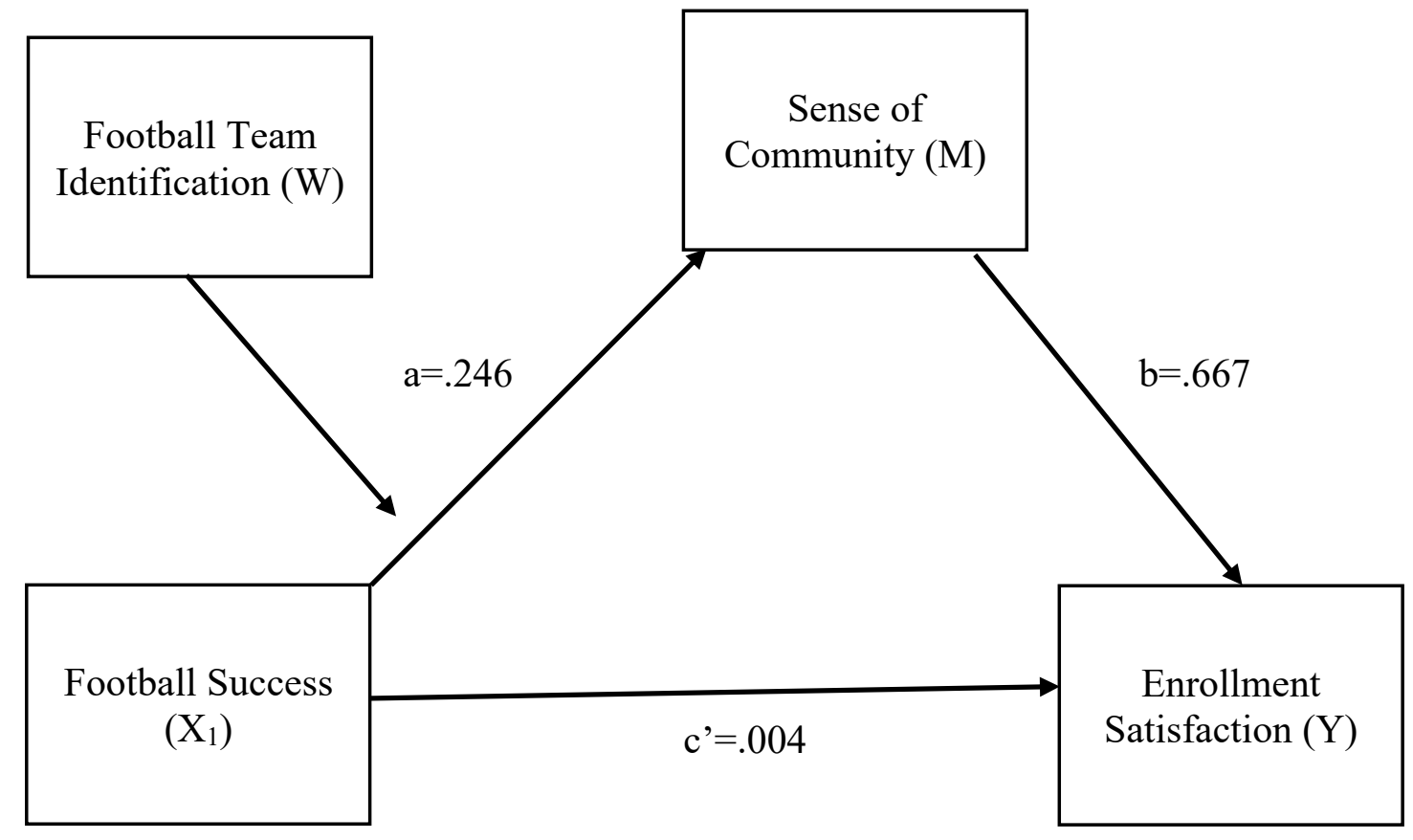


Figure 13

Results of Moderated Mediation Analysis \#2

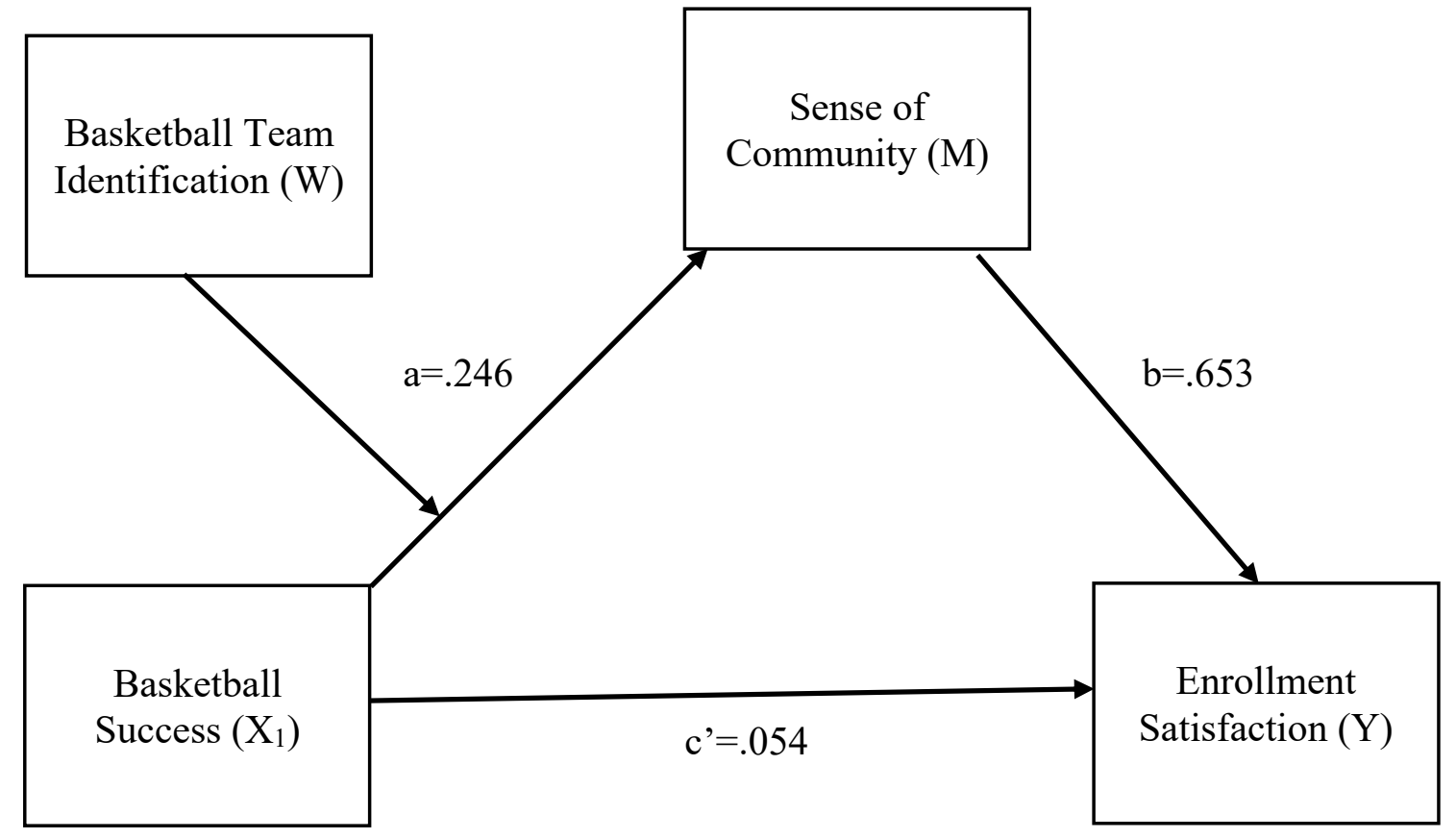

\section{Results and Analysis of Research Question 3}

RQ3: Which factors are most important to Group of Five and Power Five students' subjective perceptions of athletic success?

To address RQ3, descriptive statistics were obtained for each of the 13 success measurements that have been employed by previous literature to measure the objective construct of success. Power Five and Group of Five students received a mean score for each of these 13 measurements. For Power Five students, the most important measurement to their subjective perceptions of football success was improvement from previous year) $(M=5.16)$, followed by overall winning percentage $(M=5.04)$. For Power Five students, the most important measurement to their subjective perceptions of basketball success was NCAA Tournament appearances $(M=5.33)$, followed by number of games won in the NCAA Tournament $(M=5.26)$. 
Conversely, for Group of Five students's subjective perceptions of football success, the most important measurement was overall winning percentage $(M=4.50)$, followed by conference winning percentage $(M=4.43)$, while for basketball success perceptions, the most important measurement to their subjective perceptions of basketball success was overall winning percentage $(M=4.39)$, followed by number of games won in NCAA Tournament $(M=4.39)$. A complete summary of this data can be found in Table 14 below. Table 15 represents correlation coefficients between team identification and each of these success measurements.

Table 14 Mean Scores of Importance of Athletic Success Factors

\begin{tabular}{lc|c}
\hline Measurement & Power Five & Group Of Five \\
\hline $\begin{array}{l}\text { Football } \\
\text { National Championships }\end{array}$ & 4.49 & 4.11 \\
Improvement from Previous Year & 5.16 & 4.37 \\
Overall Winning Percentage & 5.04 & 4.50 \\
Conference Winning Percentage & 4.91 & 4.43 \\
AP Poll Placement & 4.78 & 3.85 \\
Major Bowl Game Appearances & 5.02 & 4.22 \\
\hline Basketball & 5.89 & 3.85 \\
National Championships & 5.15 & 4.28 \\
Improvement from Previous Year & 5.11 & 4.39 \\
Overall Winning Percentage & 5.00 & 4.33 \\
Conference Winning Percentage & 4.94 & 3.80 \\
AP Poll Placement & 5.33 & 4.39 \\
NCAA Tournament Appearances & & \\
Number of NCAA Tournament Games Won & & \\
\hline
\end{tabular}


Table 15

Correlation Coefficients Between Team ID and Factors Influencing Athletic Success Perceptions

\begin{tabular}{|c|c|c|}
\hline Measurement & Power Five & Group Of Five \\
\hline \multicolumn{3}{|l|}{ Football } \\
\hline National Championships & .25 & .05 \\
\hline Improvement from Previous Year & .40 & .41 \\
\hline Overall Winning Percentage & .34 & .31 \\
\hline Conference Winning Percentage & .35 & .37 \\
\hline AP Poll Placement & .38 & .30 \\
\hline Major Bowl Game Appearances & .38 & .27 \\
\hline \multicolumn{3}{|l|}{ Basketball } \\
\hline National Championships & .48 & .16 \\
\hline Improvement from Previous Year & .44 & .37 \\
\hline Overall Winning Percentage & .40 & .27 \\
\hline Conference Winning Percentage & .42 & .32 \\
\hline AP Poll Placement & .45 & .29 \\
\hline NCAA Tournament Appearances & .42 & .22 \\
\hline Number of NCAA Tournament Games Won & .38 & .17 \\
\hline
\end{tabular}

\section{Summary of Results}

The purpose of this study was to measure athletic success' impact on college enrollment decisions, campus sense of community, and enrollment satisfaction, while also attempting to uncover the most influential factors in students' personal definitions of athletic success. Before proceeding to the data analysis stage, the instrument was reviewed by a panel of experts and underwent a pilot study. The edits made during this 
stage improved the instrument's ability to address the problem and research questions.

The survey was distributed through a combination of Amazon MTurk, freshmen Facebook pages, and professors/administrators at various FBS institutions. After eliminating incomplete responses, a total of 225 questionnaires were deemed suitable for further analysis. An exploratory factor analysis was conducted on the Importance of Athletics on Enrollment scale, which was created for this study, with all four items loading significantly onto one factor (eigenvalue $=3.192$ ). The survey instruments were then tested for convergent and discriminant validity using a confirmatory factor analysis, where the factor structure was deemed appropriate based on the model fit indices.

The first research question was addressed using a hierarchical multiple linear regression. The first block consisted of three control variables (race, football team identification and basketball team identification), which significantly predicted the importance of athletics on enrollment $\left(R^{2}=.203\right)$. The second block, which contained the main predictor variables (football success perceptions and basketball success perceptions), did not significantly predict the importance of athletics on enrollment ( $\triangle R$ $\left.{ }^{2}=.012, p>.05\right)$

To address RQ2, two separate moderated mediation analyses were conducted; one with football success perceptions as the independent variable and football team identification as the moderating variable, and another with basketball success perceptions as the independent variable and basketball team identification as the moderating variable. The first analysis did not find a significant direct effect between football success perceptions and enrollment satisfaction $(\beta=.004, \mathrm{p}=.95)$, as well as a non-significant moderated mediation effect for the entire model $(\beta=-.017,95 \% C I=-.069, .031)$. 
However, a significant path was observed between football success perceptions and sense of community $(\beta=.246, p<.01)$, as well as between sense of community and enrollment satisfaction $(\beta=.667, p<.01)$.

The second mediation analysis produced nearly identical results. A nonsignificant direct effect between perceptions of basketball success and enrollment satisfaction was observed $(\beta=.054, p>.05)$, as was a non-significant moderated mediation effect $(\beta=.010,95 \% C I=-.040, .053)$. Moreover, basketball success perceptions were again found to significantly influence sense of community $(\beta=.246, p$ $<.05)$, with sense of community also significantly relating to enrollment satisfaction $(\beta=$ $.653, p<.01)$. The implications of these two analyses will be discussed in chapter five.

Lastly, RQ3 was analyzed using descriptive statistics. While the Power Five subsample reported higher mean scores on every success subjectivity item for both football and basketball, there were some noteworthy in-group differences. For example, conference winning percentage was the second most important item influencing football success perceptions for Group of Five students, while this same measurement was fourth for Power Five students. For basketball success items, Group of Five placed the most importance on overall winning percentage, while this same item was fourth for Power Five students. Implications of this research question, particularly as it pertains to success subjectivity, will be discussed in chapter five next. 


\section{CHAPTER V \\ DISCUSSION}

The purpose of this study was to incorporate current students' perspectives to measure football and basketball success' impact on college enrollment decisions, campus SOC, and enrollment satisfaction, while also attempting to uncover the most influential factors impacting students' personal, subjective definitions of athletic success. Since increased student interest and enhanced campus life are one of the primary justifications for FBS institutions' spending patterns, it is essential that both academics and practitioners better understand the benefits received from football and basketball success. Further, by better understanding the effect that prominent, successful athletic programs have on students' enrollment decisions and overall campus climate, university officials will be able to develop more effective campaigns to appeal to potential and current students.

This chapter contains five sections: First, an interpretation of the results will discuss the sample characteristics, as well as an interpretation of the results for each of the three (3) research questions. The second section will discuss theoretical implications of the study, and how the results contribute to the body of literature surrounding the Flutie Effect. Next, the third section will provide practical implications from this study, specifically, how university officials can use the results to improve their operations. Fourth, study limitations will be highlighted and discussed, concluding with directions for future research. 


\section{Interpretation of Study Results}

\section{Sample Characteristics}

The findings related to the sample characteristics of this study contribute to the

literature by incorporating primary data to measure the impact of football and basketball success on college students' enrollment decisions. As chapters one and two discuss, previous research on the Flutie Effect has been limited to secondary, correlational data between athletic success and application numbers. The current study gathered data from 225 undergraduate students across six FBS institutions, with both the Power Five and Group of Five level having three conferences represented.

To solicit participation, the study utilized a combination of Amazon MTurk workers, social media posts on freshmen Facebook pages, and enlisting professors and university officials to administer the survey link to their students. Respondents were representative of the general college student population in regard to Sex according to data from Hussar et al. (2020). However, the Chi-square test suggested that the study sample was not representative of the college student population in regard to Race. For example, as Table 3 indicates, only $52.4 \%$ of the college student population is white, while this group comprised $70.7 \%$ of this study's sample. Further, the Hispanic/Latino population was also underrepresented in this study. Despite making up approximately $20.5 \%$ of the college student population (Hussar et al., 2020), Hispanic/Latino students were only 4.9\% of the sample demographics. This suggests that, while the study's results are generalizable to students across gender lines, they are less generalizable with regard to race.

\section{Athletic Success and Enrollment Decisions}


RQ1 examined the impact of perceived football and basketball success on students' enrollment decisions, controlling for both football team identification and basketball team identification. Football team identification $(B=.408)$ was found to be the strongest predictor of the importance of athletics on enrollment. This finding suggests that team identification, not team performance, is more likely to predict how much importance students place on athletics when making their enrollment decision.

The non-significant prediction from both football success and basketball success perceptions conflicts with previous Flutie Effect literature, which has found a significant, positive correlation between football and basketball team performance and the number applications received (McEvoy, 2005; Pope \& Pope, 2009). While schools may justify their increased athletic spending and subsidization levels by citing increased application numbers, these results suggest that when relying on success alone, institutions must take their efforts a step further to turn these applicants into enrolled students. Specifically, football and basketball success alone do not appear to play a significant role in students' enrollment decisions. Rather, the students who place the most importance on athletics in their enrollment decision are those with a vested interest in the schools' football team, a valuable finding to collegiate athletic departments.

These findings also simultaneously support previous Flutie Effect literature, which has found that football is a stronger student recruitment tool than basketball (Pope \& Pope, 2009; Toma \& Cross, 1998). In the current study, football team identification was a stronger predictor of the importance of athletics in enrollment than basketball team identification. Since football programs tend to receive more allocated funds than basketball programs (Whiteside et al., 2011), schools may cite the return on this 
investment being higher. Specifically, students who are highly identified with the football team are more likely to place a high importance on athletics in their enrollment choice than students who are only highly identified with the basketball team. Taken together, these results suggest that football team identification is a more efficient tool for student recruitment than basketball team identification, football success, or basketball success.

Moreover, examining this study's findings seem to support literature regarding the college student choice process. For example, the factors that influence students' application decisions are different than those that influence their enrollment decisions (Chapman, 1986; Galotti \& Mark, 1994; Hossler \& Gallagher, 1987). Both subjective success perceptions variables having a positive impact on students' enrollment decisions may suggest that, in conjunction with previous Flutie Effect literature, that football and basketball success can influence students' decisions to apply to an institution. However, these success variables did not significantly predict enrollment decisions. Thus, athletic success alone may influence application decisions, but in the absence of high team identification levels, does not carry enough weight to get students to actually enroll. This further supports higher education research which has found that students' application factors are different than their enrollment factors and simultaneously dispels some of the findings surrounding the Flutie Effect.

\section{Sense of Community and Enrollment Satisfaction}

RQ2 examined the impact of football and basketball success on students' enrollment satisfaction, with the mediating role of sense of community and the moderating role of team identification on the pathway between success and sense of community. The findings supported those from previous literature, which has shown that 
the presence of athletics can effectively foster SOC on college campuses (Clopton, 2007; 2008; Stensland et al., 2019). The direct path between both football and basketball success and SOC reinforces these findings, suggesting that while athletics can increase campus SOC, this relationship positively fluctuates with subjective team performance.

Football and basketball success' significant pathways to sense of community provides support for institutions' spending arguments that successful athletics serve as a powerful unifier for current students. Further, the lack of significant moderated mediation suggests that the social benefits of supporting successful football and basketball programs are not limited to highly identified fans. Comparing these findings to those from RQ1, athletic success is more effective at enhancing current students' experiences than it is for attracting potential students, with these current student benefits not being predicated upon a certain level of team identification. Thus, colleges and universities may struggle to continue justifying their athletic subsidization by citing football and basketball success' impact on potential student interest. However, they may find the results from RQ2 more encouraging, and choose to highlight athletic success' effect on current students.

Moreover, despite not directly predicting enrollment satisfaction, athletic success significantly predicted sense of community, which went on to strongly predict enrolment satisfaction. This suggests that, while athletic success alone is not enough to increase students' satisfaction with the enrollment decision, athletic success can effectively improve campus climate through improved sense of community, which can then go on to increase enrollment satisfaction. Instead of trying to directly market how successful football and basketball teams create a more satisfactory undergraduate experience, 
institutions should incorporate these findings to try and use athletic success to cultivate campus SOC, which may subsequently generate higher satisfaction.

Taken collectively, these findings provide greater insight into potential justifications for increased athletic spending and subsidization patterns. Athletic success' significant impact on sense of community suggests football and basketball success alone may have a more substantial effect on current students' college experiences than they do on attracting potential students. Subsequently, colleges and universities should justify their expenditures by citing the social benefits that current students receive from football and basketball success, as opposed to highlighting potential student interest. Further, these officials can point to the institution-wide benefits of football and basketball success not being predicated upon team identification levels like they are for potential students.

\section{Success Perceptions}

RQ3 was concerned with uncovering the most important factors contributing to students' subjective perceptions of football and basketball success. Specifically, this research question sought to compare the importance of these factors between Power Five and Group of Five students. Table 14 in the previous chapter listed the mean scores for each success variable, broken down by type of institution (Power Five or Group of Five). Table 16 below reports the rank of each success measurement within its respective group.

Table 16

Rankings of Factors Influencing Athletic Success Perceptions

\begin{tabular}{l|l}
\hline Power Five & Group Of Five \\
\hline $\begin{array}{l}\text { Football } \\
\text { 1. Improvement from Previous Year }\end{array}$ & $\begin{array}{l}\text { Football } \\
\text { 1. Overall Winning Percentage }\end{array}$ \\
$\begin{array}{l}\text { 2. Overall Winning Percentage } \\
\text { 3. Major Bowl Game Appearances }\end{array}$ & $\begin{array}{l}\text { 3. Improvement from Previous } \\
\text { Year }\end{array}$
\end{tabular}


4. Conference Winning Percentage

5. AP Poll Placement

6. National Championships
4. Major Bowl Game Appearances

5. National Championships

6. AP Poll Placement

\section{Basketball}

1. NCAA Tournament Appearances

2. Number of NCAA Tournament Games Won

3. Improvement from Previous Year

4. Overall Winning Percentage

5. Conference Winning Percentage

6. AP Poll Placement

7. National Championships

\section{Basketball}

1. Overall Winning Percentage

2. Number of NCAA Tournament Games Won

3. NCAA Tournament Appearances

4. Conference Winning Percentage

5. Improvement from Previous Year

6. National Championships

7. AP Poll Placement

As shown in Table 16, there are several interesting differences between the most important factors in Power Five and Group of Five students' subjective definitions of athletic success. First, for factors influencing subjective football success perceptions, Group of Five students rated conference winning percentage as the second most important factor, while it was fourth amongst Power Five students. Since this is the first known study attempting to unpack how/what students consider successful, there is a dearth of literature to compare or contrast these results to. However, this particular finding makes sense based upon the current landscape of college football. 
For example, given the financial problems that many Group of Five schools face relative to their Power Five counterparts (Jones, 2018), "tune-up" games are becoming increasingly common in FBS football. "Tune-up," or "cupcake" games involve Power Five teams paying large sums of money (often called guarantees) to Group of Five teams in the hopes of starting their seasons off with a resounding, blowout victory (Kirshner, 2016). While Group of Five schools commonly receive six or seven-figure payouts from these games (Mandell, 2017), it also means they regularly enter in-conference play with several losses. Since Group of Five students may expect their school's football team to lose several out-of-conference "tune-up games," this could explain why they placed more value on conference winning percentage within this study.

Conversely, other results depicted in Table 16 contradict conventional wisdom. For example, with the factors influencing basketball success perceptions, Group of Five students' top-ranked factor was overall winning percentage, while this same factor was fourth amongst Power Five students. Group of Five schools' basketball programs participate in "one-bid" conferences, meaning that, without winning their conference tournament, their chances of making the NCAA Tournament are extremely low (Mast \& Gleeson, 2021). In fact, Selbe (2021) points out that no Group of Five conference sent more than two teams to the 2021 NCAA Men's Basketball Tournament. Comparatively, every Power Five conference had at least five schools qualify for the 2021 Tournament (NCAA, 2021). Since overall winning percentage is the main prerequisite for Power Five teams qualifying for the NCAA Tournament, it is surprising that Power Five students placed less emphasis on this success metric than Group of Five students. 
In sum, these findings both align and conflict with what one would predict about students' most important success factors. However, the uneven sample size ( $\sim 75 \%$ Power Five) means that further research on athletic success subjectivity is warranted. Implications and suggestions based on this research question will be discussed in subsequent paragraphs.

\section{Practical Implications}

The problem the current study attempted to address was whether colleges and universities are receiving the anticipated institution-wide benefits from successful football and basketball performances. In the wake of progressively increased spending behaviors, it is important to understand the return on investment these institutions receive from these expenditures. This section will present practical implications from the study's findings, broken down by research question.

\section{The Flutie Effect}

RQ1 was concerned with the impact of football and basketball success on the importance of athletics on students' enrollment decisions. The results indicate that colleges and universities may receive institution-wide benefits from athletic programs, but should not lean too heavily on the benefits to come strictly from team performance. Rather, if university officials want to use football or basketball success to increase potential student interest, they would be better off trying to use team performance as a springboard to getting potential students identified with the teams.

For example, in the opening round of the 2021 NCAA Men's Basketball Tournament, the Abilene Christian Wildcats pulled off a shocking upset over the University of Texas Longhorns. Following the upset victory, Abilene Christian president 
Phil Schubert told local media that the school could expect increased applications and enrollment this upcoming fall (Goldberg, 2021). The applications component of Schubert's statement is likely true, as previous literature has regularly correlated unforeseen, successful athletic performances to increased student applications (McEvoy, 2005; Pope \& Pope, 2009). However, if this study's results are any indication, the increased enrollment portion of President Schubert's statement should be taken with a caveat. If Abilene Christian (or any other institution in a similar position) wants to capitalize on athletic accomplishments by using them to increase enrollment, they may wish to focus their efforts on getting potential students identified with the Cougars' basketball team.

In sum, the primary practitioner implication for RQ1 is that football and basketball success alone are not sufficient to increase student enrollment. Instead, college and university officials should treat team identification as an intermediary of sorts. Athletic and admissions departments can develop campaigns focused on increasing high school students' identification levels with the football or basketball team, which may then go on to influence their decision to attend that particular institution. For example, when marketing a successful football or basketball performance to potential students, university personnel should avoid over-emphasizing the actual success. Rather, the marketing campaign should center around selling students on why being identified with that schools' football and basketball teams is preferrable to being identified with other schools' teams.

\section{Sense of Community and Enrollment Satisfaction}


RQ2 sought to examine the impact of perceived football and basketball success perceptions on students' enrollment satisfaction, with the mediating role of sense of community and moderating effect of team identification. The findings from this research question provide greater support for university's spending justifications than the findings from RQ1. Given the direct relationship between athletic success and SOC, as well as between SOC and enrollment satisfaction, practitioners may use these results in several ways.

First, colleges and universities should continue to market the social benefits of football and basketball success. While previous research has found that the presence of athletics can increase campus SOC (Stensland et al., 2019), this study implies that institutions receive greater SOC in times of success. Colleges and universities may use these results to justify their spending and subsidization behaviors by citing the enhanced campus SOC that arises from successful performances. Further, the lack of significant moderation from team identification signifies that supporting the football and basketball team may be a universal rallying point for all students. For example, the Texas A\&M Aggies football team are known for their " $12^{\text {th }}$ man," a nickname for the loyal Aggie fans that pack Kyle Field for every home football game. Texas A\&M can use these findings to highlight that attending Aggies football games are a valuable social outlet for students of all backgrounds (i.e., not just highly identified Aggies fans) to make friends and create a tighter-knit environment on campus. Specifically, these benefits and outcomes are stronger when students believe that Texas A\&M's performance is successful.

Further, the relationship between SOC and enrollment satisfaction is also valuable information for colleges and universities. Institutional officials should market how 
enhanced SOC can make students more satisfied with their decision to attend that college or university, which may result in additional benefits. For example, if institutions are able to use SOC to increase students' enrollment satisfaction, it is likely that satisfied students may donate money as alumni. A financial outcome such as this would make it easier for schools to justify their athletic expenditures. However, institutions will not be able to receive these benefits (SOC and enrollment satisfaction) if they are unable to convert potential students into enrolled ones. Thus, marketing departments still need to concentrate their efforts on how to use athletics to aid their enrollment efforts before they can receive beneficial outcomes from their current students. In other words, these benefits will be moot if potential students choose to enroll at another institution.

\section{Success Perceptions}

RQ3 attempted to uncover the most influential factors toward Power Five and Group of Five students' subjective perceptions of football and basketball success. While there are several practical implications, the uneven sample sizes (roughly $80 \%$ Power Five students) mean the findings should be taken with caution. One implication is that when developing marketing campaigns around the football team, Group of Five schools should highlight conference winning percentage. As discussed in the previous chapter, Group of Five schools regularly enter their conference football games with 2-3 losses as a result of playing "tune-up" games. However, students may still perceive the season as successful, so long as the team wins a high percentage of their conference games. For example, if a Group of Five football team finishes with an 8-4 record, but go 7-1 in conference play, the results suggest that students will likely perceive the season as successful, which can be marketed accordingly. 
Another practical implication is that even elite Power Five football and basketball programs should not place too heavy an emphasis on national championships. As evidenced in Table 16, national championships were the least important factor amongst Power Five students for both football and basketball. Further, of the five Power Five institutions in the sample, three of the schools' basketball teams have appeared in the championship game of the NCAA Men's Basketball Tournament since 2013. Despite the relatively high objective performance of these men's basketball programs, national championships still had the lowest mean score amongst Power Five students' factors influencing basketball success perception. Given the sample size and makeup, these findings should be taken with caution. However, the findings still suggest that even elite basketball programs such as Duke, Kansas, and North Carolina should avoid marketing a "national championship or bust" mentality to students.

\section{Theoretical Implications}

\section{Social Identity Theory}

The results from this study advance Social Identity Theory in several ways. First, one of SIT's core concepts is that what benefits one's social group collectively takes priority over the individuals' personal interest (Brewer, 1991). The results from RQ2 support this principle. The absence of significant moderated mediation suggests that regardless of their team identification levels, students recognize that football and basketball success contributes to a stronger campus community and climate. For instance, even if students are not personally invested in the football and basketball teams' performances, they understand that it is important to their institution's student body as a whole, and thus, it becomes important to themselves as well. 
Secondly, the results from RQ2 may be partially attributable to BIRGing and CORFing behavior, concepts which are underpinned by SIT (Wann \& Branscombe, 1990). Since the findings indicated that SOC is heightened when students perceive high levels of football and basketball success, students may feel that these successful performances reflect positively on themselves and the rest of the student body. In other words, when the team is successful, they may feel like "we" are successful too.

Conversely, when the teams are not performing at a successful level, students view this as detrimental to the student body and campus social climate, and instead opt to view the performances as "they" failed.

\section{The Flutie Effect}

The "Flutie Effect" refers to the relationship between team performance and the number of student applications (McEvoy, 2005). Previous research has established a positive correlation between football and basketball success and applications (McEvoy, 2005; Murphy \& Trandel, 1994; Pope \& Pope, 2009; Toma \& Cross, 1998). The current study attempted to further explore this phenomenon by examining athletic success' impact on enrollment, not just application decisions.

The results somewhat contradict previous literature by showing that while athletic success may drive students to apply to an institution, success alone is not sufficient enough to get students to actually enroll. Future studies may wish to critically examine correlational studies between success and applications and opt to distinguish between applications increases and enrollment increases. However, this study's results contribute to the body of literature surrounding the college student choice process. As discussed extensively in chapter two, the factors that influence students' application decisions are 
different than those which influence the official enrollment choice. Thus, while the results partially dispel correlational studies examining the Flutie Effect, they reinforce findings from higher education literature about how students' application decisions differ from their enrollment choice (Chapman, 1986; Galotti \& Mark, 1994; Hossler \& Gallagher, 1987).

\section{Athletic Success, Sense of Community, and Enrollment Satisfaction}

Sense of community refers to feelings of support or togetherness individuals feel from a group setting (Warner et al., 2013). Athletics can be a way to create SOC on college campuses by providing a universal rallying point for students, and SOC may also make students more satisfied with their enrollment decision. There is currently a gap in the literature regarding how campus SOC fluctuates with team performance, and how this goes onto impact satisfaction. Given that current students' are key stakeholders in collegiate athletics' current spending model, as their tuition dollars are commonly used to subsidize football and basketball programs, this study sought to fill this important gap.

Football and basketball success perceptions were shown to significantly predict SOC, with SOC also significantly predicting enrollment satisfaction. These findings bolster the literature surrounding athletics' impact on campus climate and SOC (Stensland et al., 2019) and SOC's effect on student satisfaction (Conn, 2017). Specifically, the findings show that these outcomes (SOC and Satisfaction) are, in fact, greater during times of athletic success. However, the lack of a direct path between athletic success and enrollment satisfaction contradicts literature correlating athletic support to satisfaction (Hanson et al., 2019). Subsequently, future research may choose to look at whether athletic success directly influences other outcome variables, as well as 
any other variables that mediate the relationship between athletic success and enrollment satisfaction

\section{Athletic Success Subjectivity}

Despite the plethora of studies that have examined athletic success' relationship with some beneficial outcome, such as increased applications, academic prestige, donation intentions, or student retention, there is a lack of research regarding success as a subjective construct. Given the disparity between Power Five and Group of Five schools in their financial inputs, it is possible that students at these institutions may value different success metrics. The results from this research question can aid theory and future research in several ways.

Future research involving athletic success' impact on a particular outcome (i.e., application numbers) can use these findings to select the success measurement most aligned with the sample. For example, if the sample consists of mostly Power Five basketball programs, conference winning percentage would be a more appropriate objective measurement than overall winning percentage. Conversely, if the sample is disproportionately Group of Five students, overall winning percentage would be preferable to conference winning percentage.

Secondly, as discussed in chapter two, while football and basketball success has consistently correlated to increased application numbers, the specific percentage increase has varied from study to study. It is possible that conflicting results may be a function of which success measurement was used. Future research may wish to do a "post-hoc" of sorts to see if selecting a different success metric that is more aligned with the sample provides more consistent results about the nature of this relationship. 


\section{Limitations}

First, one Power Five school accounted for approximately $80 \%$ of the responses. While significant measures were taken to include students from as many majors and backgrounds as possible (see chapter 4), this is nonetheless a noteworthy limitation. Specifically, within RQ3, future studies with more robust samples may indicate that the most important success measurements from this study are not generalizable across the FBS landscape.

Another limitation is the potential for students' opinions on SOC and enrollment satisfaction to change as they matriculate in their academic careers. Approximately $44 \%$ of the sample was made up of freshmen and sophomores, so these students may have different views on these two constructs as juniors and seniors. This limitation is particularly salient in wake of the COVID-19 pandemic. For example, as the pandemic continues, students' inability to attend football and basketball games with a large group

of friends may significantly alter their perceptions of campus SOC. Given the significant pathway observed in RQ2, such an occurrence would also likely impact their enrollment satisfaction.

Conversely, another limitation is recall bias of success perceptions. While asking students to indicate their perceptions of football and basketball success at the time of enrollment was deemed the most appropriate method to analyze RQ1, it is undoubtedly a limitation. It is possible that even highly identified football and basketball fans do not recall exactly how well the teams performed at the time of their enrollment decision, and thus their responses in this study may not reflect how they felt at the time. This limitation is amplified considering that seniors were the most represented undergraduate class in the 
sample (32.0\%). Future studies may wish to take additional measures to ensure that students' clearly recall their success perceptions at the time of enrollment.

\section{Future Research}

This study chose to focus on football and men's basketball success, since these are the most profitable and commercialized sports at colleges and universities (Whiteside et al., 2011). However, future research may wish to expand and explore how success in other sports impacts institution-wide outcomes. For example, did the continued success of the University of Connecticut Women's Basketball Team play a significant role in students' enrollment decisions?

Another avenue for future research is to utilize program history and tradition as the independent variable. As Mixon and Trevino (2005) point out, football and basketball programs commonly play at an elite level for a small number of years but are unable to maintain this performance over a longer period of time. For example, the University of Miami Hurricanes won four national championships during an eight-year stretch between 1983 and 1991. However, the Hurricanes have only appeared in one major bowl game in the past 16 seasons. For Miami students, while the football team's success may not draw them to enroll at Miami, they may still be attracted to the school's rich heritage and tradition. Future research should attempt to demarcate between success and tradition.

Lastly, future studies may wish to introduce sport identification as a predictor of

the importance of athletics on enrollment, as opposed to team identification. It is possible that even if students are not necessarily identified with their schools' football and basketball programs, they are highly identified fans of the sport itself. In this case, students may consider their general identification as a college football or college 
basketball fan more important than team identification when making their enrollment decision.

\section{Study Summary}

Division I FBS athletic departments' spending has reached unprecedented levels (Huml et al., 2019), meaning many institutions are becoming increasingly reliant on institutional funding, particularly student fees (Lipford \& Slice, 2018; Osborne et al., 2020). The most common justifications for this spending is that schools receive enhanced visibility and increased applications from football and basketball success (Bass et al., 2015; Bremmer \& Kesselring, 1993), and that athletics cultivates a strong campus sense of community (SOC) by giving current students a common interest to rally around (Stensland et al., 2019). However, no studies to date have examined the impact that football and basketball success has on students' actual enrollment choice, as well as how campus SOC changes with subjective team performance. Thus, the purpose of this study was to incorporate current students' perspectives to measure athletic success' impact on college enrollment decisions, campus SOC, and enrollment satisfaction, while also attempting to uncover the most influential factors to students' personal definitions of athletic success.

The study found that neither football nor basketball success significantly predicted the importance of athletics on undergraduate students' enrollment decisions. Rather, the strongest predictor of this variable was football team identification. However, football and basketball success was found to significantly predict sense of community, which also went on to significantly predict students' satisfaction with their enrollment decision. Further, the lack of moderated mediation from team identification suggest that 
football and basketball success can be a valuable method for creating a tight-knit campus community.

Implications from this study contribute to both theory and practice. This study contributes to the body of Flutie Effect and college student choice literature by further highlighting the need to distinguish between factors driving students' application decisions and those driving their enrollment decisions. Additionally, the study highlights the need for college and university administrators to shift their focus away from using team success to increase enrollment and to place more emphasis on converting potential students into highly identified fans. However, once potential students become enrolled students, administrators may use football and basketball success to directly receive institution-wide benefits such as SOC and enrollment satisfaction. 


\section{REFERENCES}

Abrams, D., \& Hogg, M. A. (1998). Prospects for research in group processes and intergroup relations. Group Processes \& Intergroup Relations, 1(1), 7-20. https://doi.org/10.1177/1368430298011002

Abrams, J. (2006, October 04). NCAA asked to justify tax-exempt status. Washington Post http://www.washingtonpost.com/wpdyn/content/article/2006/10/04/AR2006100401464.html? noredirect=on

Adelson, A. (2018, December 2). Unbeaten UCF 'disappointed' to miss CFP but excited for Fiesta Bowl. ESPN. https://www.espn.com/collegefootball/story/_id/25437132/ucf-knights-disappointed-miss-cfp-excited-fiestabowl-1su-tigers.

Amir, O., Rand, D. G., \& Gal, Y. K. (2012). Economic games on the internet: The effect of \$1 stakes. PLoS ONE, 7(2): e31461.

Arai, A., Ko, Y. J., \& Kaplanidou, K. (2013). Athlete brand image: scale development and model test. European Sport Management Quarterly, 13(4), 383-403. https://doi.org/10.1080/16184742.2013.811609

Archives of NCAA Revenues and Expenses Reports by Division. (n.d.). https://ncaaorg.s3.amazonaws.com/research/Finances/2020RES_D1RevExp_Report.pdf 
Ashforth, B., \& Mael, F. (1989). Social Identity Theory and the Organization. The Academy of Management Review, 14(1), 20-39. https://doi.org/10.2307/258189

Bailey, B. L., Bauman, C., \& Lata, K. (1998). Student retention and satisfaction: The evolution of a predictive model. Paper presented at the 1998 Annual Forum of the Association for Institutional Research, Minneapolis, MN. (ERIC Document Retrieval System, ED424797).

Baron, R. M., \& Kenny, D. A. (1986). The moderator-mediator variable distinction in social psychological research: Conceptual, strategic, and statistical considerations. Journal of Personality \& Social Psychology, 51(6), 1173-1182. https://doi.org/10.1037/0022-3514.51.6.1173

Barratt, M. J., Potter, R., Wouters, M., Wilkins, C., Werse, B., Perala, J., Mulbjerg Pedersen, M., Nguten, H., Malm, A., Lenton, S., Korf, D., Klein, A., Heyde, J., Hakkarainen, P., Amussen Frank, V., Decorte, T., Bouchard, M. \& Blok, T. (2015). Lessons from conducting trans-national internet-mediated participatory research with hidden populations of cannabis cultivators. International Journal of Drug Policy, 26(2), 3849.

Bass, J. R., Schaeperkoetter, C. C., \& Bunds, K. S. (2015). The "Front Porch:" Examining the increasing interconnection of university and athletic department funding. ASHE Higher Education Report, 41(5), 1-103. https://doi.org/10.1002/aehe.20023

Battistich, V., \& Hom, A. (1997). The relationship between students' sense of their school as a community and their involvement in problem behaviors. American Journal of Public Health, 87(12), 1997-2001.

https://doi.org/10.2105/ajph.87.12.1997 
Battle-McDonald, W. J. (2019). The impact of collegiate athletic success and scandals on admissions applications [Unpublished master's thesis]. Duke University.

Baumer, B., \& Zimbalist, A. (2019). The impact of college athletic success on donations and applicant quality. International Journal of Financial Studies, 7(2), 1-23. https://doi.org/10.3390/ijfs7020019

Berinsky, A. J., Huber, G. A., \& Lenz, G. S. (2012). Evaluating online labor markets for experimental research: Amazon.com's Mechanical Turk. Political Analysis, 20(3), $351-368$.

Besser, H. \& Donahue, S. (1996). Introduction and overview: Perspectives on ... distance independent education, Journal of the American Society for Information Science, 47(11), 801-804.

Biscaia, R., Correia, A., Ross, S., Rosado, A., \& Maroco, J. (2013). Spectator-based brand equity in professional soccer. Sport Marketing Quarterly, 22(1), 20-32.

Boyer, E.L. \& Carnegie Foundation for Advancement of Teaching. (1990). Campus Life: In search of community. Carnegie.

Boyle, B.A., \& Magnusson, P. (2007). Social identity and brand equity formation: a comparative study of collegiate sports fans. Journal of Sport Management, 21(4), 497-520.

Braddock, J. H., \& Hua, L. (2006). Determining the college destination of African American high school seniors: Does college athletic reputation matter? Journal of Negro Education, 75(3), 532-545. 
Bremmer, D. S., \& Kesselring, R. G. (1993). The advertising effect of university athletic success: A reappraisal of the evidence. The Quarterly Review of Economics and Finance, 33(4), 409-421. https://doi.org/10.1016/1062-9769(93)90006-6

Brewer, M. B. (1991). The social self: On being the same and different at the same time. Personality and Social Psychology Bulletin, 17(5), 475-482.

https://doi.org/10.1177/0146167291175001

Brewer, M. B. (2001). The many faces of Social Identity: Implications for political psychology. Political Psychology, 22(1), 115-125. https://doi.org/10.1111/0162$\underline{895 \times .00229}$

Brunt, C. (2020, December 20). Coastal Carolina, Cincinnati headline Bowl Day snubs. AP News. https://apnews.com/article/college-football-cincinnati-bearcatsfootball-football-coronavirus-pandemic-coastal-carolina-chanticleers-football4648e07add75dbfd1cbb436999278f15

Burke, P. J., \& Tully, J. C. (1977). The measurement of role identity. Social Forces, 55(4), 881-897. https://doi.org/10.2307/2577560

Byrum, T. (2017, May 11). Major mias, underseeding Mid-Majors. NBC Sports. https://www.nbcsports.com/washington/ncaa/2017-ncaa-tournament-major-biasunderseeding-mid-majors.

Cattel, R.C. (1966). The scree test for the number of factors. Multivariate Behavioral Research, 1, 246-276.

Chalip, L. (2006). Toward a distinctive sport management discipline. Journal of Sport Management, 20(1), 1-21. https://doi.org/10.1123/jsm.20.1.1 
Chapman, R. G. (1986). Toward a theory of college selection: A model of college search and choice behavior. Advances in Consumer Research, 13, 246-250.

Chavis, D.M., \& Newbrough, J.R. (1986). The meaning of "community" in community psychology. Journal of Community Psychology, 14(4), 335-340.

Chressanthis, G. A., \& Grimes, P. W. (1993). Intercollegiate sports success and first-year student enrollment demand. Sociology of Sport Journal, 10(3), 286-300. https://doi.org/10.1123/ssj.10.3.286

Chu, D. (1989). The character of American higher education and intercollegiate sports. State University of New York Press.

Chung, D. (2013). The dynamic advertising effect of collegiate athletics. Marketing Science, 32(5), 679-98. https://doi.org/10.2139/ssrn.2345220

Cialdini, R.B., Borden, R.J., Thorne, A., Walker, M.R., Freeman, S., \& Sloan, L.R. (1976). Basking in reflected glory: Three (football) field studies. Journal of Personality and Social Psychology, 34(3), 366-375. https://doi.org/10.1037/00223514.34.3.366

Clopton, A. W. (2007). Predicting a sense of community amongst students from the presence of intercollegiate athletics: What roles do gender and BCS-affiliation play in the relationship? The SMART Journal, 4(1), 95-110.

Clopton, A. W. (2008). Southern comfort?: Exploring regional differences in the relationship between fan identification and sense of community among college students. Journal for the Study of Sports and Athletes in Education, 2(1), 9-27. https://doi.org/10.1179/ssa.2008.2.1.249

Cohen, J. (1992). A power primer. Psychological Bulletin, 112(1), 155-159. 
Coleman, B. J., Dumond, J. M., \& Lynch, A. K. (2010). Evidence of bias in NCAA tournament selection and seeding. Managerial and Decision Economics, 31(7), 431-452. https://doi.org/10.1002/mde.1499

Conn, S. M. (2017). Predictors of tuition worth: Psychological sense of community, institutional integrity, and student thriving. Christian Higher Education, 16(3), 142-158. https://doi.org/10.1080/15363759.2016.1250685

Crawford, B. (2018, April 28). ESPN FPI ranks college football's toughest conferences. 247Sports. https://247sports.com/LongFormArticle/ESPN-FPI-ranks-collegefootballs-toughest-conferences-SEC-Big-Ten-ACC-Big-12-146569402/.

Creswell, J. W. (2008). Educational research: Planning, conducting, and evaluating quantitative and qualitative research. Pearson.

Cronin, J.J., Brady, M.K., \& Hult, G.T.M. (2000). Assessing the effects of quality, value, and customer satisfaction on consumer behavioral intentions in service environments. Journal of Retailing, 76(2), 193-218. https://doi.org/10.1016/s0022-4359(00)00028-2

Crump, M. J., McDonnell, J. V., \& Gureckis, T. M. (2013). Evaluating Amazon's Mechanical Turk as a tool for experimental behavioral research. PloS one, 8(3), e57410.

Darzi, M. A., \& Bhat, S. A. (2018). Personnel capability and customer satisfaction as predictors of customer retention in the banking sector: A mediated-moderation study. International Journal of Bank Marketing, 36(4), 663-679.

https://doi.org/10.1108/ijbm-04-2017-0074 
Davidson, W., \& Cotter, P. R. (1991). The relationship between sense of community and subjective well-being: A first look. Journal of Community Psychology, 19(3), 246-253. https://doi.org/10.1002/1520-6629(199107)19:3<246::aidjcop2290190308>3.0.co;2-1

Dellenger, R. (2019, September 24). Group of Five's success another reason for CFP expansion. Sports Illustrated. https://www.si.com/college/2019/09/25/group-offive-playoff-expansion-power-5-boise-state-ucf

Denhart, M., \& Ridpath, D. (2011). Funding the arms race: A case study of student athletic fees. Center for College Affordability and Productivity. Center for College Affordability. https://files.eric.ed.gov/fulltext/ED536146.pdf

Díaz, G. R. (2017). The influence of satisfaction on customer retention in mobile phone market. Journal of Retailing and Consumer Services, 36, 75-85. https://doi.org/10.1016/j.jretconser.2017.01.003

Dodd, D. (2020, September 29). With near-empty stands, college football's home-field advantage on pace to be worst in 15 years. CBS Sports. https://www.cbssports.com/college-football/news/with-near-empty-standscollege-footballs-home-field-advantage-on-pace-to-be-worst-in-15-years/.

Donavan, D.T., Carlson, B.D., \& Zimmerman, M. (2005). The influence of personality traits on sports fan identification. Sport Marketing Quarterly, 14(1), 31-42.

Dosh, K. (2018, June 25). Already, Loyola And Villanova Have Seen Benefits From Basketball Success. Forbes. https://www.forbes.com/sites/kristidosh/2018/06/25/loyola-and-villanovas- 
basketball-success-positively-impacts-both-universities-for-years-tocome/\#24830e5b1e52

Duffy, T. (2014, March 24). Wichita State: Just Another NCAA Tournament Casualty. The Big Lead. https://www.thebiglead.com/posts/wichita-state-just-another-ncaatournament-casualty-01dxkn9xargs.

Noël-Elkins, A., \& Forrester, D.J. (2011). The contribution of campus recreational sports participation to perceived sense of campus community. Recreational Sports Journal, 35, 24-34.

End, C. M., Dietz-Uhler, B., Harrick, E. A., \& Jacquemotte, L. (2002). Identifying with winners: A reexamination of sport fans' tendency to BIRG. Journal of Applied Social Psychology, 32(5), 1017-1030. https://doi.org/10.1111/j.15591816.2002.tb00253.x

Enright, M., Lehren, A. W., \& Longoria, J. (2020, March 9). Hidden figures: College students may be paying thousands in athletic fees and not know it. NBC. https://www.nbcnews.com/news/education/hidden-figures-college-students-maybe-paying-thousands-athletic-fees-n1145171

Fabrigar, L.R., \& Wegener, D.T. (2012). Factor analysis. Oxford University Press.

Fairley, S., \& Tyler, B.D. (2012). Bringing baseball to the big screen: Building sense of community outside of the ballpark. Journal of Sport Management, 26, 258-270.

Feezell, T. (2009). Adding football and the "uses" of athletics at NCAA Division II and Division III institutions. New Directions for Higher Education, 148, 65-72. https://doi.org/10.1002/he.369

Feinstein, J. (2019, February 9). This March Madness should have more room for midmajors, but don't bet on it. Chicago Tribune. 
https://www.chicagotribune.com/sports/college/ct-spt-ncaa-tournament-midmajors-20190209-story.html.

Festinger, L. (1954). A theory of social comparison processes. Human Relations, 7(2), 117-140. https://doi.org/10.1177/001872675400700202

Field, A. P. (2009). Discovering statistics using SPSS. SAGE.

Fink, J.S., Trail, G.T., \& Anderson, D.F. (2002). An examination of team identification: which motives are most salient to its existence. International Sports Journal, 6(2), $195-207$.

Fisher, R.J., \& Wakefield, K. (1998). Factors leading to group identification: A field study of winners and losers. Psychology \& Marketing, 15(1), 23-40. https://doi.org/10.1002/(sici)1520-6793(199801)15:1<23::aid-mar3>3.0.co;2-p

Follmer, D. J., Sperling, R. A., \& Suen, H. K. (2017) The role of MTurk in education research: Advantages, issues, and future directions. Educational Researcher, $46(6), 329-34$.

Fornell, C., \& Larcker, D. F. (1981). Structural equation models with unobservable variables and measurement error: Algebra and statistics. Journal of Marketing Research, 18(3), 382-388. https://doi.org/10.2307/3150980

French, S., Wood, L., Foster, S.A., Giles-Corti, B., Frank, L., \& Learnihan, V. (2013). Sense of community and its association with the neighborhood built environment. Environment and Behavior, 46, 677-697. doi:10.1177/0013916512469098

Fulks, D. L. (2017). Revenues and expenses, 2004-2016: Division I intercollegiate athletics programs report. Indianapolis, IN: NCAA. NCAA.org 
http://www.ncaa.org/sites/default/files/2017RES_D1-

RevExp_Entire_2017_Final_20180123.pdf

Funk, D., Jordan, J., Ridinger, L., \& Kaplanidou, K. (2011). Capacity of mass participant sport events for the development of activity commitment and future exercise intention. Leisure Sciences, 33(3), 250-268.

https://doi.org/10.1080/01490400.2011.564926

Galotti, K. M., \& Mark, M. C. (1994). How do high school students structure an important life decision? A short-term longitudinal study of the college decisionmaking process. Research in Higher Education, 35(5), 589-607. https://doi.org/10.1007/bf02497089

Gardner, S. (2009). Conceptualizing success in doctoral education: Perspectives of faculty in seven disciplines. The Review of Higher Education, 32(3), 383- 406.

Goidel, R.K., \& Hamilton, J.M. (2006). Strengthening higher education through gridiron success? Public perceptions of the impact of national football championships on academic quality. Social Science Quarterly, 87(4), 851-862.

https://doi.org/10.1111/j.1540-6237.2006.00439.x

Goins, B. (2017, July 31). UCF keeps athletic programs competitive with student fees. Nicholson Student Media. http://www.nicholsonstudentmedia.com/sports/ucfkeeps-athletic-programs-competitive-with-student-fees/article_cefef444-6da711e7-a4f4-1f21271dd603.html

Goldberg, R. (2021, March 24). Abilene Christian president Says win over Texas Earned School close To' \$120M. Bleacher Report. 
https://bleacherreport.com/articles/2938028-abilene-christian-president-says-winover-texas-earned-school-close-to- $120 \mathrm{~m}$

Gorusch, R. L. (1983). Factor Analysis (2nd ed.). Hillsdale, NJ: Lawrence Erlbaum Associates.

Han, H., Kim, W., Lee, S., \& Kim, H-R. (2018). How image congruity and satisfaction impact customer retention at luxury restaurants: A moderated mediation framework. Social Behavior \& Personality: An International Journal, 46(6), 891904. https://doi.org/10.2224/sbp.6767

Hanson, T. A., Bryant, M. R., \& Lyman, K. J. (2019). Intercollegiate athletic programs, university brand equity and student satisfaction. International Journal of Sports Marketing and Sponsorship, 21(1), 106-126. https://doi.org/10.1108/ijsms-102018-0102

Hartsell, J. (2015, January 23). Fees fuel smaller colleges' athletics Mid-major schools depend on students. The Post and Courier.

https://www.postandcourier.com/sports/fees-fuel-smaller-colleges-athletics-midmajor-schools-depend-on-students/article 86d44376-c925-5f46-8b77Oba3dca72ed3.html

Hauser, D. J., Paolacci, G., \& Chandler, J. J. (2018). Common concerns with MTurk as a participant pool: Evidence and solutions. In Kardes, F., Herr, P., \& Schwarz, N (Eds), Handbook in Research Methods in Consumer Psychology. (1 ${ }^{\text {st }}$ Ed., 319337). Routledge. https://doi.org/10.31234/osf.io/uq45c 
Hayes, A. F. (2012). PROCESS: A versatile computational tool for observed variable mediation, moderation, and conditional process modeling. http://www.afhayes.com/public/process2012.pdf

Hayes, A. F. (2013). Introduction to mediation, moderation, and conditional process analysis: A Regression-Based Approach. Guilford Press.

Hayes A.F., \& Rockwood, N.J. (2017). Regression-based statistical mediation and moderation analysis in clinical research: observations, recommendations, and implementation. Behaviour Research and Therapy, 98, 39-57.

Heere, B., \& James, J. D. (2007). Sports teams and their communities: Examining the influence of external group identities on team identity. Journal of Sport Management, 21(3), 319-337. https://doi.org/10.1123/jsm.21.3.319

Henseler, J., Ringle, C.M., \& Sarstedt, M. (2015). A new criterion for assessing discriminant validity in variance-based structural equation modeling. Journal of the Academy of_Marketing Science, 43(1), 115-135.

Henson, R.K. \& Roberts, J.K. (2006). Use of exploratory factor analysis in published research: Common errors and some comment on improved practice. Educational and Psychological Measurement, 66(3), 393-416.

Hickman, D. C., \& Meyer, A. G. (2017). Does athletic success influence persistence at higher education institutions? New evidence using panel data. Contemporary Economic Policy, 35(4), 658-676. https://doi.org/10.1111/coep.12208

Hogg, M.A., \& Ridgeway, C.L. (2003). Social Identity: Sociological and social psychological perspectives. Social Psychology Quarterly, 66(2), 97-100. 
Hogg, M. A., \& Terry, D. J. (2000). Social Identity and self-categorization processes in organizational contexts. The Academy of Management Review, 25(1), 121-140. https://doi.org/10.2307/259266

Horn, J. L. (1965). A rationale and test for the number of factors in factor analysis. Psychometrika, 30, $179-185$

Hossler, D., \& Gallagher, K. S. (1987). Studying student college choice: A three-phase model and the implications for policy makers. College and University, 2(3), 207221.

Hu, L., \& Bentler, P. M. (1999). Cutoff criteria for fit indexes in covariance structure analysis: Conventional criteria versus new alternatives. Structural Equation Modeling, 6(1), 1-55. https://doi.org/10.1080/10705519909540118

$\mathrm{Hu}, \mathrm{S}$, and D. Hossler. (2000). Willingness to pay and preference for private institutions. Research in Higher Education, 41(6), 685-701

Huddy, L. (2001). From social to political identity: A critical examination of Social Identity Theory. Political Psychology, 22(1), 127-156. https://doi.org/10.1111/0162-895x.00230

Huml, M. R., Pifer, N. D., Towle, C., \& Rode, C. R. (2019). If we build it, will they come? the effect of new athletic facilities on recruiting rankings for power five football and men's basketball programs. Journal of Marketing for Higher Education, 29(1), 1-18. https://doi.org/10.1080/08841241.2018.1478924

Hussar, B., Zhang, J., Hein, S., Wang, K., Roberts, A., Cui, J., Smith, M., Bullock-Mann, F., Barmer, A., \& Dilig, R. (2020). The condition of education 2020 (NCES 2020- 
144). U.S. Department of Education. Washington, DC: National Center for Education Statistics.https://nces.ed.gov/pubsearch/pubsinfo.asp?pubid=2020144

Hyun, M., \& Jordan, J. S. (2019). Athletic goal achievement: A critical antecedent of event satisfaction, re-participation intention, and future exercise intention in participant sport events. Sport Management Review, 23(2), 256-270. https://doi.org/10.1016/j.smr.2019.01.007

Jackson, D. L., Voth, J., \& Frey, M. P. (2013). A note on sample size and solution propriety for confirmatory factor analytic models. Structural Equation Modeling, 20(1), 86-97. https://doi:10.1080/10705511.2013.742388

Jackson, G. (1982). Public efficiency and private choice in higher education. Educational Evaluation and Policy Analysis. 4(2), 237-247. https://doi.org/10.3102/01623737004002237

Jacobson, B. (2003). The social psychology of the creation of a sports fan identity: A theoretical review of the literature. Athletic Insight, 5(2), 1-14.

Jensen, J. A., Turner, B. A., Delia, E., James, J., Greenwell, T. C., McEvoy, C., Ross, S., Seifried, C., \& Walsh, P. (2016). Forty years of BIRGing: New perspectives on Cialdini’s Seminal Studies. Journal of Sport Management, 30(2), 149-161. https://doi.org/10.1123/jsm.2015-0340

Jewell, R. T. (2020). NCAA Expenditure and Efficiency: Analyzing generated and allocated revenue in the Football Bowl Subdivision. Journal of Sports Economics, 21(4), 363-390. https://doi.org/10.1177/1527002520906530 
Johnson, N., Veletsianos, G., \& Seaman, J. (2020). U. S. Faculty and administrators' experiences and approaches in the early weeks of the COVID-19 pandemic. Online Learning, 24(2). https://doi.org/10.24059/olj.v24i2.2285

Johnson, R. (2018, January 23). A complete timeline of UCF's national championship claim. SBNation.com. https://www.sbnation.com/collegefootball/2018/1/23/16921710/ucf-national-championship-claim-2017.

Johnston, T. C. (2010). Who and what influences choice of university? Student and university perceptions. American Journal of Business Education, 5(10), 15-24.

Jones, D. (2018, May 16). Revenue gap between college football elite and poor just keeps widening. Penn Live. https://www.pennlive.com/pennstatefootball/2018/05/penn_state_football_revenu e pi.html

Jones, W.A., \& Rudolph, M. J. (2020). Are rising athletics allocations associated with student costs: Evidence from public NCAA Division I Universities. Higher Education Politics \& Economics, 6(1), 56-80.

Jones, W.A., Rudolph, M. J., \& Brown, M. (2018). A growth curve analysis of mandatory student athletic fees. Journal of Intercollegiate Sports, 11(2), 172-192. https://doi.org/10.1123/jis.2018-0013

Judd, C.M. \& Kenny, D.A. (2010). Data analysis in social psychology: recent and recurring issues", in Fiske, S.T., Gilbert, D.T. and Lindzey, G. (Eds), Handbook of Social Psychology, 1, 115-139.

Kaiser, H. F. (1960) The application of electronic computers to factor analysis. Educational and Psychological Measurement, 20, 141-151. 
Kenny, D. A., Kaniskan, B., \& McCoach, D. B. (2015). The performance of RMSEA in models with small degrees of freedom. Sociological Methods \& Research, 44(3), 486-507. https://doi. org/10.1177/0049124114543236

Kerka, S. (1996). Distance learning, the Internet, and the world wide web. ERIC Digest. (ERIC Document Reproduction Service No. ED 395 214).

King, D. B., O’Rourke, N., \& DeLongis, A. (2014). Social media recruitment and online data collection: A beginner's guide and best practices for accessing low-prevalence and hard-to-reach populations. Canadian Psychology, 55(4), 240-249.

Kirshner, A. (2016, June 22). College football's cupcake games are about more than just easy wins. SB Nation. https://www.sbnation.com/collegefootball/2016/6/22/11648368/scheduling-cupcake-guarantee-games-cost

Klein, R. A., Ratliff, K. A., Vianello, M., Adams, R. B., Bahník, Š., Bernstein, M. J., . . . Nosek, B. A. (2014). Investigating variation in replicability: A "many labs" replication project. Social Psychology, 45, 142-152.

Koay, K.Y., \& Derek, O.L.T. (2016). The mediating role of customer satisfaction in Customer Retention Model: A case of local automobile brands in Malaysia. Pertanika Journal Social Sciences \& Humanities, 24(S), 27-40.

Kwon, H. H., Trail, G. T., \& Lee, D. (2008). The effects of vicarious achievement and team identification on BIRGing and CORFing. Sport Marketing Quarterly, 17(4), 209-217.

LaFave, A., Kelly, E., \& Ford, J. (2018). Factors that influence student college choice. Data Point NCES 2019-119. Washington, DC: ERIC. National Center for Education Statistics. https://nces.ed.gov/pubs2019/2019119.pdf 
Landrum, R. E., Turrisi, R., \& Harless, C. (1998). University image: The benefits of assessment and modeling. Journal of Marketing for Higher Education, 9(1), 5368.

Lavigne, P. (2016, September 2). Rich get richer in college sports as poorer schools struggle to keep up. ESPN.

https://www.espn.com/espn/otl/story/_id/17447429/power-5-conference-schoolsmade-6-billion-last-year-gap-haves-nots-grows

Lawrence, H. (2013). The impact of intercollegiate athletics financial inequalities. Journal of Intercollegiate Sport, 6(1), 25-43. https://doi.org/10.1123/jis.6.1.25

Lee, S., \& Chatfield, H. K. (2011). The analysis of factors affecting choice of college: A case study of UNLV hotel college students. http://scholarworks.umass.edu/gradconf_hospitality/2011/Presentation/17/.

Letawsky, N. R., Schneider, R. G., Pedersen, P. M., \& Palmer, C. J. (2003). Factors influencing the college selection process of student-athletes: are their factors similar to non-athletes? College Student Journal, 37(4), 604-610.

Lipford, J.W., \& Slice, J.K. (2018). Who pays for college athletic spending? An examination of the evidence. The Journal of SPORT, 6(1), 18-39.

Loehlin, J. C. (2004). Latent Variable Models (4th ed.). Erlbaum.

Long, M. C. (2004). College applications and the effect of affirmative action. Journal of Econometrics, 121(1-2), 319-342. https://doi.org/10.1016/j.jeconom.2003.10.001

Lounsbury, J. W., \& DeNeui, D. (1995). Psychological sense of community on campus. College Student Journal, 29(3), 270-277. 
Lounsbury, J. W., \& DeNeui, D. (1996). Collegiate psychological sense of community in relation to size of college/university and extroversion. Journal of Community Psychology, 24(4), 381-394.

Lyons, K., \& Dionigi, R. (2007). Transcending emotional community: A qualitative examination of older adults and masters' sports participation. Leisure Sciences, 29(4), 375-389. https://doi.org/10.1080/01490400701394881

MacKinnon, D.P., Fairchild, A.J., Fritz, M.S. (2007). Mediation Analysis. Annu. Rev. Psychol, 58, 593-614

MacKinnon, D. P., Lockwood, C. M., Hoffman, J. M., West, S. G., \& Sheets, V. (2002). A comparison of methods to test mediation and other intervening variable effects. Psychological Methods, 7(1), 83-104.

Madrigal, R. (1995). Cognitive and affective determinants of fan satisfaction. Journal of Leisure Research, 27(3), 205. https://doi.org/10.1080/00222216.1995.11949745

Mandell, N. (2017, September 17). Nebraska paid \$820k to get upset by Northern Illinois. USA Today. https://ftw.usatoday.com/2017/09/nebraska-niu-money

Maringe, F. (2006). University and course choice: Implications for positioning, recruitment, and marketing. International Journal of Educational Management, $20(6), 466-479$.

Martin, W. E., \& Bridgmon, K. D. (2012). Quantitative and statistical research methods: From hypothesis to results. John Wiley \& Sons.

Maslow, A. H. (1943). A theory of human motivation. Psychological Review, 50, 370396. 
Mast, S., \& Gleeson, S. (2021, February 11). NCAA tournament Bracketology: Expect the Big ten to have the most bids and best seeding. USA Today. https://www.usatoday.com/story/sports/ncaab/2021/02/11/bracketology-2021ncaa-tournament-bubble-watch-march-madness/6718067002/

McCann, M. (2018, March 17). How UMBC can benefit from historic upset. Sports Illustrated. https:/www.si.com/college/2018/03/17/umbc-virginia-upset-dougflutie-jairus-lyles.

McCarthy, M., Pretty, G., \& Catano, V. (1990). Psychological sense of community: An issue in student burnout. Journal of College Student Personnel, 31(3), 211-216.

McCormick, R. E., \& Tinsley, M. (1987). Athletics versus academics - evidence from SAT scores. Journal of Political Economy, 95(5), 1103-1116. https://doi.org/10.1086/261505

McEvoy, C. D. (2005). The relationship between dramatic changes in team performance and undergraduate admissions applications. The SMART Journal, 2(1), 17-24.

McInnerney, J. M, \& Roberts, T. S. (2004). Online learning: social interaction and the creation of a sense of community. Educational Technology \& Society, 7(3), 7381.

McMillan, D.W., \& Chavis, D.M. (1986). Sense of Community: A definition and theory. American Journal of Community Psychology, 14(1), 6-23. https://doi.org/10.1002/1520-6629(198601)14:1<6::aidjcop2290140103>3.0.co;2-i

Messick, S. (1989). Meaning and values in test validation: The science and ethics of assessment. Educational Researcher, 18(2), 5-11. 
Midi, H., \& Bagheri, A. (2010, July). Robust multicollinearity diagnostic measure in collinear data set. Proceedings of the 4th international conference on applied mathematics, simulation, and modeling (pp. 138-142). World Scientific and Engineering Academy and Society (WSEAS).

Mitrano, J., \& Smith, R. (1990). The socioemotional functions of sport and the maintenance of community: Hurricane Hugo and horse racing in St. Croix. Arena Review, 14(1), 47-58.

Mixon, F.G., \& Ressler, R.W. (1995). An empirical note on the impact of college athletics on tuition revenues. Applied Economics Letters, 2(10), 383-387. https://doi.org/10.1080/758518995

Mixon, F., \& Trevino, L (2005). From kickoff to commencement: The positive role of intercollegiate athletics in higher education. Economics of Education Review 24(1), 97-102. https://doi.org/10.1016/j.econedurev.2003.09.005

Murphy, R. G., \& Trandel, G. A. (1994). The relation between a university's football record and the size of its applicant pool. Economics of Education Review, 13(3), 265-270. https://doi.org/10.1016/0272-7757(94)90014-0

Myrie, R (2019). Social Media: How is it Affecting College Students?". Posters@Research Events. 29. https://digitalcommons.brockport.edu/research_posters/29 NCAA.com. (2021, March 17). 2021 NCAA TOURNAMENT bids: All 68 March Madness teams. NCAA.com. https://www.ncaa.com/news/basketball$\underline{\text { men/article/2021-03-14/2021-ncaa-tournament-bids-all-68-march-madness-teams }}$ 
Noel-Elkins, A., Forrester, S., \& Elkins, D. (2019). Examining the relationship between students' perceived sense of campus community and satisfaction with school life. College Student Affairs Journal, 37(1), 28-38

Nunnally, J., \& Bernstein, I. (1994). Psychometrics theory ( $3^{\text {rd }}$ ed.). McGraw-Hill.

Oliver, R.L. (1980). A cognitive model of the antecedents and consequences of satisfaction decision. Journal of Marketing Research 17(4), 460-469. https://doi.org/10.1177/002224378001700405

Oliver, R.L. (1993). Cognitive, affective, and attribute bases of the satisfaction response. Journal of Consumer Research, 20(3), 418-430. https://doi.org/10.1086/209358

Oliver, R.L., \& Swan, J.E. (1989). Equity and disconfirmation perceptions as influences on merchant and product satisfaction. Journal of Consumer Research, 16(3), 372383. https://doi.org/10.1086/209223

Osborne, B., Jensen, J.A., \& Weight, E.A. (2020) Intercollegiate Athletics: A unique segment of the sport industry. Journal of Global Sport Management, 5(1), 13-33. https://doi.org/10.1080/24704067.2019.1669067

Palmer, C. (2018, October 3). The SEC is the Best Conference in College Football. The Harvard Crimson. https://www.thecrimson.com/column/cade-inamerica/article/2018/10/3/cade-in-america-SEC-2018/.

Paolacci, G., Chandler, J., \& Ipeirotis, P. G. (2010). Running experiments on Amazon Mechanical Turk. Judgment and Decision Making, 5(5), 411-419.

Parameswaran, R. \& Glowacka, A.E. (1995). University image: An information processing perspective. Journal of Marketing for Higher Education, 6, 41-56. 
Pedhazur, E. J. (1997). Multiple regression in behavioral research: Explanation and prediction (3rd ed.). Fort Worth, TX: Harcourt Brace.

Phillips, C. (2007). Ethnicity, identity and community cohesion in prison. In M. Wetherell, M. Lafleche, \& R. Berkeley (Eds.), Identity, ethnic diversity and community cohesion. SAGE Publications Ltd. doi:10.4135/9781446216071.n7

Phipps, C., Cooper, N., Shores, K., Williams, R., \& Mize, N. (2015). Examining the relationship between intramural sports participation and sense of community among college students. Recreational Sports Journal, 39, 105-120.

Phua, J.J. (2010). Sports fans and media use: Influence on sports fan identification and collective self-esteem. International Journal of Sport Communication, 3(2),190206. https://doi.org/10.1123/ijsc.3.2.190

Pitcher, J. (2018, September 8). Fueled by students: A look at UVa athletic fees. Daily Progress. https://www.dailyprogress.com/news/uva/fueled-by-students-a-look-atuva-athletic-fees/article_2c399288-b3be-11e8-af37-af1a2220d835.html

Pituch, K. A., \& Stevens, J. P. (2015). Intermediate statistics: A modern approach, Taylor \& Francis.

Pituch, K. A., \& Stevens, J. P. (2016). Applied multivariate statistics for the social sciences: Analyses with SAS and IBM's SPSS. Routledge.

Pope, D.G., \& Pope, J.C. (2009). The impact of college sports success on the quantity and quality of student applications. Southern Economic Journal, 75(3), 750-80.

Porter, S. R. (2004). Pros and cons of paper and electronic surveys. New Directions for Institutional Research, 121, 91-97. doi:10.1002/ir.103 
Price, I. F., Matzdorf, F., Smith, L., \& Agahi, H. (2003). The impact of facilities on student choice of university. Facilities, 21(10), 212-222.

Pretty, G., Andrewes, L., \& Collett, C. (1994). Exploring adolescents’ sense of community and its relationship to loneliness. Journal of Community Psychology, 22(4), 346-358. https://doi.org/10.1002/1520-6629(199410)22:4<346::aidjcop2290220407>3.0.co;2-j

Queirós, A., Faria, D., \& Almeida, F. (2017). Strengths and limitations of qualitative and quantitative research methods. European Journal of Education Studies, 3(9), 369387. https://doi.org/10.5281/zenodo.887089

Rees, T., Haslam, S. A., Coffee, P., \& Lavallee, D. (2015). A social identity approach to sport psychology: Principles, practice, and prospects. Sports Medicine, 45(8), 1083-1096. https://doi.org/10.1007/s40279-015-0345-4

Rickes, P. C. (2009). Make way for millennials! How today's students are shaping higher education space. Planning for Higher Education, 37(2), 7-17.

Robinson, D. (2018, October 10). Wealth disparity a major influence on college football. Athletic Business. https://www.athleticbusiness.com/college/wealth-disparity-amajor-influence-on-college-football.html

Robinson, M. J., \& Trail, G.T. (2005). Relationships among spectator gender, motives, points of attachment, and sport preference. Journal of Sport Management, 19(1), 58-80.

Robinson, M. J., Trail, G. T., Dick, R. J., \& Gillentine, A. J. (2005). Fans vs. spectators: An analysis of those who attend intercollegiate football games. Sport Marketing Quarterly, 14(1), 43-53. 
Rogerson, P. (2001). Statistical methods for geography. Sage Publishing.

Rosenberg, M. (1965). Society and the adolescent self-image. Princeton University Press. https://doi.org/10.1515/9781400876136

Ross, S.D., Bang, H., \& Lee, S. (2007). Assessing brand associations for intercollegiate ice hockey. Sport Marketing Quarterly, 16(2), 106-114.

Ross, S.D., James, J.D., \& Vargas, P. (2006). Development of a scale to measure professional sport team brand associations. Journal of Sport Management, 20(2), 260-279. https://doi.org/10.1123/jsm.20.2.260

Rovai, A. P. (2002). Building a sense of community at a distance. International Review of Research in Open and Distance Learning, 3(1).

Roy, D. P., Graeff, T. R., \& Harmon, S. K. (2008). Repositioning a university through NCAA Division I-A Football membership. Journal of Sport Management, 22(1), 11-29. https://doi.org/10.1123/jsm.22.1.11

Ruihley, B.J., Mamo, Y., Greenwell, T.C., \& Andrew, D.P.S. (2019). Increase customer retention: an examination of quality and its effects on the retention of sport participants. Journal of Sport Behavior, 42(3), 365-388.

Russo, R. D. (2017, December 19). Getting by with less: Gap grows between FBS haves, have nots. Associated Press. https://www.apnews.com/43024305e8f34c7d866804d761e4f0d3

Sanderson, J. (2013). From loving the hero to despising the villain: Sports fans, Facebook, and social identity threats. Mass Communication \& Society, 16(4), 487-509. https://doi.org/10.1080/15205436.2012.730650 
Sanderson, J., Frederick, E., \& Stocz, M. (2016). When athlete activism clashes with group values: Social identity threat management via social media. Mass Communication and Society, 19, 301-322.

Sarason, S.B. (1974). The psychological sense of community: Prospects for a community psychology. Jossey-Bass.

Schimmel, K.S. (2003). Sport. In Karen Christensen \& David Levinson (Eds.), Encyclopedia of community: From village to virtual world (pp. 1334-1336). Sage.

Schnaars, C., Berkowitz, S., \& Schrotenboer, B. (2018, June 29). Is overspending catching up to these Power 5 schools? USA Today. https://www.usatoday.com/story/sports/ncaaf/2018/06/28/college-footballoverspending-catching-up-these-big-time-schools/736222002/

Schreiner, L. A. (2013). Thriving in college. In P. C. Mather, \& E. Hulme (Eds.), Positive psychology and appreciative inquiry in higher education (pp. 41-52). College Station: Texas A \& M University.

Schreiner, L. A., \& Nelson, D.D. (2013). The contribution of student satisfaction to persistence. Journal of College Student Retention: Research, Theory \& Practice, $15(1), 73-111$.

Schumacker, R. E., \& Lomax, R. G. (2010). A beginner's guide to structural equation modeling (3rd ed.). Routledge Academic.

Selbe, N. (2021, March 14). All 68 teams in the 2021 Men's NCAA Tournament. Sports Illustrated. https://www.si.com/college/2021/03/14/ncaa-tournament-all-68teams-bracket-march-madness 
Seltzer, E. D., Stolley, M. R., Mensah, E. K., \& Sharp, L. K. (2014). Social networking site usage among childhood cancer survivors: A potential tool for research recruitment? Journal of Cancer Survivorship, 8(3), 49-54.

Šíma, J., Ruda, T. (2019). Using the SERVQUAL model in prediction of customer satisfaction in Czech fitness centres. Management, 7(1), 42-49. https://doi.org/10.17265/2328-2185/2019.01.004

Sloan, L R. (1989). The motives of sports fans. In J.H. Goldstein (Ed.).Sports games and play: Social and psychological viewpoints ( $2^{\text {nd }}$ ed.), 175-240. Lawrence Erlbaum Associates.

Smith, C. (2018, September 25). College football's most valuable teams: Texas A\&M jumps to No. 1. Forbes. https://www.forbes.com/sites/chrissmith/2018/09/11/college-footballs-mostvaluable-teams/\#160a496e6c64

Smith, D. R. (2008). Big-time college basketball and the advertising effect, does success really matter? Journal of Sports Economics, 9(4), 387-406. https://doi.org/10.1177/1527002507310805

Snyder, C.R., Higgins, R.L., \& Stucky, R.J. (1983). Excuses: Masquerades in search of frace. Contemporary Society, 14(3), 402-404. https://doi.org/10.2307/2071382

Snyder, C.R., Lassegard, M., \& Ford, C.E. (1986). Distancing after group success and failure: Basking in reflected glory and cutting off reflected failure. Journal of Personality and Social Psychology, 51(2), 382-388. https://doi.org/10.1037/0022$\underline{3514.51 .2 .382}$ 
Solikhah, A., Hartoyo, H., \& Yuliati, L. N. (2016). The influence of personality, motivation, brand image, and environment on students' intention in choosing Bogor Agricultural University (IPB). Journal of Consumer Sciences, 1(1), 14-32.

Son, C, Hegde, S, Smith, A, Wang, X, \& Sasangohar, F. (2020). Effects of COVID-19 on college students' mental health in the United States: Interview survey study. Journal of Medical Internet Research, 22(9).

Sparks, A. (2020, December 14). Vanderbilt's first winless football season ends after Georgia game canceled over COVID-19. The Tennessean. https://www.tennessean.com/story/sports/college/vanderbilt/2020/12/14/vanderbil t-football-winless-season-georgia-game-canceled-covid-19/6547664002/

Steiger, J. H., \& Lind, J. (1980) Statistically-based tests for the number of common factors. Paper presented at the Annual Spring Meeting of the Psychometric Society, Iowa City.

Stensland, P.J., Taniyev, O., Scola, Z., Ishaq, F.J., Wilkerson, Z., \& Gordon, B.S. (2019). The ties that bind: Examining Division I athletics as a social anchor. Journal of Issues in Intercollegiate Athletics, 12, 287-313.

Stevens, J.P. (2012) Applied Multivariate Statistics for the Social Sciences ( $5^{\text {th }}$ ed.) Routledge. https://doi.org/10.4324/9780203843130

Stryker, S., \& Burke, P. J. (2000). The past, present, and future of an identity theory. Social Psychology Quarterly, 63(4), 284-297. https://doi.org/10.2307/2695840

Suhr, D. (2006). Exploratory or confirmatory factor analysis. SAS Users Group International Conference (pp. 1-17). Cary: SAS Institute, Inc. 
Sutton, W. A., McDonald, M. A., Milne, G. R., \& Cimperman, J. (1997). Creating and fostering fan identification in professional sports. Sport Marketing Quarterly, $6(1), 15-22$.

Swyers, H. (2005). Community America: Who owns Wrigley Field? International Journal of the History of Sport, 22(6), 1086-1105.

https://doi.org/10.1080/09523360500286783

Tajfel, H. (1978). Differentiation between social groups: Studies in the social psychology of intergroup relations. Academic Press.

Tajfel, H., \& Turner, J. C. (1979). An integrative theory of intergroup conflict. In W. G. Austin, \& S. Worchel (Eds.), The social psychology of intergroup relations (pp. 33-37). Brooks/Cole.

Tajfel, H., \& Turner, J.C. (1986). The Social Identity Theory of intergroup behavior. In S. Worchel \& W. Austin (Eds.), Psychology of intergroup relations ( $^{\text {nd }}$ ed, pp. 724). Nelson Hall.

Terenzini, P. T., Cabrera, A. F., \& Bernal, E. M. (2001). Swimming against the tide: The poor in American higher education. Commissioned Report for the College Entrance Examination Board.

Theofanidis, D. \& Fountouki, A. (2018). Limitations and delimitations in the research process. Perioperative Nursing, 7(3), 155-162.

http://doi.org/10.5281.zenodo.2552022

Toma, J.D. (2003). Football U: Spectator sports in the life of the American university. University of Michigan Press. https://doi.org/10.3998/mpub.16594 
Toma, J. D., \& Cross, M. E. (1998). Intercollegiate athletics and student college choice: Exploring the impact of championship seasons on undergraduate applications. Research in Higher Education, 39(6), 633-661. https://doi.org/10.1023/A:1018757807834

Tracy, M. (2017, December 3). College Football Playoff: Alabama Is In, Ohio State Is Out. The New York Times. https://www.nytimes.com/2017/12/03/sports/collegefootball-playoff.html.

Trail, G. T., Anderson, D. F., \& Fink, J. S. (2005). Consumer satisfaction and identity theory: A model of sport spectator conative loyalty. Sport Marketing Quarterly, $14(2), 98-111$.

Trail, G.T., Fink, J. S., \& Anderson, D. F. (2003). Sport spectator consumption behavior. Sport Marketing Quarterly, 12(1), 8-17.

Trail, G., \& James, J. (2001). The motivation scale for sport consumption: assessment of the scale's psychometric properties. Journal of Sport Behavior, 24(1), 108-127.

Trail, G. T., Kim, Y.-K., Kwon, H. H., Harrolle, M. G., Braunstein-Minkove, J. R., \& Dick, R. (2012). The effects of vicarious achievement on BIRGing and CORFing: Testing moderating and mediating effects of team identification. Sport Management Review, 15(3), 345-354.

Tucker, I. (2004). A reexamination of the effect of big-time football and basketball success on graduation rates and alumni giving rates. Economics of Education Review, 23(6), 655-61. https://doi.org/10.1016/j.econedurev.2004.03.001

Tucker, I. (2005). Big-time pigskin success: Is there an advertising effect? Journal of Sports Economics, 6(2) 222-29. https://doi.org/10.1177/1527002504263398 
Tucker, I., and Amato, L. (1993). Does big-time success in football or basketball affect SAT scores. Economics of Education Review, 12(2), 177-181. https://doi.org/10.1016/0272-7757(93)90029-g

Tucker, I., \& Amato, L. (2006). A reinvestigation of the relationship between big-time basketball success and average SAT scores. Journal of Sports Economics, 7(4), 428-440. https://doi.org/10.1177/1527002505275096

Turner, J. C., Brown, R. J., \& Tajfel, H. (1979). Social comparison and group interest in ingroup favouritism. European Journal of Social Psychology, 9(2), 187-204. https://doi.org/10.1002/ejsp.2420090207

Twigg, C.A. (1997). Is technology a silver bullet? Educom Review, 28-29.

Voorhees, C. M., Brady, M. K., Calantone, R., \& Ramirez, E. (2016). Discriminant validity testing in marketing: An analysis, causes for concern, and proposed remedies. Journal of the Academy of Marketing Science, 44(1), 119-134.

Wakefield, K., \& Wann, D. (2006). An examination of dysfunctional sport fans: Method of classification and relationships with problem behaviors. Journal of Leisure Research, 38(2), 168-196. https://doi.org/10.1080/00222216.2006.11950074

Wall L.B., Vuillermin, C., Miller, P.E., Bae, D.S., \& Goldfarb, C.A. (2020). Convergent validity of PODCI and PROMIS domains in congenital upper limb anomalies. Journal of Hand Surgery, 45(1), 33-40.

Walsh, P. \& Ross, S.D. (2010). Examining brand extensions and their potential to dilute team brand associations. Sport Marketing Quarterly, 19(4), 132-142.

Wanless, L., Watanabe, N. M., Lawrence-Benedict, H. J., \& Fodor, A. (2019).

Contextualizing the financial disparity discussion: Modeling Power Five and 
Group of Five athletic revenues. Journal of Issues in Intercollegiate Athletics, 12, $22-45$.

Wann, D., \& Branscombe, N. (1990). Die-hard and fair-weather fans: Effects of identification on BIRGing and CORFing tendencies. Journal of Sport and Social Issues, 14(2), 103-117. https://doi.org/10.1177/019372359001400203

Wann, D., Royalty, J. \& Roberts, A. (2000). The self-presentation of sport fans: Investigating the importance of team identification and self-esteem. Journal of Sport Behavior, 23(2), 198-206.

Warner S. \& Dixon, M.A. (2011). Understanding sense of community from the athlete's perspective. Journal of Sport Management, 25, 257-271.

Warner, S., \& Dixon, M.A. (2013). Sport and community on campus: Constructing a sport experience that matters. Journal of College Student Development, 54(3), 283-298. https://doi.org/10.1353/csd.2013.0044

Warner, S., Kerwin, S., \& Walker, M. (2013). Examining sense of community in sport: Developing the multidimensional 'SCS' Scale. Journal of Sport Management, 27(5), 349-362. https://doi.org/10.1123/jsm.27.5.349

Warner, S., Shapiro, S.L., Dixon, M.A., Ridinger, L.L., \& Harrison, S.B. (2011). The football factor: Shaping community on campus. Journal of Intercollegiate Athletics, 4, 236-256.

Weiner, J.F. (2018). An examination of box office relationship quality and relationship selling in Division I college athletics. Electronic Theses and Dissertations. Paper 3030. https://doi.org/10.18297/etd/3030 
Wenner, L.A., \& Gantz, W. (1989). The audience experience with sports on television. In L.A. Wenner (Ed.), Media, sports \& society (pp. 241-269). Sage.

Whiteside, E., Hardin, M., \& Ash, E. (2011). Good for society or good for business?

Division I sports information directors' attitudes toward the commercialization of sports. International Journal of Sport Communication, 4(4), 473-491.

https://doi.org/10.1123/ijsc.4.4.473

Wong, S.L., Epperson, A.E., Rogers, J., Castro, R.J., Jackler, R.K., \& Prochaska, J.J. (2020) A multimodal assessment of tobacco use on a university campus and support for adopting a comprehensive tobacco-free policy. Preventive Medicine, $133,1-7$

Yoh, T., Mohr, M., \& Gordon, B. (2008). Assessing satisfaction with campus recreation facilities among college students with physical disabilities. Recreational Sports Journal, 32(2) 106- 113.

Yoon, Y., Wang, R., \& Jeong, S. (2016). Role of fanship in college satisfaction through using SNS for sports. Journal of Multidisciplinary Research, 8(3), 23-40.

Zhao, X., Lynch Jr., J.G., \& Chen, Q., (2010). Reconsidering Baron and Kenny: myths and truths about mediation analysis. Journal of Consumer Research, 37(2), 197206.

Zillmann, D., Blyant, J., \& Sapolsky, B.S. (1989). Enjoyment from sports spectatorship. In J.H. Goldstein (Ed.), Sports, games, and play: Social and psychological viewpoints, 2nd ed., 241-278. Erlbaum.

Zimbalist, A. (2013). Inequality in intercollegiate athletics: Origins, trends, and policies. Journal of Intercollegiate Sport, 6(1), 5-24. https://doi.org/10.1123/jis.6.1.5 
Appendix A

Team Brand Association Scale (Ross et al., 2006)

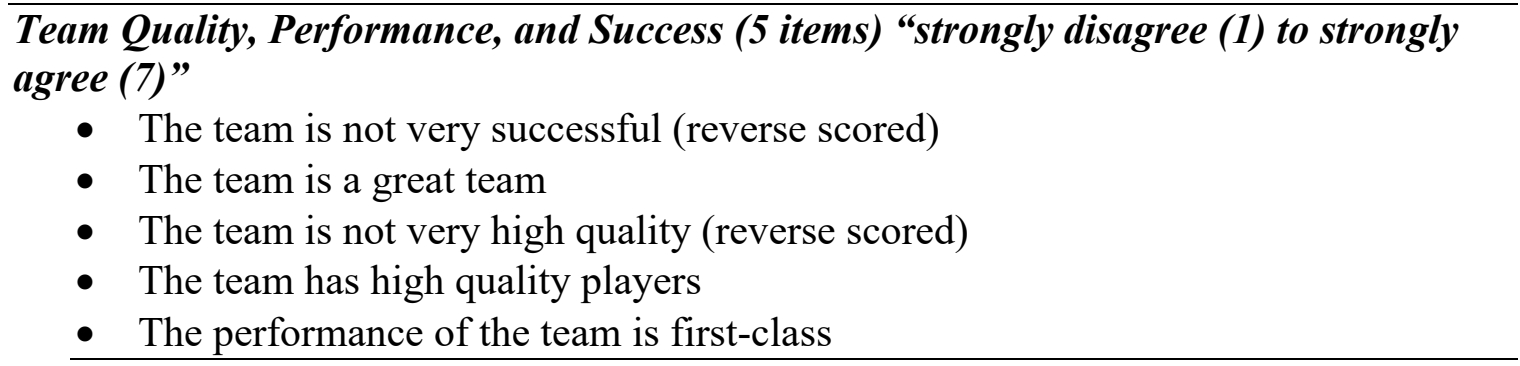

Athletics and Enrollment Scale

Athletics and Enrollment Decisions (4 items) "strongly disagree (1) to strongly agree

(7)”

- (School's name) athletics played an important role in my enrollment decision

- If it weren't for (school's name) athletics, I would have attended another school

- It was important for me to attend a school with FBS athletics

- (School's name) athletics attracted me to this school

College Sense of Community Scale (Warner et al., 2011)

\section{Sense of Community (6 items)}

- There is a real sense of community at [this university]

- There is a strong feeling of togetherness on campus,

- There is a sociable atmosphere at [this university]

- I feel very attached to [this university]

- I feel like I belong here at [this university]

- Students at [this university] feel they can get help if they are in trouble

Satisfaction Scale (Oliver, 1980)

Enrollment Satisfaction (3 items) "strongly disagree (1) to strongly agree (7)"

- I am happy that I attended [this university]

- I am satisfied with my decision to attend [this university]

- I did the right thing by attending [this university]

Athletic Success Subjectivity

Athletic Success Variables as Items

- National championship victories (Toma \& Cross, 1998);

- Relative changes in winning percentage (McEvoy, 2005), measured as year-overyear improvement 
- Overall winning percentage (Smith, 2008);

- Conference winning percentage (McCormick \& Tinsley, 1987; Murphy \& Trandel, 1994)

- Major Bowl Game Appearances (Bremmer \& Kesselring, 1993)

- Placement in Associated Press' (AP) Poll (Pope \& Pope, 2009)

- Appearances in NCAA Basketball Tournament (Pope \& Pope, 2009)

- Number of Rounds won in NCAA Basketball Tournament (Mixon \& Ressler, 1995)

Team Identification Index (Trail \& James, 2001)

Team Identification (3 items) "Strongly Disagree (1), Strongly Agree(7)"

- I consider myself to be a "real" fan of the (team name) team

- I would experience a loss if I had to stop being a fan of the (team name) team

- Being a fan of (team name) is very important to me 


\section{CURRICULUM VITA}

Addison M. Pond

1900 S Floyd St. Apt 621A - Louisville, KY 40208 - (615) 587-5212 • Email:

ampond01@louisville.edu

\section{EDUCATION}

Ph.D. in Educational Leadership and Organizational Development University of Louisville Specialization: Sport Administration Advisor: T. Christopher Greenwell, Ph.D.

Dissertation Title: Re-Examining the Flutie Effect

Master of Science in Sport Management

Northern Illinois University

Bachelor of Arts in Sport Management

Christian Brothers University

Honors: Summa Cum Laude
May 2021 (anticipated) Louisville, KY

\section{TEACHING EXPERIENCE}

Graduate Teaching Assistant

University of Louisville - Louisville, $K Y$

- Instructor of Record for:

- HSS 114: Fitness Walking (Spring 2019)

- SPAD 281: Principles of Sport Administration (Fall 2019 - Online; Spring 2020)

- SPAD 383: Sport Marketing (Fall 2020 - Online)

- SPAD 404: Financial Principles in Sport (Spring 2020 - Online)

- SPAD 437: Data and Analytics (Fall 2020 - Online)

- SPAD 489: Legal Aspects in Sport (Spring 2021)

- Graduate Teaching Assistant: SPAD 281: Principles of Sport Administration (Fall 2018;

Spring 2019)

- Assisted with daily class activities

- Guest lectured on various topics

- Prepared and graded quizzes on a weekly basis

\section{Adjunct Professor}

August 2017 - December 2017

Rock Valley Community College - Rockford, IL

- Instructor of Record for FWS 250: Intro to Sport Management (27 students) 
- Prepared and presented lectures on course content; graded all assignments, quizzes, and tests

- Coordinated industry professionals' class visits

Graduate Teaching Assistant

January 2017 - May 2018

Northern Illinois University - DeKalb, IL

- Graduate Teaching Assistant for:

- LESM 341: Administration of Intercollegiate Athletics (Spring 2018; Fall 2017)

- LESM 360: Sport Facility and Event Management (Spring 2018)

- LESM 365: Communication Strategies of Exercise and Sport (Spring 2017)

- LESM 442: Promotion of Sport and Fitness Programs (Fall 2017)

- Assisted with daily class activities

- Graded assignments and presentations as needed

\section{Guest Lecturer Experience}

- SPAD 281: Principles of Sport Administration

- Intercollegiate Sport (Fall 2019; Spring 2019; Fall 2018)

- Sport and Social Media (Fall 2019; Spring 2019; Fall 2018)

- Sport Facility and Event Management (Fall 2019; Spring 2019)

- SPAD 524: Management of Professional Baseball (Graduate Level):

- History of Minor League Baseball (Spring 2019)

- Central High School (KY) - SPAD Sport Marketing Magnet Program

- Sport and Social Media (Fall 2018)

- LESM 365: Communication Strategies of Exercise and Sport

- Sport and Social Media (Spring 2017)

\section{RESEARCH AND SCHOLARLY ACTIVITY}

Peer-Reviewed Publications

- Lee, Y.L., Pond, A.M., Kulkarni, A., \& Frederick, E.L. (in review). Exploring social media commentary pertaining to the culture of South Korean ice-skating. Submitted to SAGE Open

- Lee, Y.L, Pond, A.M., George, C., \& Hums, M. (in review). The KUSF and the NCAA: A comparative study of national collegiate sport organizations' academic policies. Submitted to Asian Pacific Education Review.

- Hambrick, M. E., \& Pond, A.M. (2020). Evaluating the rise of electric scooters through Porter's Five Forces framework. SAGE Business Cases.

http://dx.doi.org/10.4135/9781529741100.

- Pond, A.M., Cocco, A. R. \& Spencer, T. C. (2020). Road back to glory: How the NCAA football video game franchise could make a comeback. SAGE Business Cases. https://doi.org/10.4135/9781529727951

\section{Peer-Reviewed Publications In Progress}


- $\quad$ Pond, A.M., Allen, J.T., Greenwell, T.C., \& Lee, Y.L. (Data analysis). Athletic Success and Donation Intentions: Does Sense of Community Mediate? To be submitted to Journal of Issues in Intercollegiate Athletics.

\section{Conference Presentations}

- Lee, Y., Pond, A.M., \& Kulkarni, A. (2021, March). Exploring social media commentary pertaining to the culture of South Korean Ice-skating. International Association for Communication and Sport Conference.

- $\quad$ Pond, A.M., Allen, J.T., Greenwell, T.C., \& Lee, Y. (2021, February). Athletic Success and Donation Intentions: Does Sense of Community Mediate? Applied Sport Management Association Conference.

- Pond, A.M., Cocco, A.R., \& Spencer, T.C. (2020, March). Road back to glory: How the NCAA Football video game franchise could make a comeback. Poster presented the Sport and Recreation Law Association Conference. Louisville, KY.

- Howell, S.M., Morehead, C.A., Simmons, J.M., Pond, A.M., \& McEvoy, C.D. (2018, October). "Give a Little Bit..." An empirical examination of current student understanding of and intention to join a university's athletics fundraising program. Poster presented at the Sport Marketing Association Conference. Dallas, TX.

- Howell, S.M., \& Pond, A.M. (2018, April). Predicting attendance in Minor League Baseball: An exploration of promotions, timing, and weather for the Carolina and Midwest Leagues. College of Education Graduate Student Research Symposium. DeKalb, IL.

- Howell, S.M., Schaeperkoetter, C.C., Pond, A.M., Einhouse, A., Dietz, B.L., \& Neely, M.X. (2018, April). To join or not to join... That is the question: An empirical comparison of student intention to join a university's athletics fundraising program. Poster presented at the College Sport Research Institute Conference. Columbia, SC.

- Howell, S.M., \& Pond, A.M. (2017, November). Predicting attendance in Minor League Baseball: An exploration of promotions, timing, and weather for the Carolina and Midwest Leagues. Poster presented at the Sport Marketing Association Conference. Boston, MA.

- $\quad$ Schaeperkoetter, C.C., Howell, S.M., \& Pond, A.M. (2017, November). Career Plan Project in the classroom: Mapping a road to career success in sports. Oral presentation given at the Sport Marketing Association Conference: Pedagogy Symposium. Boston, MA.

Graduate Research Assistant

August 2016 - May 2018

Northern Illinois University - DeKalb, IL

- Helped gather data and hand out surveys for multiple studies

- Entered data into Microsoft Excel and interpreted results

- Presented findings at academic conferences

PROFESSIONAL EXPERIENCE

Facilities and Event Operations Intern

Summers 2015 - 2016 
Vanderbilt University - Nashville, TN

- Assisted with a wide variety of tasks associated with managing Vanderbilt University's athletic facilities

- Helped operate the 2015 NCAA Baseball Regional Tournament

- Helped organize, set up and run Luke Bryan concert at the football stadium

\section{Sports Information Assistant}

August 2012 - May 2016

Christian Brothers University - Memphis, TN

- Set up, kept score and stats, announced, and took down campus athletic events for six sports

- Used StatCrew Software to work baseball/softball, and soccer games

- Took photographs for website

\section{SERVICE AND VOLUNTEER EXPERIENCE}

- Member, North American Society for Sport Management (Spring 2019-Current)

- Volunteer, NFL Draft-Green Team (2019)

- Volunteer, NCAA Men's Final Four-Rush to Recycle (2019)

- Member, UofL Sport Administration Masters Student Admissions Committee (2019)

- Member, UofL SPAD Association (2018 - present)

- UofL COSMA Accreditation Team (2019)

- Helped prepare all pertinent documents for the University of Louisville's 2019 COSMA site visit

- Became familiar with the formal COSMA accreditation process

- Member, Northern Illinois University Grad Sport Society (August 2016 - May 2018)

- Member, Kappa Sigma fraternity, scholarship chair, service chair (Spring and Fall 2014)

\section{HONORS AND AWARDS}

- Outstanding Graduate Student Award, Northern Illinois University (Spring 2018)

- Student Leadership Award, Christian Brothers University (Spring 2013)

- Dean's List, Christian Brothers University (Fall 2012 - Spring 2016)

\section{COMPUTER EXPERIENCE AND OTHER SKILLS}

- PC and Macintosh Computers and Operating Systems (proficient)

- Microsoft Office: Excel, PowerPoint, Teams, and Word (proficient)

- Blackboard Teaching Systems: online teaching system and environment (proficient)

- SPSS: general-purpose statistical analysis and data management software (moderate) 